Argonne National Laboratory, a U.S. Department of Energy Office of Science laboratory, is operated by The University of Chicago under contract W-31-109-Eng-38.

DISCLAIMER
This report was prepared as an account of work sponsored by an agency of
the United States Government. Neither the United States Government nor
any agency thereof, nor The University of Chicago, nor any of their
employees or officers, makes any warranty, express or implied, or assumes
any legal liability or responsibility for the accuracy, completeness, or
usefulness of any information, apparatus, product, or process disclosed, or
represents that its use would not infringe privately owned rights. Reference
herein to any specific commercial product, process, or service by trade name,
trademark, manufacturer, or otherwise, does not necessarily constitute or
imply its endorsement, recommendation, or favoring by the United States
Government or any agency thereof. The views and opinions of document
authors expressed herein do not necessarily state or reflect those of the
United States Government or any agency thereof.

Available electronically at http://www.doe.gov/bridge

Available for a processing fee to U.S. Department of Energy and its contractors, in paper, from:

U.S. Department of Energy

Office of Scientific and Technical Information

P.O. Box 62

Oak Ridge, TN 37831-0062

phone: (865) 576-8401

fax: (865) 576-5728

email: reports@adonis.osti.gov 
ANL-03/34

\title{
NUCLEAR ENERGY PLANT OPTIMIZATION (NEPO) FINAL SCIENTIFIC/TECHNICAL REPORT
}

\section{PROJECT 3-13 \\ "MECHANICAL BEHAVIOR OF IRRADIATED STRUCTURAL STAINLESS STEELS"}

\author{
by \\ J. I. Cole, R. S. Daum, H. Tsai, D. L. Porter, T. R. Allen* \\ Nuclear Technology Division \\ Argonne National Laboratory-West \\ P. O. Box 2528 \\ Idaho Falls, ID 83403-2528 \\ And \\ B. D. Wirth** \\ University of California \\ Lawrence Livermore National Laboratory \\ 7000 East Ave. \\ Livermore, CA 94551-0808
}

December 2003

* Currently at University of Wisconsin

**Currently at University of California Berkeley 
LIST OF FIGURES $\ldots \ldots \ldots \ldots \ldots \ldots \ldots \ldots \ldots \ldots \ldots \ldots \ldots \ldots \ldots$

LIST OF TABLES. ................................... viii

$1.0 \quad$ Executive Summary. . . . . . . . . . . . . . . . . . . . . . 1

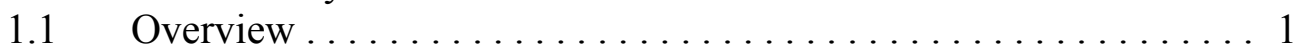

$1.2 \quad$ Research Approach . . . . . . . . . . . . . . . . . 1

1.3 Research Progress and Summary .................. 2

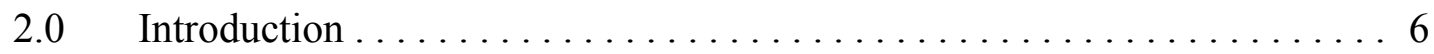

$3.0 \quad$ Background $\ldots \ldots \ldots \ldots \ldots \ldots \ldots \ldots \ldots \ldots \ldots$

3.1 Deformation Behavior in Unirradiated Stainless Steels . . . . . . . . 8

3.1.1 Evolution of the Deformation Microstructure . . . . . . . . 8

3.1.2 Deformation-Induced Twinning ............. 9

3.2 Tensile Behavior of Irradiated Stainless Steel. . . . . . . . . . . . . . 9

3.3 The Impact of Radiation Induced Microstructures on Alloy Failure

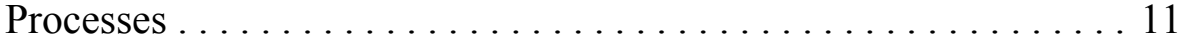

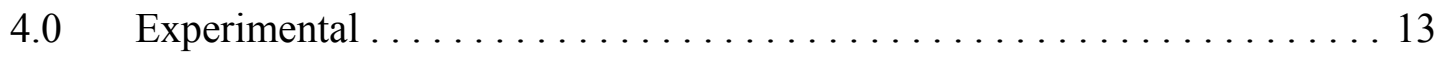

$4.1 \quad$ Sample Fabrication . . . . . . . . . . . . . . . . . . . 13

4.1.1 Unirradiated Materials . . . . . . . . . . . . . . 13

4.1.2 Irradiated Materials .. . . . . . . . . . . . . . 13

4.2 Setup of Constant Extension Rate Test Framework \& Drive Systems . . . . . . . . . . . . . . . . . . . . . 15

4.3 Experimental Procedures for TEM Characterization of Irradiated SS Hexagonal Duct Materials . . . . . . . . . . . . . . . . . . 17

4.3.1 Thin Foil Preparation. . . . . . . . . . . . . . . . 17

4.3.2 Void and Dislocation Analysis . . . . . . . . . . . . 18

$4.4 \quad$ Shear Punch Fixture Set Up. . . . . . . . . . . . . . . . . . . 18

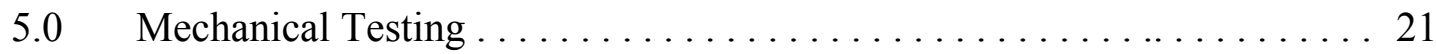

5.1 Tensile Testing of Unirradiated Coldwork 316 SS. . . . . . . . 21

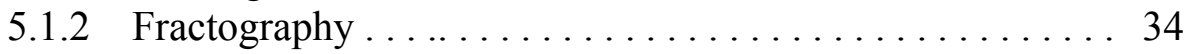

5.1 .3 Finite Elemental Analaysis. . . . . . . . . . . . 34

5.1 .4 Specimen Design Using FEA. . . . . . . . . . . . . 34

5.1.5 Single Edge Notch Tensile Sample Testing . . . . . . . . . . . 40

5.2 Mechanical Testing on Irradiated Tensile Samples. . . . . . . . . . . . 43

5.2 .1 Summary of Tests on Irradiated Materials. . . . . . . . . . 50

5.3 Shear Punch Testing ..................... 51 


\section{TABLE OF CONTENTS (CONT'D)}

\section{$\underline{\text { Page }}$}

$6.0 \quad$ Microstructural Evaluation . . . . . . . . . . . . . . . . 52

6.1 Analysis of Work Hardened Microstructure in Unirradiated

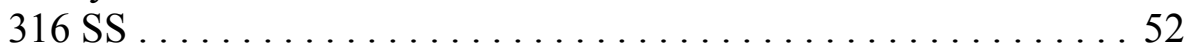

6.1.2 Post Tensile Test TEM of Cold-Worked 316. . . . . . . . . 52

6.2 Microstructural Analysis of Irradiated Coldworked 316 SS . . . . . 55

6.3 Microstructure Analysis of Irradiated Solution Annealed 304. . . . 59

$7.0 \quad$ Deformation Modeling . . . . . . . . . . . . . . . . . 61

7.1 Cold-Worked Materials Constitutive Modeling. . . . . . . . . . . . 61

7.2 Modeling Framework for Irradiated Steels . . . . . . . . . . . . . . . . . . . . . 62

7.3 Dispersed Barrier Modeling . . . . . . . . . . . . . . 65

7.4 Mechanical Properties Correlations using Equation of State. . . . . 67

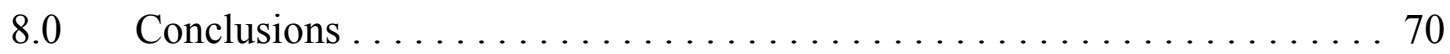

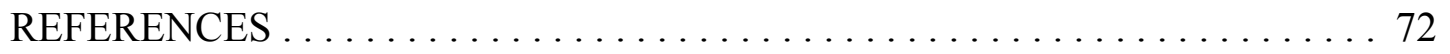




\section{LIST OF FIGURES}

1. Flow Chart Experimental \& Modeling Paths to Achieve Understanding of Link Between Deformation Process and IASCC . . . . . . . . . . 1

2. Experimental Data and Model Fit of Flow Stress for 0, 25 and 50\% ColdWorked 316 SS Tested at $400^{\circ} \mathrm{C}$ and $1 \mathrm{E}-3 / \mathrm{Sec} \ldots \ldots \ldots \ldots . \ldots 4$

3. Schematic of IASCC Process in Irradiated Stainless Steel. . . . . . . . . . 6

4. Plot Showing Temperature-Dose Regimens of Various Experimental Reactors Overlaid on the PWR Temperature-Dose Regime. . . . . . . . . . 7

5. Schematic of Effect of Irradiation on Yield Strength as a Function of Dose and Temperature in Austenitic Stainless Steels . . . . . . . . . . . . . . 10

6. Predicted Fracture Map for Irradiated 316 Stainless Steels. . . . . . . . . . . . . . 12

7. Schematic of EBR-II Core and Assembly Hexagonal Ducts . . . . . . . . . . 14

8. Plot of Dose-Rate as a Function of Row in the EBR-II Core . . . . . . . . . . . 14

9. Image of Coupled Actuators (with LVDT) on a Common Driveshaft for Simultaneous Testing of Two Specimens at the Same Strain-Rate. . . . . . . . . . 17

10. Schematic of Sheer Punch Fixture. The Entire Fixture is Inserted Into the Load Frame of Instron UTS to Conduct the Test . . . . . . . . . . . . . . . 19

11. Image of Instron UTS with Furnace and Fixtures in Place to Conduct Shear Punch Mechanical Tests . . . . . . . . . . . . . . . . . . . . . . 20

12. Close Up of Shear Punch Fixture and Testing Platform . . . . . . . . . 20

13. Engineering Stress Vs. Strain Reponses for Un-Notched and Notched (DENT Design) 0\% CW Specimens Tested at Strain Rates . . . . . . . . . 25

14. Engineering Stress Vs. Strain Responses for Un-Notched and Notched (DENT Design) 25\% CW Specimens Tested at Strain Rates. . . . . . . . . . . . . 26

15. Ensgineering Stress Vs. Strain Responses for Un-Notched and Notched (DENT Design) 50\% CW Specimens Tested at Strain Rates . . . . . . . . . 27

16. Engineering Stress Vs. Strain Responses for Un-Notched and Notched Specimens at 400 and $500^{\circ} \mathrm{C}$ with (a) 0, (b) 25, and (c) 50\% Cold-Work . .... . 28

17. $0.2 \%$ Yield Strength (YS) and Ultimate Tensile Strength (UTS) Versus \% CW for (a) Un-Notched and (b) Notched Specimens Tested at 0.001/Sec. . 29

18. Uniform Elongation (\%UE), Total Elongation (\%TE), and Reduction Area (\%RA) Versus \%CW for Un-Notched Specimens tested at $0.001 / \mathrm{Sec}$. . . 31

19. Failure Time Versus $\% \mathrm{CW}$ for Notched and Un-Notched Specimens tested

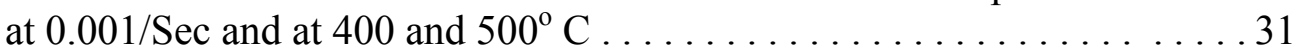

20. True Stress Vs. True Strain Plots with Power Law Fits ( $\mathrm{s}=\mathrm{Ken}$ ) for All Un-Notched Specimens (a), (b) $0 \%$ (c), (d) $25 \%$, and (e), (f) $50 \% \ldots \ldots .32$

21. $0.2 \%$ Yield and Ultimate Tensile Strengths of Un-Notched Specimen as a Function of Temperature at (a) $10^{-3}$ and (b) $10^{-5} \mathrm{Sec}^{-1} \ldots \ldots \ldots \ldots 33$

22. Semi-Log Plots of $0.2 \%$ Yeld and Ultimate Tensile Strengths of Notched Specimen (DENT Design) as a Function of Strain Rate . . . . . . . . . . 33

23. Plot of Yield Strength as a Function of Temperature and Log Strain

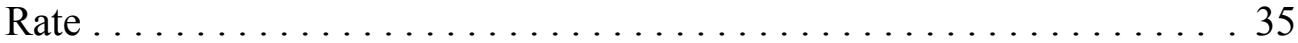




\section{LIST OF FIGURES (CONTD.)}

24. SEM Fractographs at Low and High Magnification of Failed DENT Specimens (Notch Surfaces at Top) Fabricated . . . . . . . . . . . 36

25. SEM Fractograph of (a) 25 and (b) $50 \%$ CW Specimen Showing Mixed Microvoid Tearing and Shear Fracture in the Shear Areas . . . . . . . . . 37

26. FEA Results Showing the Stress Distribution at the Ultimate Tensile Stress (Prior to Plastic Instability) . . . . . . . . . . . . . . . . 38

27. Geometric Parameters of Study for Optimal Notch Design; a-Notch Angle r-Notch Tip Radius, Polar Coordination System (r,q) of Notch-Tip . . . . 39

28. Stress Distribution in the Reduced Gauge Section Containing a $60^{\circ}$ Notch with Fixed Depth of $0.019-i n c h \ldots \ldots \ldots \ldots \ldots \ldots \ldots \ldots \ldots \ldots \ldots$

29. Normalized Stress Vs. Distance Ahead of the Notch Tip at $\mathrm{q}=0$ for DENT

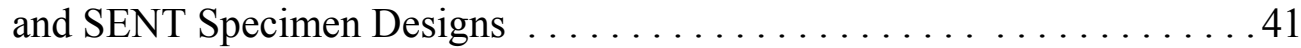

30. (a) Un-Notched (a/W=0), (b) DENT (a/W=0.322), (c) SENT (a/W= $0.161)$, and (d) SENT (a/W $=0.091)$ Specimen Designs . . . . . . . . . 42

31. Load Vs. Actuator Displacement Responses for SENT Specimens Fabricated from 25 and $50 \% \mathrm{CW}$ Materials . . . . . . . . . . . . . . 44

32. Stereoscopic Images of Post-Test SENT Specimens Fabricated from 50\% CW Material Showing Through-Thickness Shear Fracture . . . . . . . . . . . 44

33. Stereoscopic Images of SENT Specimen Fabricated from $25 \% \mathrm{CW}$ Material Prior to Fracture Showing Plane-Stress Mode I Crack Growth . . . 45

34. Stress-Strain Curves for 316 Samples Tested at $\sim 375^{\circ} \mathrm{C}$ and Following



35. Yield Strength for EBR-II 316 Stainless Steel. . . . . . . . . . . . . . . 47

36. Total Elongation for EBR-II 316 Stainless Steel . . . . . . . . . . . . . . . 48

37. Hardening for EBR-II Stainless Steel. . . . . . . . . . . . . . 48

38. Areas of Fracture Surface in $20 \%$ Cold-Worked 316 Irradiation to $30 \mathrm{dpa}$ Showing Ductile Dimples with Facets . . . . . . . . . . . . . . . . . 49

39. Areas of Fracture Surface in $20 \%$ Cold-Worked 316 Irradiation to $47 \mathrm{dpa}$ Showing a faceted surface. . . . . . . . . . . . . . . . . . 50

40. Low Magnification TEM Image of Unirradiated 316 SS . . . . . . . . . 53

41. Weakbeam Darkfield Images of Dislocation Structure in Coldworked

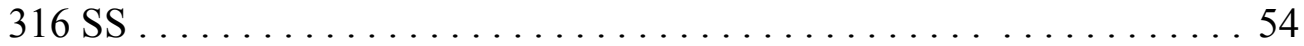

42. TEM Micrographs of 316 SS Following 25\% Strain in Uniaxial Tension a) $0 \% \mathrm{CW}$ (SA) b) $25 \%$ Work . . . . . . . . . . . . . . 56

43. Void Contrast TEM Images of the 316 SS Hex Duct Samples, a) 7 dpa, $373^{\circ} \mathrm{C}$, b) $30 \mathrm{dpa}, 379^{\circ} \mathrm{C}$ and c) $32 \mathrm{dpa} 380^{\circ} \mathrm{C} \ldots \ldots \ldots \ldots \ldots \ldots$

44. Representative Bright Field TEM Micrograph Taken in Dislocation Contrast Illustrating the Defect Structure that Develops . . . . . . . . . . 58

45. TEM Micrographs of Solution Annealed 304 Irradiated to a) $11 \mathrm{dpa}$

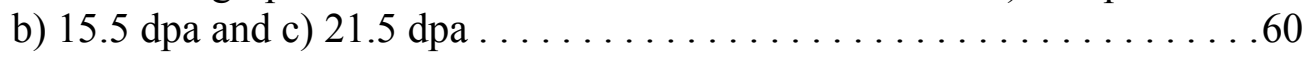

46. Strain-Hardening Rate Data and Fits for 0, 25, and 50\% Cold-Worked Stainless Steel, Tested at $400^{\circ} \mathrm{C}$ and a Strain-Rate of $10^{-3} \mathrm{~s}^{-1} \ldots \ldots \ldots 62$ 
47. Strain-Hardening Rate Data and Fits for 0,25 , and $50 \%$ Cold-Worked Stainless Steel, Tested at $500^{\circ} \mathrm{C}$ and a Strain-Rate of $10^{-3} \mathrm{~s}^{-1} \ldots \ldots \ldots 63$

48. Modeling of the Incremental Flow Stress or Strain-Hardening Rate and Fitting to Tensile Date to Determine C1 Defect Generation C2......... 63

49. Influence of Test Temperature and Cold-Work Level on Model Constants

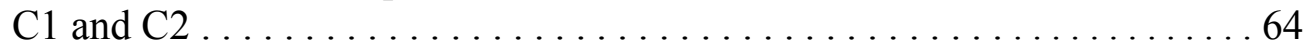

50. Predicted Stress-Strain Behavior as a Function of Defect Density (Increasing Radiation Damage) ........................ 65

51. Calculated Yield Strength Contributions from Various Obstacles Quantified in the TEM Microstructure ...................67

52. Calculated Yield Strength as a Function of Strain-Rate and for Various Structure Parameters . . . . . . . . . . . . . . . . . . . . . . . . 69 
1. $\quad 3 / 4 "$ Samples for Irradiated Cold-Worked $316 \ldots \ldots \ldots \ldots \ldots \ldots$

2. $\quad 3 / 4$ " Samples from irradiation Solution - Annealed $304 \ldots \ldots \ldots \ldots$. . . . 16

3. Summary of Mechanical, Testing, and Fractographic Properties for $0 \%$ Cold-Worked 316 SS . . . . . . . . . . . . . . . . . . . . 22

4. Summary of Mechanical, Testing, and Fractographic Properties for $25 \%$ Cold-Worked 316 SS. . . . . . . . . . . . . . . . . . 23

5. Summary of Mechanical, Testing, and Fractographic Properties for 50\% Cold-Worked 316 SS . . . . . . . . . . . . . . . . . . 24

6. Dislocation Densities in the Cold-Worked 316 SS. . . . . . . . . . . . 55

7. Void and Dislocation Sizes and Densities for the EBR-II 316 TEM Samples . . . . . . . . . . . . . . . . . . . . . . . . . . . . 57

8. Precipitate Size and Densities for the 3 TEM Samples Examined. . . . . . . 59

9. Void and Dislocation Sizes and Densities for the EBR-II Solution Annealed 304 SS TEM Samples. . . . . . . . . . . . . . . . . . . . . . . . 59 


\subsection{Executive Summary}

\subsection{Overview}

The overall objective of this 3 year research program has been to support the aging management programs for LWR reactors through the extended 60 -year lifetimes by adding to the knowledge base of irradiation-induced effects on the mechanical properties and cracking resistance of stainless steel (SS) core components. Over the course of this project, efforts have focused on enhancing the understanding of the link between deformation and fracture behavior in work-hardened and irradiated stainless steels. This understanding is achieved through a combination of mechanical testing, microstructural characterization, and development of models to describe the observed behavior. The understanding gained provides a foundation for evaluating the aging behavior of components during in-core service in terms of radiation embrittlement and alloy susceptibility to irradiation assisted stress corrosion cracking (IASCC). A flow chart illustrating the link between the tensile testing, microstructural evaluation and modeling efforts is provided in Figure 1.

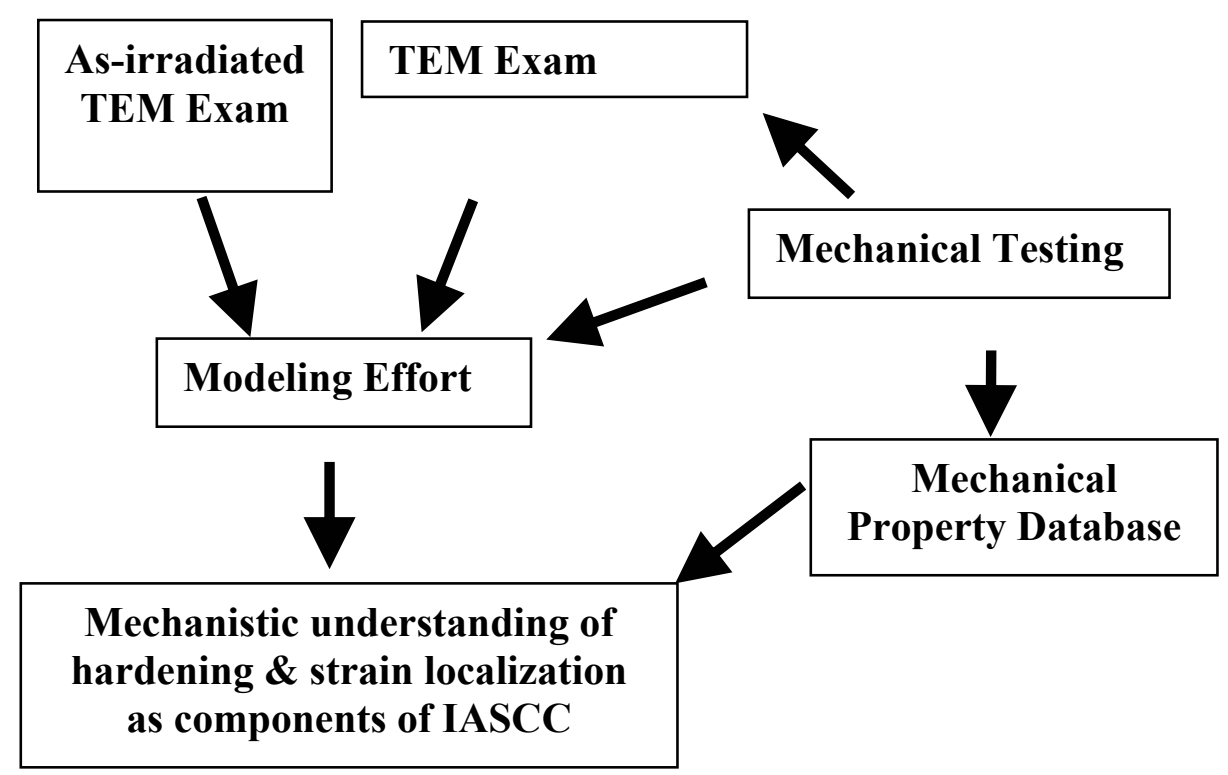

Figure 1. Flow chart experimental and modeling paths to achieve understanding of link between deformation process and IASCC.

\subsection{Research Approach}

The initial workscope of the project was planned for a 4 year time period. As the project was terminated at the end of the $3^{\text {rd }}$ year, some of the planned workscope was not completed. During the first phase of the research program, mechanical tests were performed on cold-worked austenitic stainless steels over a range of temperatures and strain rates to provide information on the relationship between hardening (yield strength increases) and deformation and fracture. The goal was to produce with cold-work the 
hardening required to embrittle the stainless steel in much the same way as does irradiation hardening. Irradiation hardening can be more effective in producing brittle fracture behavior, and susceptibility to stress corrosion cracking, so the tensile testing employs a specimen with a sharp notch to constrain plastic flow, and the tests are done at slow strain rate to encourage intergranular fracture. The mechanical testing was complemented by efforts to build physically based models which couple with experiments to relate the underlying materials microstructure to mechanical properties. The data generated in this work, along with data generated by future DOE work on deformation and data generated by joint EPRI/EDF projects, can be used in improving the knowledge base on irradiated material deformation and in developing the deformation models to aid in reactor aging management.

In the second phase of the project, work was expanded to include irradiated EBR-II hexagonal duct material; both solutions annealed 304 and $20 \%$ cold work 316 stainless steels (SS). In an effort to understand the link between the radiation-induced microstructural evolution and changes in deformation and fracture process, samples were characterized employing transmission electron microscopy (TEM) and tested in uniaxial tension. The focus of this work is, from a combination of microstructural and mechanical data, to form the input basis for a model to describe long term radiation effects on the deformation and fracture behavior of structural stainless steels. An additional goal of these tests was to further evaluate the mechanisms responsible for enhanced alloy cracking susceptibility in reactor environments. Both mechanical and chemical factors are believed to play a role in irradiation assisted stress corrosion cracking (IASCC). If mechanical factors are dominant, it should be possible to produce intergranular cracking in the irradiated material in the absence of environment. As with the cold work alloy studies, samples were fabricated with a notch to constrain plastic flow and tested at slow strain rates to evaluate fracture behavior.

To complement the tensile behavior studies, work was also conducted to establish a shear punch small specimen testing technique. There are several reasons that it is beneficial to develop small volume mechanical testing techniques. These reasons include limited space in materials test reactors, limited amount of irradiated material available for testing, and a desire to reduce the overall radiation exposure risk during testing. Several small testing techniques have been developed including scaled down tensile samples, automatic ball indentation and shear punch tests. The validity of the shear punch has been fairly well established for determining mechanical properties information from the widely used $3 \mathrm{~mm}$ TEM type discs.

The modeling effort in this study was twofold. Early in the project, modeling efforts focused on the development of constitutive equations based on fundamental microstructural parameters. To complement this work, previously developed dispersed barrier hardening and equation of state correlations were also explored as methods of predicting irradiated stainless steel tensile behavior from a limited dataset. 


\subsection{Research Progress and Summary}

\section{Evaluation of Deformation and Fracture Behavior of Coldworked 316 SS}

The first task of this study was to understand the effect of hardening mechanisms on the yield and post-yield flow behavior of cold-worked SS. A mechanical testing campaign was carried out on solution annealed, $25 \%$ and $50 \%$ coldworked stainless steels. The engineering properties of $50 \%$ cold-worked $316 \mathrm{SS}$ indicate that $0.2 \%$ yield stress and ultimate strength are comparable to those of irradiated $20 \%$ cold-worked $316 \mathrm{SS}$. However, both 25 and $50 \%$ cold-work $316 \mathrm{SS}$ show significantly less ductility compared to irradiated $20 \%$ cold-worked $316 \mathrm{SS}$. This result suggests that the strain-hardening capacity is significantly reduced by cold-working but is less affected by irradiation.

To further understand the hardening mechanisms, this study utilized the stress-strain response, coupled with examinations of the post-deformation microstructure by Transmission Electron Microscopy (TEM), to model the post-yield flow stress. The true stress $(\sigma)$ can be described by yield $\left(\sigma_{\mathrm{y}}\right)$ and plastic $\left(\sigma_{\mathrm{pl}}\right)$ stress components:

$$
\sigma(\varepsilon, \dot{\varepsilon}, \mathrm{T})=\sigma_{\mathrm{y}}(\dot{\varepsilon}, \mathrm{T})+\sigma_{\mathrm{pl}}(\varepsilon, \dot{\varepsilon}, \mathrm{T})
$$

eq. 1

where $\varepsilon$ is the equivalent true plastic strain, $\varepsilon$ is the strain rate, and T is temperature. $\sigma_{\mathrm{pl}}$ is related to the dislocation density $(\rho)$ according to the Kock's description [1]:

$$
\sigma_{\mathrm{pl}}=\mathrm{M} \alpha \mathrm{Gb} \sqrt{ }_{\rho} \text { and } \mathrm{d} \rho / \mathrm{d} \varepsilon=\mathrm{M}\left(\mathrm{c}_{1} \sqrt{ }_{\rho}-\mathrm{c}_{2} \rho\right) \text {, }
$$

eq. 2

where $\mathrm{M}$ is the Taylor Factor, $\alpha$ is a numerical constant that describes dislocation interactions determined by atomistic modeling, $G$ is the shear modulus, $b$ is the Burgers vector, and $\mathrm{c}_{1}$ and $\mathrm{c}_{2}$ are material dependent and describe dislocation generation and annihilation, respectively. Figure 2 shows a plot of $\mathrm{d} \sigma_{\mathrm{pl}} / \mathrm{d} \varepsilon$ vs. $\varepsilon$ for various levels of cold-work to determine $c_{1}$ and $c_{2}$. Results from subsequent testing and TEM examination of specimens deformed to $\approx 25$ and $75 \%$ of the total plastic strain indicate that the model based on Equations 1 and 2 shows excellent agreement with experimental results.

The second task of the study on cold worked material has been to determine the fracture mechanisms of $316 \mathrm{SS}$ and the environmental and material conditions that correspond to the transgranular-to-intergranular fracture transition. To delineate the transition between transgranular and intergranular fracture, tensile testing of un-notched and notched specimens has been conducted for the full range of temperatures and strain rates of this study. Regardless of the level of cold-work, no evidence of intergranular fracture was observed. In fact, fracture was dominated by a damage accumulation process of microvoid coalescence and/or through-thickness shear instability. This result indicates that the transition to intergranular fracture in inert atmospheres occurs either (i) at strain rates $<1 \mathrm{E}-7 / \mathrm{sec}$ and/or temperatures $>500^{\circ} \mathrm{C}$, (ii) by the combined effects of hardening and strain localization only induced by irradiation, or (iii) a combination of (i) and (ii). 


\section{Evaluation of Radiation Effects on Deformation and Fracture Behavior of Irradiated SS}

The focus of the second phase of the project was to evaluate the deformation and fracture behavior of irradiated SS, and how this behavior is linked to changes in material microstructure during irradiation. To accomplish this task, solution annealed 304 and coldworked 316 SS which had been irradiated in EBR-II was retrieved for mechanical testing and microstructural

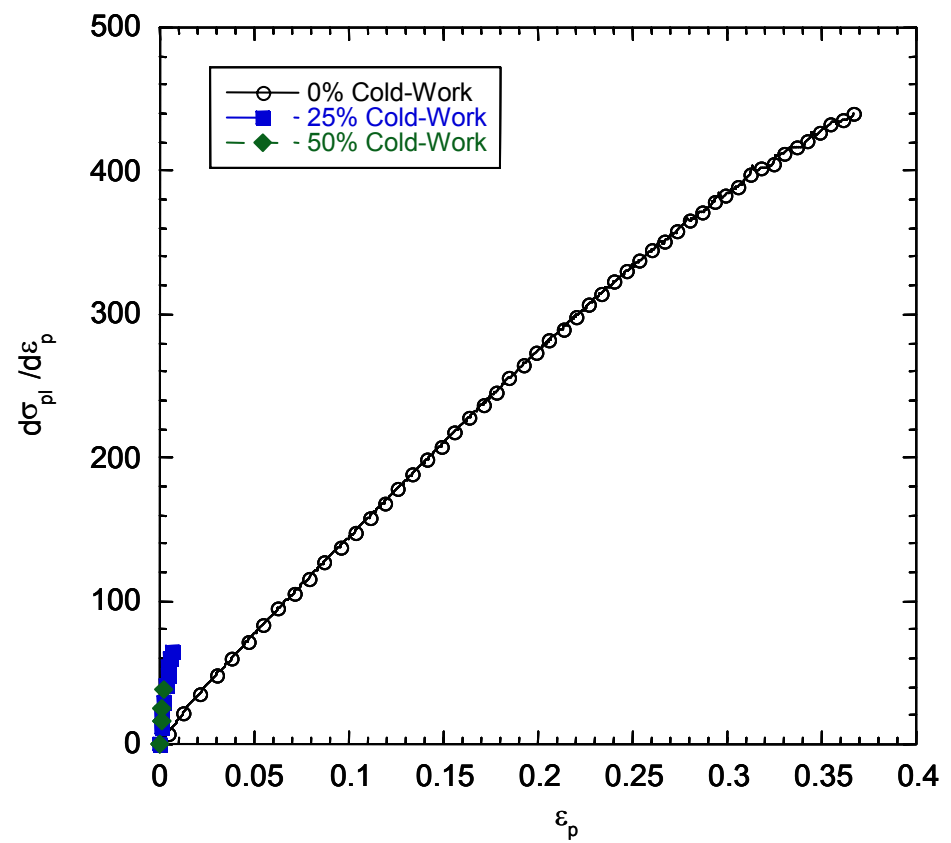

Figure 2. Experimental data and model fit of flow stress for 0,25 , and $50 \%$ cold-worked $316 \mathrm{SS}$ tested at $400^{\circ} \mathrm{C}$ and $1 \mathrm{E}-3 / \mathrm{sec}$.

characterizaiton. Some of the workscope planned for the irradiated materials was not completed due to early termination of the project and significant delays associated with the conduct of tests in the hot-cells. A failed window in the hot cell facility used for fabrication of irradiated test samples led to an extended shutdown of the facility. As a result of the shut down and concurrent escalation of the costs to machine samples and perform experiments in the hot cells, only 2 of the 7 planned tensile tests on irradiated 316 were performed prior to termination of the project. In addition, since the workscope for the solution annealed 304 was planned for the final unfunded year of the project (FY 2004) no, mechanical testing was performed on these materials. As per the workscope for the final funded year of the project (FY 2003), microstructural characterization was conducted on the solution annealed 304 .

The results from the two tests on the $20 \%$ coldworked 316 SS conducted in this study were compared to those of earlier studies conducted on similar $12 \%$ and $20 \%$ coldworked material irradiated in EBR-II [2,3]. As expected, substantial strengthening occurred in the materials due to the irradiation. Much of the strengthening occurred early in the 
irradiation and the subsequent increase with dose is modest. Strengthening is more pronounced in samples irradiated and tested at lower temperatures. In comparing $12 \%$ coldworked to $20 \%$ coldworked materials, the yield strength for each condition approached similar values with increasing dose, however, the rate of increase in strength differed with cold-work and irradiation temperature. The $12 \%$ cold-worked steel irradiated and tested at lower temperature $\left(\sim 380^{\circ} \mathrm{C}\right)$ had the fastest rate of strength increase. Differences in elongation were also noted. The $12 \%$ cold-worked steel irradiated and tested at lower temperature $\left(\sim 380^{\circ} \mathrm{C}\right)$ and the $20 \%$ cold-worked 316 had the fastest rate of decrease in total elongation. The total elongation for the $20 \%$ coldworked stainless steel reached $2 \%$ at $47 \mathrm{dpa}$, a low value. At this high dose and low elongation, the fracture was starting to transition from ductile to a more channeled fracture. The data on 316 stainless steel indicates degradation due to swelling and changes in mechanical properties.

316 SS samples irradiated to 7, 30 and 32 dpa were characterized in the TEM. The $7 \mathrm{dpa}$ microstructure was composed of dislocation loops and network dislocations. No voids and only a few precipitates were observed in the 7 dpa sample. The two higher dose samples contained large populations of voids, precipitates and dislocation loops. These defects will act as obstacles to dislocation motion during subsequent plastic deformation, the primary reason for the substantial increase in strength observed in the tensile tested irradiated materials. Samples of solution annealed 304 irradiated to 11, 15.5, and 21.5 dpa were also examined. A high density of voids and precipitates were observed in all of the samples, indicating the rate of swelling in solution annealed 304 is substantially greater than 316 .

A constitutive model based on microstructural inputs was developed for the irradiated material. The model predicted general trends in observed behavior in terms of increased alloy strength and the development of a yield point.

\section{Shear Punch Mechanical Testing}

One of the tasks in original project workscope was to establish the capability to perform shear punch mechanical testing capabiltiy and conduct tests on irradiated samples in the final year of the project. The shear punch capability was established initially for non radiactive samples. Due to a greater interest in conducting tests on irradiated samples resources were shifted from testing unirradiated samples to setting up the shear punch system for testing on irradiated materials. This task was accomplished, however due to termination of the project, testing of irradiated samples could not be performed. 


\subsection{Introduction}

Stainless steels reactor internals experience a wide variety of material property degradations caused by exposure to the reactor-core operating environment. Among these types of degradations are an increased susceptibility to stress-corrosion cracking (SCC), a reduction in toughness and ductility, a reduced resistance to fatigue cracking, grain-boundary weakening, and stress relaxation. These deleterious effects are all influenced by the mechanical properties of the material and how these properties are affected by alloy microstructural evolution during irradiation exposure over a wide range of temperature and irradiation dose. The mechanical behavior also affects the behavior of such steels during repair processes such as welding. Therefore, understanding the link between alloy microstructural changes and bulk properties changes is a critical aspect of understanding the degradation and repair of the reactor internals.

A degradation mechanism of concern in light water reactors is irradiation assisted stress corrosion cracking (IASCC), which is manifested as intergranular fracture. Both grain boundary corrosion and grain boundary decohesion may play a role in causing IASCC [4]. A diagram indicating the major mechanisms considered relevant for IASCC is shown in Figure 3. For pressurized water reactors, IASCC occurs in a non-oxidizing environment and therefore the cracking may be related to changes in mechanical properties during irradiation. The 1999 Cooperative IASCC Research (CIR) Program

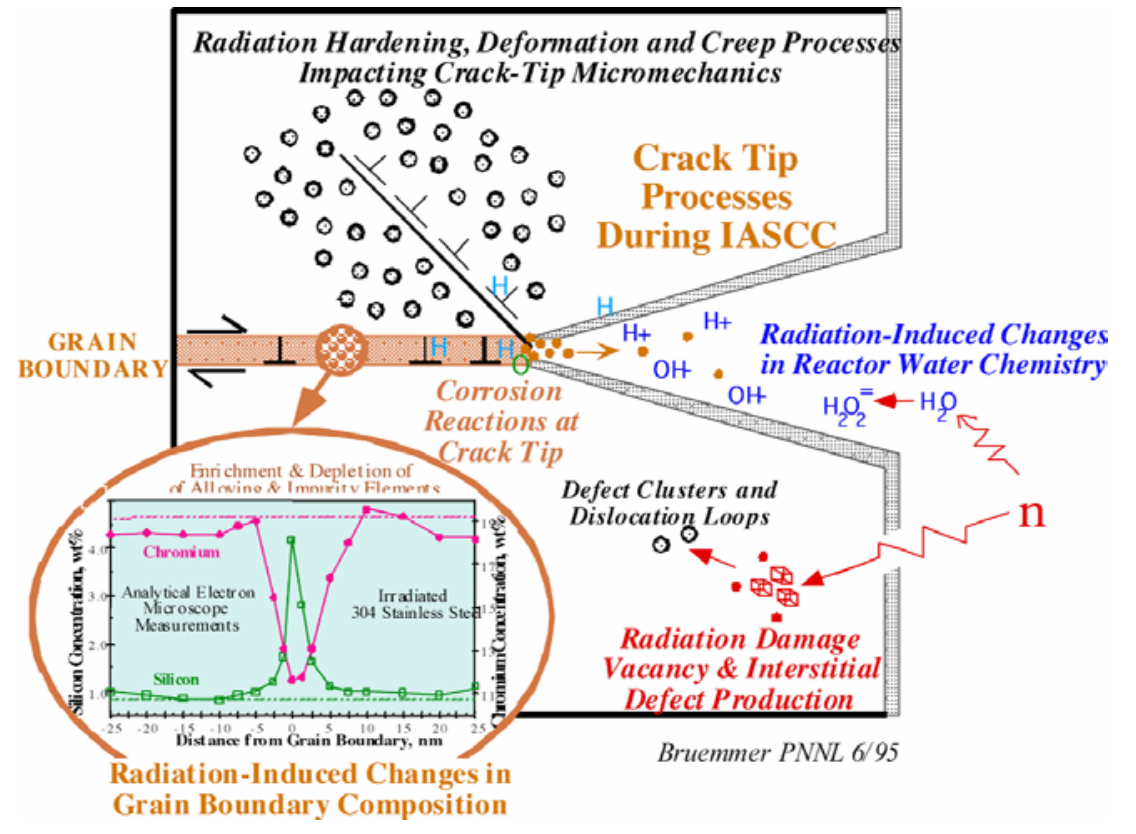

Figure 3. Schematic of IASCC process in irradiated stainless steel.

1999 Annual Summary highlights the fact that

both hardening and strain localization may contribute to IASCC [5]. Cold-work can increase the yield strength, but cannot contribute to strain localization. The CIR report specifically recommended testing of cold-worked material to help isolate the effects of strain localization from hardening. 
In addition to isolating effects of strain hardening and flow localization in coldworked material, it is important to understand actual processes in irradiated materials. However, there is limited material available for testing, and the expense of conducting irradiations is quite significant. A valuable materials resource exists for evaluating the long-term effects of radiation on reactor structural materials. This resource is the reactor hardware from EBR-II that has been retrieved during shutdown. These materials provide the opportunity to obtain data on swelling and mechanical behavior at the upper bound of PWR operating conditions. The plot shown in Figure 4 illustrates the overlap of various experimental reactor temperature-dose regimes with those expected in a PWR. EBR-II materials experience conditions similar to those at the high end of the PWR temperature environment, and doses spanning much of the expected PWR lifetime. To add to the radiation effects knowledge base and increase the understanding of the effect of radiation damage on mechanical properties and fracture behavior, these EBR-II materials were tested and characterized as part of the NEPO 3.13 program.

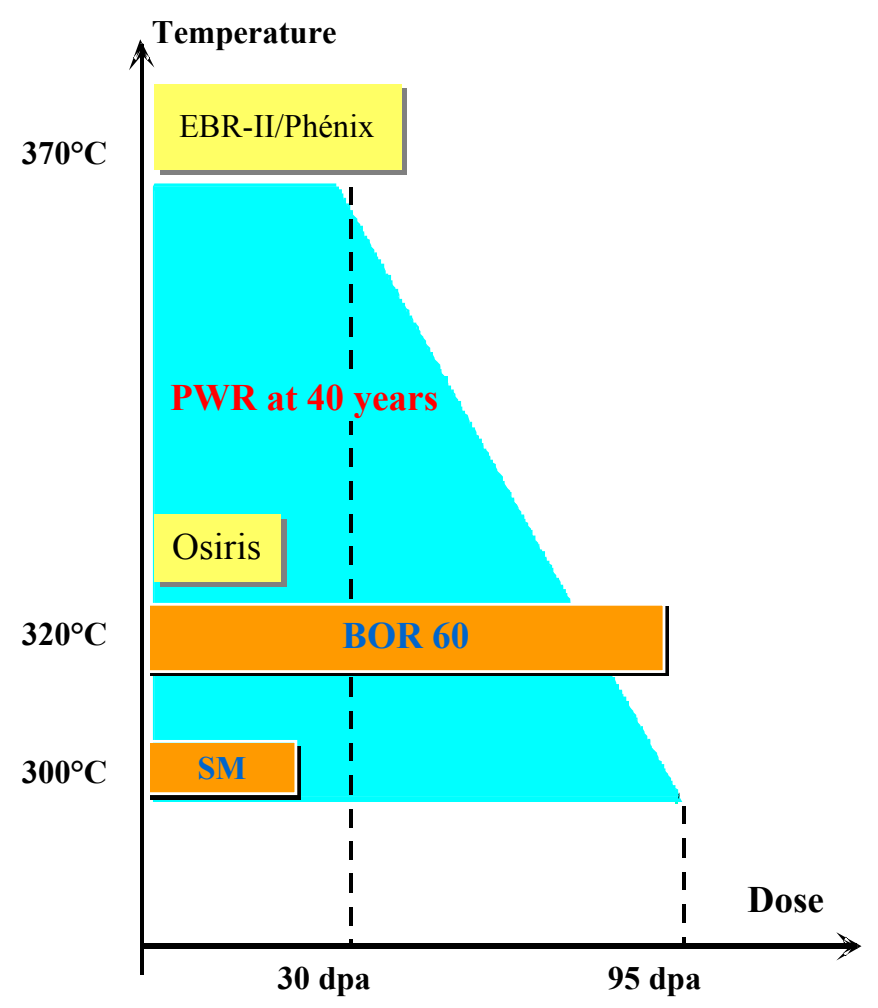

Figure 4. Plot showing temperature-dose regimes of various experimental reactors overlaid on the PWR temperature-dose regime [6].

The layout of this report is as follows. The next section in this report will review the general trends in deformation behavior of both unirradiated and irradiated stainless steel. Following this background overview, results from the present study will be presented. These results are divided into three sections covering mechanical testing, microstructural analysis and deformation modeling. 


\subsection{Background}

\subsection{Deformation Behavior in Unirradiated Stainless Steels}

\subsubsection{Evolution of the Deformation Microstructure}

Below $0.5 \mathrm{~T}_{\mathrm{m}}$ (melting temperature) the deformation characteristics of austenitic SS can include dislocation slip, planar faulting, twinning and martensite formation. Specific behavior will be influenced by deformation temperature and alloy composition. In turn, composition and temperature influence two factors of critical importance to deformation behavior: alloy stability against the formation of martensite and the stacking fault energy (SFE).

Austenite stabilizers, such as $\mathrm{C}$ and $\mathrm{Ni}$, tend to inhibit the formation of martensite with decreasing concentrations raising the temperature at which martensite is stable $\left(\mathrm{M}_{\mathrm{S}}\right.$ temperature). Similar compositional dependencies are observed for the temperature at which deformation-induced martensite forms $\left(\mathrm{M}_{\mathrm{d}}\right)$. Additionally SS SFE can vary over a wide range, from $\sim 20 \mathrm{~mJ} / \mathrm{m}^{2}$ for $304 \mathrm{SS}$ and as much as $80 \mathrm{~mJ} / \mathrm{m}^{2}$ for particular grades of $316 \mathrm{SS}$ [7]. Although there is a complex relationship between SFE and composition, alloying elements which tend to increase SFE include $\mathrm{Ni}, \mathrm{Mo}$, and $\mathrm{C}$, while $\mathrm{Cr}, \mathrm{Si}, \mathrm{N}$, and $\mathrm{Mn}$ appear to lower SFE. A direct correlation between increasing $\mathrm{Ni}$ content and increasing SFE was indicated by work performed by Douglass et al. [8] covering a variety of SS grades.

Deformation below $\mathrm{M}_{\mathrm{d}}$, induces the formation of a high density of extended stacking faults. These stacking faults act as sites for the transformation from $\gamma$ to $\varepsilon$ (hcp) martensite[9,10]. With further deformation $\alpha^{\prime}$ (bcc) martensite lathes form preferentially within the bands of $\varepsilon$ martensite. This transformation will continue to occur with increasing deformation until the bulk of the metal is $\alpha^{\prime}$ martensite.

At temperatures above $\mathrm{M}_{\mathrm{d}}$, deformation in a Fe-18Cr-14Ni-4Si [11] alloy was seen to occur by the glide of perfect or narrowly separated dislocations ( $0-2 \%$ strain). With increasing strain up to $\sim 7 \%$, extended stacking faults formed. A strain of $10 \%$ deformation produced a combination of $\varepsilon$ martensite and microtwins as identified by electron diffraction. In low SFE $\left(\gamma<15 \mathrm{~mJ} / \mathrm{m}^{2}\right)$ alloys, dissociation of partial dislocations occurs at relatively low strain $(<0.05)$ and planar arrays of extended stacking faults develop. Frequently, these stacking faults will extend across the entire width of the grain. Clustering of stacking faults into bands can lead to the formation twins with increasing strain.

The observed deformation behavior in materials with higher SFE is significantly different. In high SFE $\left(\gamma>40 \mathrm{~mJ} / \mathrm{m}^{2}\right)$, alloy deformation begins with dislocation glide on the primary slip plane (plane with the greatest resolved shear stress). With increasing 
strain, dislocations become entangled with other dislocations formed on secondary slip systems. As the dislocation density builds up, the entangled dislocations cross-slip and dislocation rearrangement leads to the formation of a equiaxed dislocation cell network where low dislocation regions are separated by dense dislocation walls with neighboring volume elements being misoriented from one another_[12].

At intermediate SFE ( $\left.15 \mathrm{~mJ} / \mathrm{m}^{2}<\gamma<30 \mathrm{mj} / \mathrm{m}^{2}\right)$, such as the case with austenitic SSs, mixed deformation takes place. Individual grains may deform by slip or twinning, depending on the orientation of the resolved shear stress to the primary slip plane. When the tensile axis is oriented in the $[100]<001>$ or $\{110\}<112>$ direction relative to the slip planes, deformation by twinning is preferred. Other orientations lead to dislocation slip as the primary mode of deformation.

The stress-strain behavior of unirradiated SS is typical of most ductile alloys. A region of linear hardening is followed by a region of parabolic hardening, followed by nonuniform deformation and failure. Alloys with lower SFEs will typically have lower rates of work hardening, as coplanar dislocation motion inhibits the entanglement. Typical elongations for annealed SSs tested at room temperature approach $\sim 55 \%$.

\subsubsection{Deformation-Induced Twinning}

Twins readily form in heavily deformed or irradiated SSs. Twin formation can reduce ductility and lead to rapid work hardening during plastic deformation. The role of twinning during deformation of irradiated materials has rarely been considered and the process is not well understood.

A particular characteristic of twinning in low SFE alloys is that the twins formed are fine_[13]. Venables [14] suggests that there is a transition in behavior from low SFE to high SFE. The stress strain curves for twinning in high SFE alloys show a significant yield drop at the onset of deformation twinning, while low SFE alloys show a continuous transition through the yield point. This behavior is thought to be a consequence of the facility of which nucleation and propagation of twins occur. In high SFE materials, nucleation is difficult, but once the twin stress is reached, the twins propagate in a catastrophic manner similar to a massive transformation. On the other hand, twin nucleation in low SFE materials is easy, while the propagation of the twin through the dislocation forest is difficult.

\subsection{Tensile Behavior of Irradiated Stainless Steel}

Post-irradiation tests show that for 300 series SS substantial yield stress (YS) increases and ductility and fracture toughness decreases occur in these alloys as reviewed by Lucas [15]. Yield strengths as much as 4 to 6 times the unirradiated value have been observed [16], while uniform elongation can drop to $<3 \%$. This type of behavior is believed to have a strong impact on cracking susceptibility[17]. A general, but not universal trend of behavior is that higher strength leads to increased cracking susceptibility. The postirradiation changes in tensile properties of austenitic SS have been studied quite 
extensively for a variety of grades and conditions. Some specific experimental findings will be reviewed in terms of general trends in the changes in mechanical properties following irradiation. It must be noted that the majority of studies are done out of reactor which may have a significant impact on behavior. One of the major difficulties in analyzing the data is the variability of both testing conditions and experimental findings. A summary of YS trends as a function of irradiation dose for various irradiation temperatures is shown in Figure 5 [18-22].

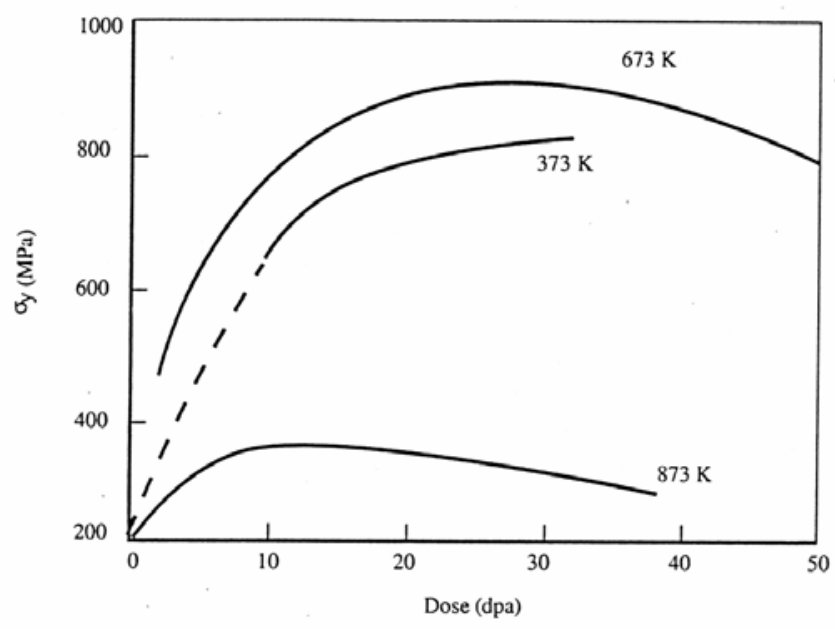

Figure 5. Schematic of effect of irradiation on yield strength as a function of dose and temperature in austenitic stainless steels.

Bloom et al.[23] tested type $304 \mathrm{SS}$ samples irradiated between 93 and $371{ }^{\circ} \mathrm{C}$ at a fluence of $7 \times 10^{20} \mathrm{n} / \mathrm{cm}^{2}(<1 \mathrm{dpa})$ at room temperature. The (YS) and ultimate tensile strength (UTS) showed a maximum at $\sim 150^{\circ} \mathrm{C}$. A significant decrease in the YS was seen between 300 and $350^{\circ} \mathrm{C}$. Total elongation for these samples decreased from approximately $48 \%$ at $93^{\circ} \mathrm{C}$ to $\sim 26 \%$ at $300^{\circ} \mathrm{C}$. The strain hardening rate was much higher at the lower temperatures and the load elongation curves exhibited a yield drop at higher temperatures, but not at lower test temperatures. These observations provide a definite indication of a transition in deformation behavior as a function of irradiation temperature.

Martin et al. [24] examined tensile properties of 304 and 347 SS irradiated from 150 to $750^{\circ} \mathrm{C}$ and tested from 25 to $850^{\circ} \mathrm{C}$. Specimens were irradiated in ORR to a dose of $\sim 7$ $\mathrm{X} 10^{20} \mathrm{n} / \mathrm{cm}^{2}(<1 \mathrm{dpa})$. The work hardening coefficient of these alloys also decreased over unirradiated material and significant decreases in ductility with increasing temperature at irradiation temperatures less than $1 / 2 \mathrm{~T}_{\mathrm{m}}$ and deformation temperatures $<$ $600^{\circ} \mathrm{C}$ were observed. The decrease in ductility was associated with a substantial decrease in uniform elongation and failure occurred by shear destabilization not brittle failure as is the case for unirradiated materials failing due to phenomena such as 
hydrogen embrittlement. Above $600^{\circ} \mathrm{C}$, the yield stress appeared to be unaffected by the radiation damage.

Similar behavior was also seen by Holmes et al. [25] for an 18-8 type SS irradiated at $352^{\circ} \mathrm{C}$ and tested from $23-371^{\circ} \mathrm{C}$. The irradiation dose was $\sim 1.4 \times 10^{22} \mathrm{n} / \mathrm{cm}^{2}(\mathrm{E}>0.18$ $\mathrm{MeV}$ ) in EBR-II. The YS was normalized by dividing the room temperature shear modulus by the shear modulus at the testing temperature. Radiation damage raised the YS significantly above the annealed YS. The YS gradually decreased with increasing testing temperature, but was still greater than the annealed YS even when the testing temperature was well above the initial irradiation temperature. The irradiation-produced Frank loops were $\sim 40 \mathrm{~nm}$ in diameter and the irradiated microstructure also contained a population of octahedral cavities. Following annealing at $\sim 593^{\circ} \mathrm{C}$, faulted loops transformed to form dislocation networks and a corresponding reduction in YS was observed. The authors argue that the decrease in YS with temperature results from the fact that at low temperatures loops act as short range barriers to dislocation motion which can be bypassed with a combination of stress and thermal activation. At high temperatures, short range barriers are ineffective in hardening and only long range barriers are involved in hardening. Disappearance of Frank loops and a significant drop in YS indicates Frank loop interactions are principally responsible for the hardening.

The reduction in uniform elongation is believed to be a direct consequence of the reduction in work hardening. In unirradiated materials work hardening occurs by the generation and intersection of dislocations which increases the flow stress. If a localized region begins to neck, it will harden and nearby regions will deform. In irradiated materials, defect clearing can lead to work softening, necking is not inhibited and ultimately the sample fails with little uniform elongation when deformed in tension. This failure is caused by shear instability and the formation of shear bands.

In summary, the effect of irradiation on the tensile properties is to increase YS and reduce the uniform elongation. Hardening peaks are seen for a wide range of conditions and heats between 250 and $300^{\circ} \mathrm{C}$ while uniform elongation drops substantially. These transitions in tensile behavior are attributed to the development of the radiation-induced microstructure.

\subsection{The Impact of Radiation Induced Microstructures on Alloy Failure Processes}

Failure modes in metals can be plotted on a fracture map and the one for 316 stainless steel is shown in Figure 6 [26]. In both unirradiated and irradiated material, as the temperature decreases, smaller strain rates are required to cause intergranular fracture. Irradiation increases the yield strength, shifting the transgranular/intergranular demarcation to higher strain rates, potentially contributing to intergranular failure in LWR components. Heavily cold-working unirradiated steel will also increase the yield strength, shifting the transgranular/intergranular demarcation to higher strain rates.

Though the yield strength of stainless steel can be increased to similar levels by both cold-work and irradiation, the underlying microstructures are quite different. The 
strengthening mechanism in cold-worked material is the increased dislocation density which inhibits dislocation motion. In irradiated material, the underlying microstructure can consist of both network dislocations and dispersed barriers such as dislocation loops, voids, and precipitates. Additionally, in irradiated material, the grain boundary composition changes significantly, potentially degrading grain

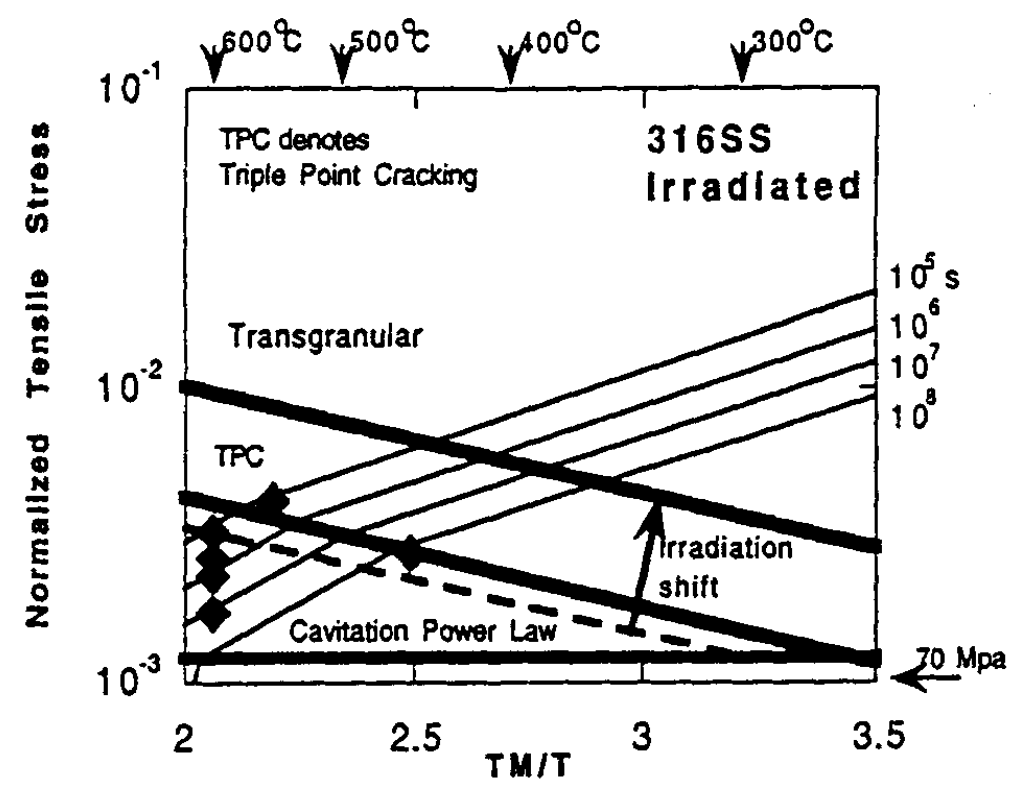

Figure 6. Predicted fracture map for irradiated 316 stainless steel. Irradiation is assumed to increase the yield stress by a factor of three and to decrease the time-tofracture by a factor of $\mathbf{1 0}$. The diamond symbols indicate observed IG fracture for irradiated 304 stainless steel. The contours for fracture times are shown. The mode shift from unirradiated (dashed line) to irradiated (bold line) is shown for the TG/triple-point crack transition [26].

boundary cohesion. Therefore, while cold-working may shift the TG/IG demarcation line, cold-work alone may not be sufficient to induce intergranular failure at LWR relevant conditions. 


\subsection{Experimental}

\subsection{Sample Fabrication}

\subsubsection{Unirradiated materials}

Commercially available sheet type 316 stainless steel material was purchased at a thickness of $1.87 \mathrm{~mm}(0.0735 \mathrm{in}$.) Pieces were sheared to approximately $15.2 \mathrm{~cm}(6 \mathrm{in}$.) long and $2.5 \mathrm{~cm}\left(1 \mathrm{in}\right.$.) wide. All pieces were then annealed for 2 hours at $1100^{\circ} \mathrm{C}$ and rolled 8 passes.

Three material conditions were produced for the mechanical testing matrix, 1) the reduction from $1.87 \mathrm{~mm}$ to $0.94 \mathrm{~mm}(0.0735$ in. to 0.037 in. $)$ produced a $50 \% \mathrm{CW}$ material, 2) the reduction from $1.23 \mathrm{~mm}$ to $0.94 \mathrm{~mm}(0.0485$ in. to 0.037 in.) produced a $25 \% \mathrm{CW}$ material and finally 3$)$, the annealed $0.94 \mathrm{~mm}(0.037 \mathrm{in}$.) thick material produced a $0 \%$ (SA) material. Tensile samples were then fabricated from the three materials conditions by electric discharge machining (EDM). Samples notches (both single and double edge) were produced with a conventional milling machine. Tensile testing of all specimens was conducted at temperatures between 280 and $500^{\circ} \mathrm{C}$ in flowing argon gas and at strain rates of $1 \mathrm{E}-7$ to $1 \mathrm{E}-3 / \mathrm{sec}$. Additionally, transmission electron microscopy samples were prepared from each of the 3 conditions.

\subsubsection{Irradiated Materials}

\section{Selection and Preparation of Tensile Blanks from Irradiated EBR-II Hexagonal Ducts}

The tensile testing of irradiated austenitic stainless steels in this project was done using materials taken from assembly hardware which had been used in the Experimental Breeder Reactor II (EBR-II). Specifically hexagonal-shaped tubes, approximately $1 \mathrm{~mm}$ thick (0.040 inches) were used to encase various core, reflector, and blanket materials. These ducts extended vertically through the EBR-II core, the reactor coolant entering one end and exiting the top. Therefore, the operating temperature increased with axial position on the duct and the neutron flux peaked at core centerline. Samples representing a variety of irradiation doses and operating temperatures could therefore be selected from a single duct (EBR-II assembly).

Material taken from below core centerline on EBR-II assemblies that were irradiated in outer rows, is closest to the operating temperatures experienced in a light water reactor (LWR). A core diagram and schematic of the hexagonal duct geometry is shown in Figure 7. Initial materials tests during EBR-II reactor operation were performed in the fueled area of the core, where dose-rates were significantly higher. Dose-rates in the reflector and blanket regions more closely resemble those of LWR's and these ducts were selected for the present study. A diagram of dose-rate versus core position is shown in Figure 8. Two materials (AISI Types 304 and 316 stainless steel) and starting material conditions were chosen. These were 20\% cold-worked 316 (CW316 SS) and solutionannealed 304 stainless 


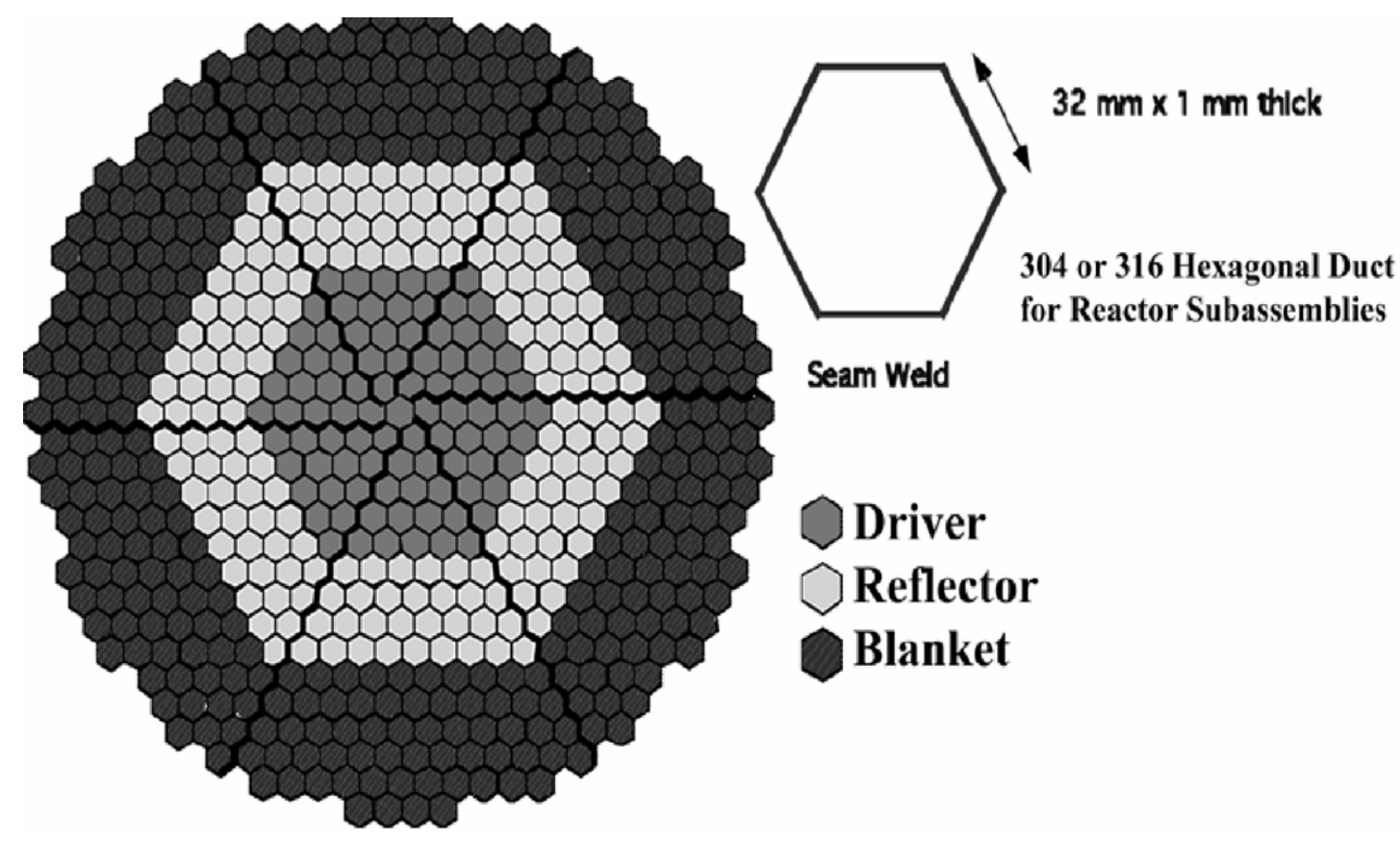

Figure 7. Schematic of EBR-II core and subassembly hexagonal ducts.

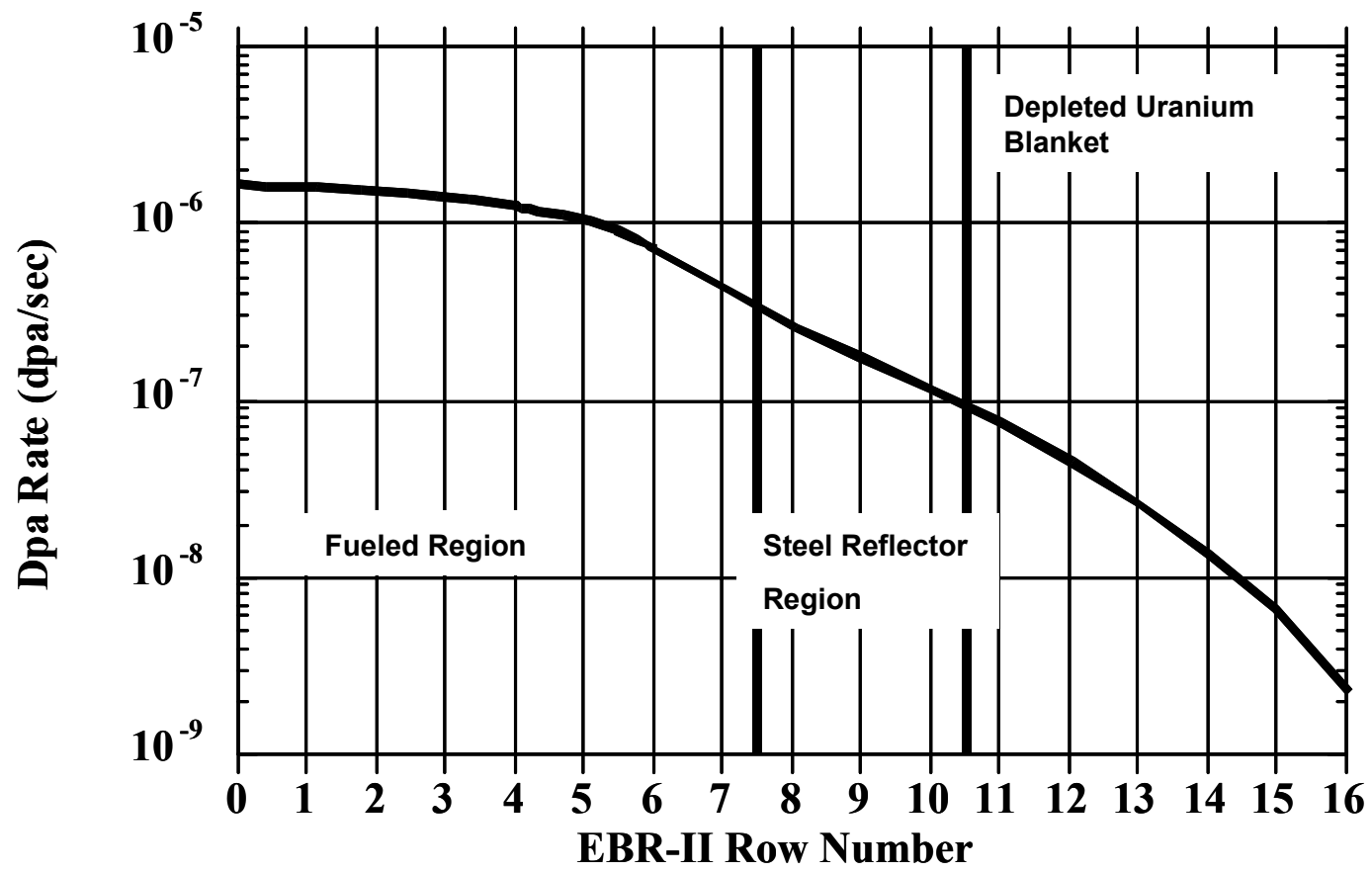

Figure 8. Plot of dose-rate as a function of row in the EBR-II core 
steel (SA304 SS). The assemblies chosen were S-1951 (CW316 SS) and U-9018 (SA304 SS). S-1951 had been irradiated in Row 8 of EBR-II while U-9018 had been irradiated in Row 10.

Sampling locations were chosen to provide the best coverage of sample conditions for material characterization, as well as tensile and shear punch testing. The numbers of samples obtained from each duct were:

- Twelve tensile blanks from each material

- Six $2 \mathrm{~cm}$ round disks from each material, from which

- $3 \mathrm{~mm}$ round disks were prepared for

TEM characterization and shear punch testing

Extra $2 \mathrm{~cm}$ discs were machined to use as backup samples. All samples from the $20 \%$ coldworked 316 and solution-annealed 304 stainless ducts have now been machined in the Hot Fuels Examination Facility (HFEF) hot cells. Final tensile sample geometries were attained through electro-discharge machining in the hot cells at ANL Chicago. Operating temperature and neutron dose conditions have been calculated for the tensile blanks, which are now at ANL-E for final machining and testing, and these conditions are listed in Tables 1 and 2.

\subsection{Setup of Constant Extension Rate Test Framework \& Drive Systems}

For the purpose of testing at the slow strain-rates proposed for the test matrix a constant extension rate tensile test system (CERT) was constructed consisting of two load trains. Load train A possesses a high extension rate drive (HERD) system, while load train B consists of a low extension rate drive (LERD) system. The system was designed to drive both load train actuators using either the HERD motor or the LERD motor or the HERD and LERD motors can each drive one actuator simultaneously. This flexibility permits two specimens to be tested simultaneously at the same strain-rate. For instance, this feature allowed two $10^{-7} \mathrm{sec}^{-1}$ tests, which last 3-4 weeks, to be run simultaneously but at different temperatures. An image of the CERT system is provided in Figure 9. The LERD system is capable of conducting tests with displacement rates as low as $1.3 \times 10^{-8} \mathrm{inch} / \mathrm{sec}$ or an equivalent specimen strain rate of approximately $2 \times 10^{-8} / \mathrm{sec}$.

Furnace and specimen temperatures are acquired using a digital signal recorder. Temperature readings from two Type $\mathrm{K}$ thermocouples $(\mathrm{T} / \mathrm{C})$ are directly saved on a 3.5-inch floppy disk for later analysis. A fixed $\mathrm{T} / \mathrm{C}$ in the wall of the furnace is used to control the furnace power and was earlier calibrated to another thermocouple spot-welded to a "dummy" specimen; this way, testing can be conducted without the need for a spot-welded T/C. Testing was conducted with the furnace holes plugged by top and bottom endcaps to prevent heat loss from the furnace and a flowing argon $(99.999 \%$ Ar) gas purge at $800 \mathrm{cc} / \mathrm{min}$, which 
Table 1. 3/4" Samples from Irradiated Cold-Worked 316

\begin{tabular}{|c|c|c|c|c|c|}
\hline Assembly & $\frac{\text { Material }}{\text { S-1951 }}$ & Flat \# & Sample \# & Dose, dpa & $\frac{\text { Operating }}{\mathbf{T},{ }^{\circ} \mathbf{C}}$ \\
\hline S-1951 & $\begin{array}{c}20 \% \mathrm{CW} \\
316\end{array}$ & 3 & SD1 & 5 & 373 \\
\hline S-1951 & $\begin{array}{c}20 \% \mathrm{CW} \\
316\end{array}$ & 4 & SD2 & 9 & 373 \\
\hline S-1951 & $\begin{array}{c}20 \% \mathrm{CW} \\
316\end{array}$ & 5 & SD4 $^{*}$ & 7 & 380 \\
\hline S-1951 & $\begin{array}{c}20 \% \mathrm{CW} \\
316\end{array}$ & 5 & SD5 $^{*}$ & 30 & 393 \\
\hline S-1951 & $\begin{array}{c}20 \% \mathrm{CW} \\
316\end{array}$ & 6 & SD6 & 6 & 373 \\
\hline
\end{tabular}

*thinned and punched for TEM/shear punch discs

Table 2. 3/4" Samples from Irradiated Solution-Annealed 304

\begin{tabular}{|c|c|c|c|c|c|}
\hline Assembly & Material & Flat \# & Sample \# & Dose, dpa & $\begin{array}{c}\text { Operating T, } \\
\text { C }\end{array}$ \\
\hline U-9018 & SA304 & 1 & UD1 & 4 & 372 \\
\hline U-9018 & SA304 & 1 & UD2 & 14 & 378 \\
\hline U-9018 & SA304 & 2 & UD3* & 15.5 & 380 \\
\hline U-9018 & SA304 & 5 & UD4* & 11 & 373 \\
\hline U-9018 & SA304 & 5 & UD5* & 21.5 & 384 \\
\hline U-9018 & SA304 & 6 & UD6 & 30 & 379 \\
\hline
\end{tabular}

*thinned and punched for TEM/shear punch discs 


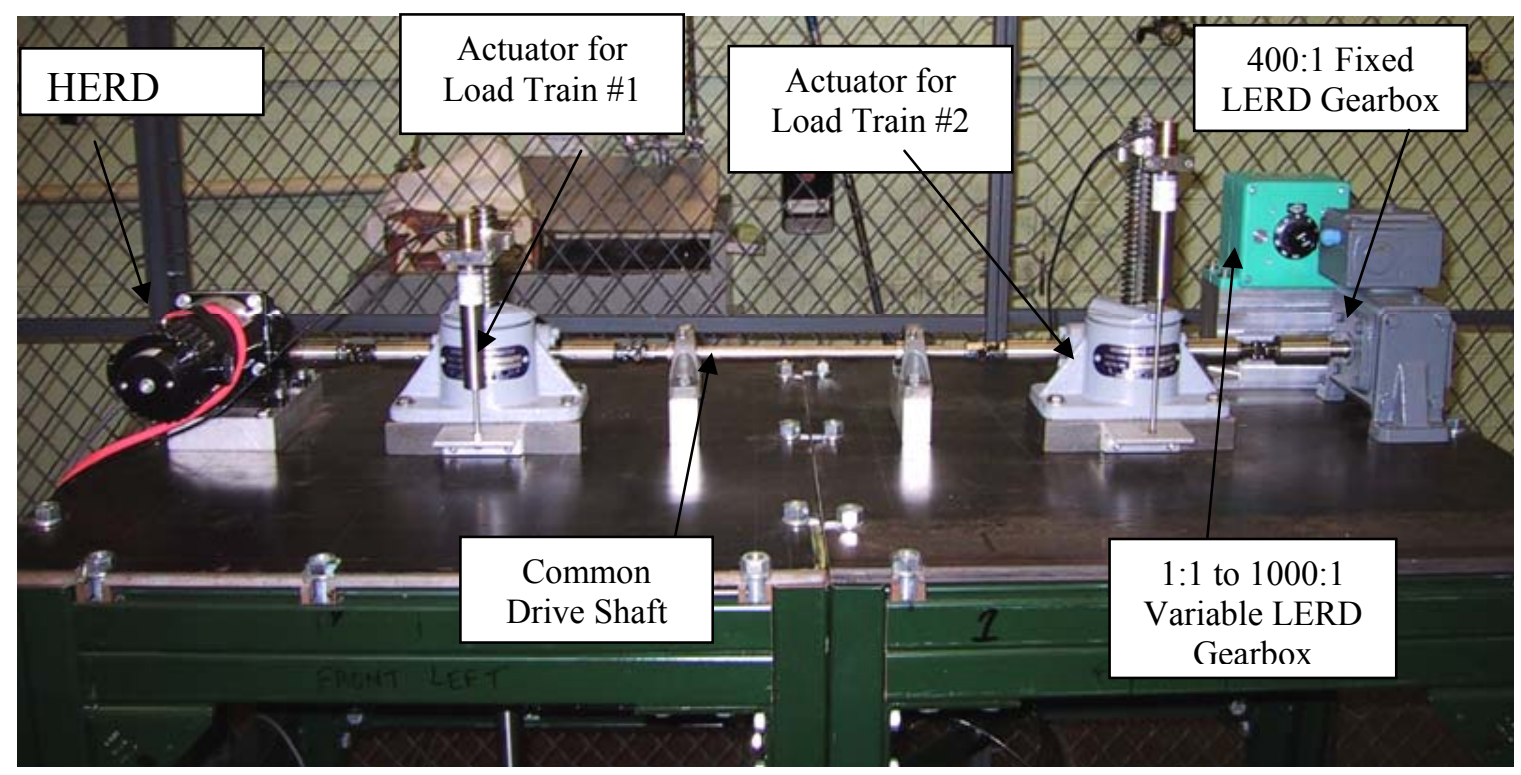

Figure 9. Image of coupled actuators (with LVDT) on a common drive shaft for simultaneous testing of two specimens at the same strain-rate; also shown components of the LERD (motor not shown) and HERD systems.

equates to a complete exchange of the furnace cavity atmosphere approximately every 1.5 minutes.

\subsection{Experimental procedures for TEM Characterization of Irradiated SS Hexagonal Duct Materials}

Microstructural analysis for irradiated solution annealed 304 and coldworked 316 SS hex duct samples was carried out in a JEOL 2010 transmission electron microscope equipped with energy dispersive x-ray detector and a scanning transmission electron detector attachment. The microscope was operated at an accelerating voltage of $200 \mathrm{kV}$. The following sections will describe the analysis techniques used and detail the experimental results.

\subsubsection{Thin Foil preparation:}

Several $3 \mathrm{~mm}$ TEM discs were punched from each of the $2 \mathrm{~cm}$ density discs. The discs were punched using a custom disc-punch located inside the HFEF hot cell facility. The TEM discs were then ground out of cell to approximately 150 microns thick and thinned to electron transparency using a South Bay Technology single jet electropolisher (flipping the sample half way through polishing). The electrolyte used was a solution of $95 \%$ methanol/ $5 \%$ perchloric acid at polishing temperatures between -45 and $-30^{\circ} \mathrm{C}$. The measured radioactivity of the electropolished TEM disks ranged between approximately 20 and $100 \mathrm{mr} / \mathrm{hr} \beta / \gamma$, a level which allowed routine radiological handling of the samples. 


\subsubsection{Void and Dislocation Analysis:}

To perform defect density measurements, it was necessary to determine sample thickness in the analysis regions. This was accomplished using convergent beam electron diffraction (CBED) with an electron probe size on the order of $10-15 \mathrm{~nm}$. Pixel intensity profiles across the scanned CBED disk image were used to measure fringe spacing. The spacings were then converted to a thickness value as described in reference [27]. Both magnification and camera length were calibrated on the TEM prior to making quantitative measurements.

Microstructural analysis was carried out in 2 or 3 grains, analyzing several fields of view in each grain. Void number densities were counted using a freeware image analysis program entitled NIH image. Void diameters were also measured in several regions to determine the void size distribution. In taking images of the voids, a large deviation from the Bragg condition was used to minimize contrast from the dislocation structure.

Because of the high density of radiation produced defects, details of the dislocation structure could not be discerned under bright-field (BF) imaging conditions, therefore, weak-beam darkfield (WBDF) imaging conditions were used. Under WBDF, imaging with a $<111>$ type $g$ vector reveals all of the variants of the Frank loops while 3 of the 6 variants of the perfect dislocations are visible. Loop sizes and densities were measured using procedures similar to those used in measuring the void size distributions.

For the network dislocations, the line length per volume $(\Lambda)$ was determined by measuring the number of dislocations in an area and using the stereological equation developed by Schoeck [28]:

$$
\Lambda=2 * \mathrm{P}_{\mathrm{A}}
$$

Eq. 1

where $\mathrm{P}_{\mathrm{A}}$ is the number of intersecting points (dislocations) divided by the area. This value was then multiplied by an additional factor of 2 to take into account the fact that with $\mathrm{g}_{111}$ one half of the dislocations will be invisible.

\subsection{Shear Punch Fixture Set Up}

Mechanical drawings of the fixture, which has been successfully tested at PNNL, were obtained, and fabrication of the fixture is complete. A schematic of the fixture is shown in Figure 10. Using the fixture, in combination with a conventional Instron universal testing system (UTS), mechanical properties data is determined by measuring the force/displacement relationship of a 1 $\mathrm{mm}$ rod as it penetrates through the $3 \mathrm{~mm}$ disk. Images of the Instron UTS along with a close-up of the shear punch fixture are shown in Figure 11 and 12. A capacitance-based probe is used to measure the punch displacement by measuring the gap to a conductive pin extending from the base of the punch. This capacitance is then output to an amplifier, which then converts it to a DC voltage. This voltage is then output to a computer controlled data acquisition system allowing a conversion of the displacement readings to strain values. 


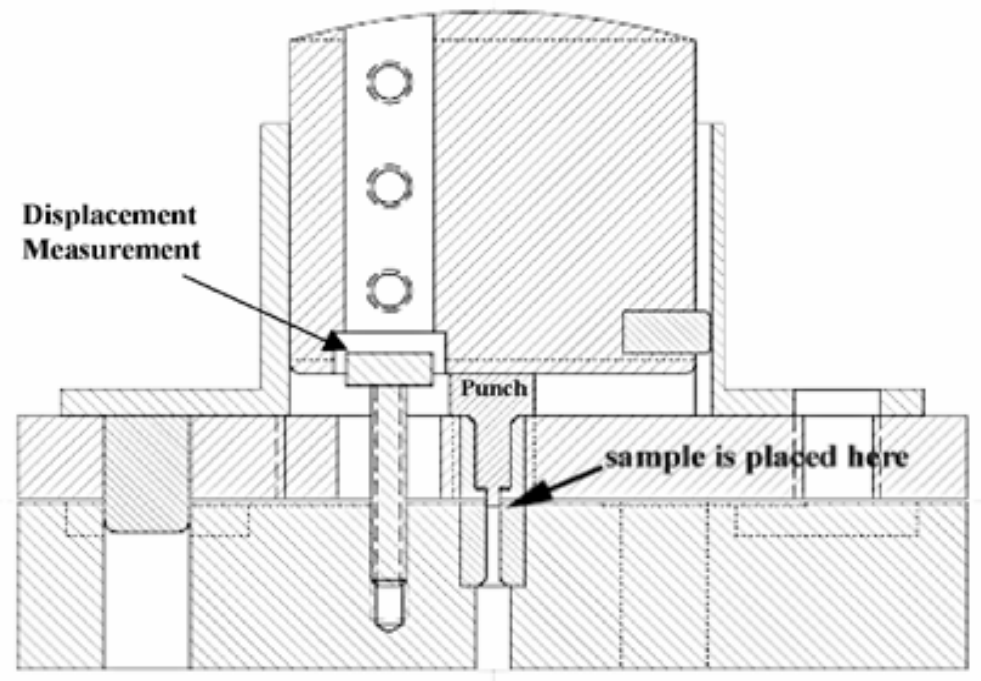

Figure 10. Schematic of shear punch fixture. The entire fixture is inserted into the load frame of the Instron UTS to conduct the test. 


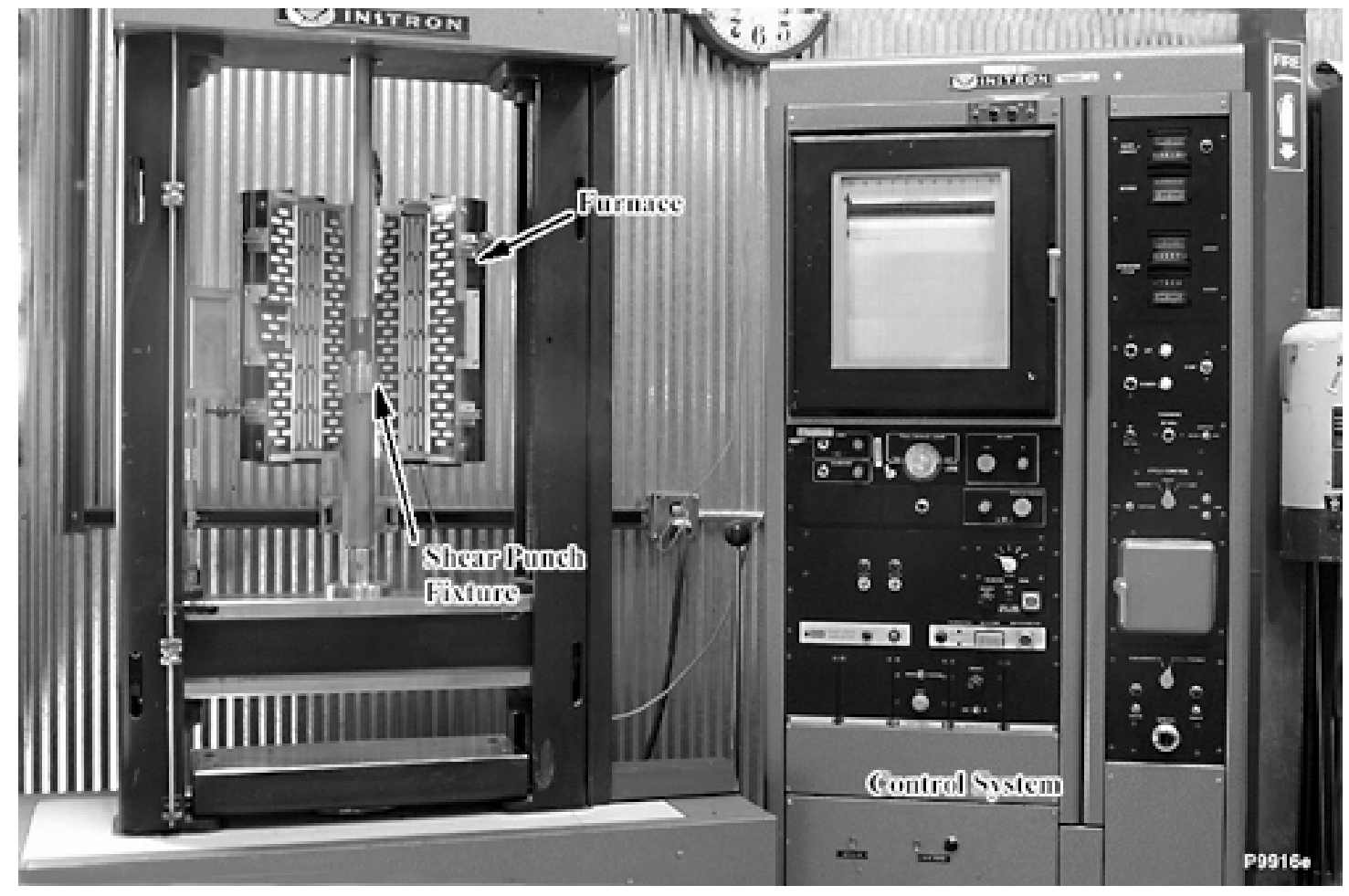

Figure 11. Image of Instron UTS with furnace and fixtures in place to conduct shear punch mechanical tests.

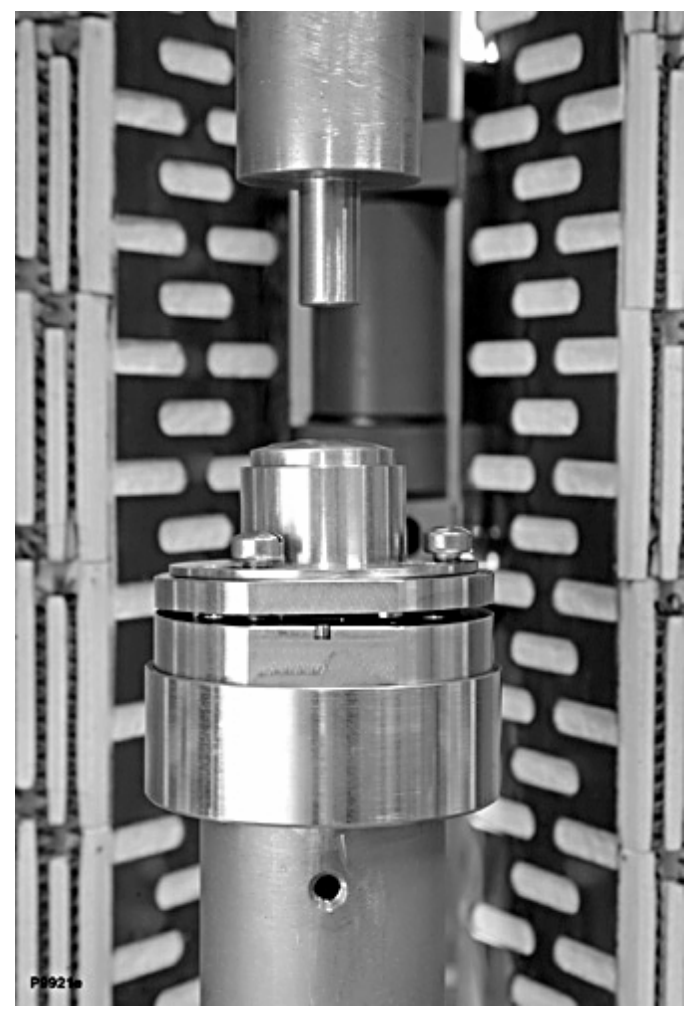

Figure 12. Close up of shear punch fixture and testing platform. 


\subsection{Mechanical Testing}

\subsection{Tensile Testing of Unirradiated Coldwork 316 SS}

To isolate the effect of bulk hardening from strain localization, tensile specimens with gauge section length of $19.0 \mathrm{~mm}$ and width of $3.00 \mathrm{~mm}$ were machined from solution annealed and work hardened $316 \mathrm{SS}$. Also, to determine fracture processes, double-edge notched specimens were machined to constrain transverse deformation and promote notch-tip stress concentration and a state of plane-stress tension.

The original plan for testing and post-test examination of un-notched tensile and double-edge notched tensile (DENT) specimens fabricated from 0, 25, and 50\% cold-worked (CW) 316SS has been completed at all planned strain-rates $\left(10^{-3}, 10^{-5}\right.$, and $\left.10^{-7} \mathrm{sec}^{-1}\right)$ and all planned temperatures $\left(280,350,400\right.$ and $\left.500^{\circ} \mathrm{C}\right)$. Results from this testing are reported in Tables 3, 4, and 5 for 0,25 , and $50 \% \mathrm{CW}$ specimens, respectively. Figures 13, 14, and 15 show the engineering stress vs. strain responses of un-notched and DENT specimens at 0,25 , and $50 \%$ $\mathrm{CW}$, respectively at temperatures of 400 and $500^{\circ} \mathrm{C}$. Note, no tests were conducted on unnotched samples at a strain rate of $10^{-7} \mathrm{~s}^{-1}$.

Engineering stress versus strain plots are calculated using the readings from the load cell and specimen LVDT and the original dimensions of the specimens as measured before the test. The original dimensions used to calculate engineering stress include the nominal thickness and width of the gauge section as measured using a 50X microscope and an $\mathrm{x}$, $\mathrm{y}$ stage with digital micrometers (accurate to 0.00005-inch); redundant measurements of thickness and width were determined using a digital caliper (accurate to 0.0005-inch) and compared to the microscope results. Engineering strain was calculated from the LVDT displacement reading and assuming a uniform gauge section of 0.75 -inch. Figure 16 shows engineering stress-strain responses for notched and un-notched specimens with 0,25 , and $50 \%$ cold-work tested at $10^{-3}$ per second and at 400 and $500^{\circ} \mathrm{C}$; in Figure 16, some responses are intentionally offset for clarity.

For the $0 \%$ cold-worked material, the yield and ultimate tensile strengths of both notched and unnotched specimens indicate that the deformation and failure path was predominantly due to a plastic-instability process. Figure 16 (a) shows a minor effect of temperature on the yield point and flow stress for un-notched specimens and little or no effect for notched specimens. Also, at higher flow stresses of un-notched specimens, dynamic strain aging is evident from small oscillations in stress; these oscillations are approximately 6-10 MPa in height and $1 \%$ in width. Figure 17 shows the minor effect of temperature on the yield and ultimate strengths.

In contrast, the "effective" yield and ultimate strengths for notched specimens fabricated from 25 and $50 \%$ cold-worked materials are greater than those measured from un-notched testing; this seems to suggest that highly cold-worked material is resistant to plastic flow in the presence of a notch and the failure occurred as the result of microcrack initiation at a notch tip followed by, most likely at these temperatures and sheet thickness, plane-stress crack propagation. The increase in yield point for notched specimens (as compared to un-notched specimens) may be representative of the resistance to crack-initiation of low strain-hardening materials and/or the 
Table 3. Summary of Mechanical, Testing, and Fractographic Properties for 0\% Cold-Worked 316SS.

\begin{tabular}{|c|c|c|c|c|c|c|c|c|c|c|c|c|c|c|c|c|}
\hline $\mathbf{A} / \mathbf{G} \#$ & $\underset{\#}{\text { Run }}$ & $\begin{array}{c}\text { Cold } \\
\text { Work }\end{array}$ & $\begin{array}{l}\text { Specimen } \\
\text { Type }\end{array}$ & $\begin{array}{l}\text { Strain } \\
\text { Rate }\end{array}$ & $\begin{array}{c}\text { Test } \\
\text { Temp. }\end{array}$ & $\begin{array}{c}0.2 \% \\
\text { YS }\end{array}$ & UTS & $\mathbf{U E}$ & $\mathbf{T E}$ & $\begin{array}{c}\text { TE } \\
\text { (scribes) }\end{array}$ & $\begin{array}{c}\text { Failure } \\
\text { Time }\end{array}$ & $\mathbf{R A}$ & $\begin{array}{l}\text { Plast } \\
\text { ic } \\
\quad R\end{array}$ & $\boldsymbol{K}$ & $n$ & $\begin{array}{c}\text { IG } \\
\text { Fracture }\end{array}$ \\
\hline & & $(\%)$ & $(\mathrm{U}$ or $\mathrm{N})$ & $\left(\mathrm{sec}^{-1}\right)$ & $\left({ }^{\circ} \mathrm{C}\right)$ & $(\mathrm{MPa})$ & $(\mathrm{MPa})$ & $(\%)$ & $(\%)$ & $(\%)$ & (minutes) & $(\%)$ & & $(\mathrm{MPa})$ & & $(\%)$ \\
\hline $620 \mathrm{D} 5$ & A007 & 0 & $\mathrm{U}$ & $10^{-3}$ & 400 & 126.4 & 386.8 & 43.8 & 48.5 & 40.0 & 9.53 & 49.5 & 0.78 & 150.2 & 0.570 & 0 \\
\hline 620D6 & $\mathrm{A} 005$ & 0 & $\mathrm{U}$ & $10^{-3}$ & 500 & 95.7 & 375.5 & 39.0 & 44.0 & 36.0 & 8.97 & 48.3 & 0.73 & 150.1 & 0.600 & 0 \\
\hline $620 \mathrm{~A} 3$ & A008 & 0 & $\mathrm{~N}$ & $10^{-3}$ & 400 & 136.0 & 384.2 & 13.0 & 15.3 & 14.2 & 3.35 & 20.9 & N/A & $\mathrm{N} / \mathrm{A}$ & $\mathrm{N} / \mathrm{A}$ & 0 \\
\hline $620 \mathrm{~A} 6$ & A006 & 0 & $\mathrm{~N}$ & $10^{-3}$ & 500 & 121.3 & 379.9 & 13.1 & 14.8 & 15.1 & 3.22 & 16.7 & N/A & $\mathrm{N} / \mathrm{A}$ & N/A & 0 \\
\hline $620 \mathrm{~A} 1$ & A034 & 0 & $\mathrm{U}$ & $10^{-5}$ & 280 & 103.7 & 389.9 & 38.0 & 41.4 & 35.5 & 586.00 & 52.5 & 0.45 & 156.3 & 0.541 & 0 \\
\hline $620 \mathrm{~A} 2$ & A037 & 0 & $\mathrm{U}$ & $10^{-5}$ & 350 & 97.4 & 395.6 & 40.0 & 42.5 & 32.8 & 594.00 & 45.5 & 0.59 & 172.5 & 0.607 & 0 \\
\hline 620D1 & A043 & 0 & $\mathrm{U}(25 \%)$ & $10^{-5}$ & 350 & 93.7 & N/A & N/A & 10.0 & 8.7 & N/A & N/A & N/A & N/A & $\mathrm{N} / \mathrm{A}$ & N/A \\
\hline 620D2 & A042 & 0 & $\mathrm{U}(75 \%)$ & $10^{-5}$ & 350 & 108.3 & N/A & N/A & 35.0 & 30.4 & $\mathrm{~N} / \mathrm{A}$ & $\mathrm{N} / \mathrm{A}$ & $\mathrm{N} / \mathrm{A}$ & N/A & N/A & $\mathrm{N} / \mathrm{A}$ \\
\hline 620D3 & A030 & 0 & $\mathrm{U}$ & $10^{-5}$ & 400 & 99.2 & 417.2 & 45.0 & 48.0 & 40.3 & 676.00 & 43.7 & 0.92 & 167.9 & 0.633 & 0 \\
\hline $620 \mathrm{D} 4$ & A022 & 0 & $\mathrm{U}$ & $10^{-5}$ & 500 & 87.5 & 381.7 & 40.5 & 44.8 & 39.2 & 587.84 & 48.9 & 0.76 & 163.5 & 0.644 & 0 \\
\hline $620 \mathrm{~A} 4$ & A029 & 0 & $\mathrm{~N}$ & $10^{-5}$ & 400 & 136.5 & 394.5 & 14.5 & 15.6 & 15.7 & 245.00 & 12.7 & $\mathrm{~N} / \mathrm{A}$ & $\mathrm{N} / \mathrm{A}$ & $\mathrm{N} / \mathrm{A}$ & 0 \\
\hline $620 \mathrm{~A} 7$ & A028 & 0 & $\mathrm{~N}$ & $10^{-5}$ & 500 & 111.3 & 374.2 & 14.0 & 15.3 & 13.1 & 231.50 & 13.7 & N/A & N/A & $\mathrm{N} / \mathrm{A}$ & 0 \\
\hline $620 \mathrm{~A} 5$ & B006 & 0 & $\mathrm{~N}$ & $10^{-7}$ & 400 & 156.5 & 422 & 14.0 & 15.8 & 15.8 & 21,183 & 15.9 & $\mathrm{~N} / \mathrm{A}$ & N/A & $\mathrm{N} / \mathrm{A}$ & 0 \\
\hline $620 \mathrm{~A} 8$ & A048 & 0 & $\mathrm{~N}$ & $10^{-7}$ & 500 & 138.6 & 399.7 & 12.7 & 15.7 & 14.9 & 19,191 & 11.6 & N/A & $\mathrm{N} / \mathrm{A}$ & $\mathrm{N} / \mathrm{A}$ & 0 \\
\hline
\end{tabular}

A/G\#: material/specimen classification according to AGHCF Quality Assurance plan.

Specimen Type (U or N): U - Un-notched or N - Notched; percentage (\%) indicates interrupted test at \% plastic strain prior to necking or maximum load

$0.2 \%$ YS: For Notched specimens, denotes an "effective" engineering stress value at $0.2 \%$ plastic strain offset.

TE (scribes): Total Elongation as measured directly from scribe marks on the gauge section.

Failure Time: Time to failure for all tests including both elastic and plastic regimes.

RA: Reduction-in-Area.

Plastic $R$ : Plastic anisotropy parameter, $\mathrm{R}=[$ (width strain)/(thickness strain) $]$

$K$ : Strength Coefficient from Power Law Fit of True Stress versus True Strain $\left(\sigma=K \varepsilon^{n}\right)$

$n$ : Strain-Hardening Exponent from Power Law Fit of True Stress versus True Strain $\left(\sigma=K \varepsilon^{n}\right)$

IG Fracture: \% of fracture surface that has an intergranular (IG) fracture appearance from SEM imaging.

N/A: Not Applicable

?: Problem or mistake in measurement.

NYD: No Yield point Detected. 
Table 4. Summary of Mechanical, Testing, and Fractographic Properties for 25\% Cold-Worked 316SS.

\begin{tabular}{|c|c|c|c|c|c|c|c|c|c|c|c|c|c|c|c|c|}
\hline $\mathbf{A} / \mathbf{G} \#$ & $\begin{array}{c}\text { Run } \\
\#\end{array}$ & $\begin{array}{c}\text { Cold } \\
\text { Work } \\
\end{array}$ & $\begin{array}{c}\begin{array}{c}\text { Specimen } \\
\text { Type }\end{array} \\
\end{array}$ & $\begin{array}{c}\text { Strain } \\
\text { Rate }\end{array}$ & $\begin{array}{c}\text { Test } \\
\text { Temp. }\end{array}$ & $\begin{array}{c}0.2 \% \\
\text { YS } \\
\end{array}$ & UTS & $\mathbf{U E}$ & $\mathbf{T E}$ & $\begin{array}{c}\mathrm{TE} \\
\text { (scribes) }\end{array}$ & $\begin{array}{c}\text { Failure } \\
\text { Time }\end{array}$ & $\mathbf{R A}$ & $\begin{array}{c}\text { Plastic } \\
R \\
\end{array}$ & $\boldsymbol{K}$ & $n$ & $\begin{array}{c}\text { IG } \\
\text { Fracture }\end{array}$ \\
\hline & & $(\%)$ & $(\mathrm{U}$ or $\mathrm{N})$ & $\left(\sec ^{-1}\right)$ & $\left({ }^{\circ} \mathrm{C}\right)$ & $(\mathrm{MPa})$ & (MPa) & $(\%)$ & $(\%)$ & $(\%)$ & (minutes) & $(\%)$ & & $(\mathrm{MPa})$ & & $(\%)$ \\
\hline 620E5 & A009 & 25 & $\mathrm{U}$ & $10^{-3}$ & 400 & 531.7 & 556.9 & 0.8 & 3.8 & 6.9 & 1.40 & 37.7 & 0.40 & 108.8 & 0.051 & 0 \\
\hline 620E6 & A010 & 25 & $\mathrm{U}$ & $10^{-3}$ & 500 & 497.5 & 517.6 & 0.8 & 3.6 & 5.1 & 1.30 & 34.3 & 0.52 & 89.6 & 0.026 & 0 \\
\hline 620B3 & $\mathrm{A} 015$ & 25 & $\mathrm{~N}$ & $10^{-3}$ & 400 & 680.5 & 682.3 & 0.2 & 0.5 & 1.1 & 0.67 & 7.9 & N/A & $\mathrm{N} / \mathrm{A}$ & N/A & 0 \\
\hline 620B6 & A014 & 25 & $\mathrm{~N}$ & $10^{-3}$ & 500 & 638.8 & 638.8 & 0.2 & 0.5 & $?$ & 0.65 & 10.2 & N/A & N/A & $\mathrm{N} / \mathrm{A}$ & 0 \\
\hline 620B1 & A033 & 25 & $\mathrm{U}$ & $10^{-5}$ & 280 & 626.0 & 643.6 & 0.6 & 3.3 & 4.3 & 84.7 & 31.8 & 0.49 & 118.1 & 0.037 & 0 \\
\hline $620 \mathrm{~B} 2$ & A036 & 25 & $\mathrm{U}$ & $10^{-5}$ & 350 & 607.4 & 630.6 & 0.6 & 3.4 & 1.5 & 84.0 & 27.2 & 0.63 & 122.1 & 0.039 & 0 \\
\hline 620E1 & A040 & 25 & $\mathrm{U}(25 \%)$ & $10^{-5}$ & 350 & 523.7 & N/A & $\mathrm{N} / \mathrm{A}$ & 0.4 & 2.0 & N/A & N/A & N/A & $\mathrm{N} / \mathrm{A}$ & $\mathrm{N} / \mathrm{A}$ & N/A \\
\hline 620E2 & A039 & 25 & $\mathrm{U}(75 \%)$ & $10^{-5}$ & 350 & 517.1 & N/A & N/A & 1.3 & 1.4 & N/A & $\mathrm{N} / \mathrm{A}$ & $\mathrm{N} / \mathrm{A}$ & $\mathrm{N} / \mathrm{A}$ & N/A & $\mathrm{N} / \mathrm{A}$ \\
\hline $620 \mathrm{E} 3$ & A018 & 25 & $\mathrm{U}$ & $10^{-5}$ & 400 & 544.7 & 579.5 & 1.2 & 3.9 & 6.7 & 97.2 & 28.5 & 0.58 & 101.0 & 0.027 & 0 \\
\hline 620E4 & A021 & 25 & $\mathrm{U}$ & $10^{-5}$ & 500 & 517.5 & 533.4 & 0.9 & 3.9 & 0.0 & 91.2 & 34.2 & 0.41 & 91.6 & 0.020 & 0 \\
\hline 620B4 & A026 & 25 & $\mathrm{~N}$ & $10^{-5}$ & 400 & 709.1 & 714.7 & 0.1 & 0.5 & 0.0 & 49.1 & 2.9 & $\mathrm{~N} / \mathrm{A}$ & $\mathrm{N} / \mathrm{A}$ & N/A & 0 \\
\hline 620B7 & A023 & 25 & $\mathrm{~N}$ & $10^{-5}$ & 500 & 656.7 & 664.3 & 0.1 & 0.6 & 0.3 & 47.8 & 2.8 & N/A & N/A & N/A & 0 \\
\hline 620B5 & A046 & 25 & $\mathrm{~N}$ & $10^{-7}$ & 400 & 742.8 & 750.6 & 0.1 & 0.6 & 3.2 & 3309 & 13.0 & N/A & $\mathrm{N} / \mathrm{A}$ & $\mathrm{N} / \mathrm{A}$ & 0 \\
\hline 620B8 & B004 & 25 & $\mathrm{~N}$ & $10^{-7}$ & 500 & 661.1 & 662.1 & 0.2 & 0.9 & 3.1 & 3306 & 11.0 & N/A & $\mathrm{N} / \mathrm{A}$ & N/A & 0 \\
\hline
\end{tabular}

A/G\#: material/specimen classification according to AGHCF Quality Assurance plan.

Specimen Type (U or N): U - Un-notched or $\mathrm{N}$ - Notched; percentage (\%) indicates interrupted test at \% plastic strain prior to necking or maximum load.

$0.2 \%$ YS: For Notched specimens, denotes an "effective" engineering stress value at $0.2 \%$ plastic strain offset.

TE (scribes): Total Elongation as measured directly from scribe marks on the gauge section.

Failure Time: Time to failure for all tests including both elastic and plastic regimes.

RA: Reduction-in-Area.

Plastic $R$ : Plastic anisotropy parameter, $\mathrm{R}=$ [(width strain $) /($ thickness strain $)]$.

$K$ : Strength Coefficient from Power Law Fit of True Stress versus True Strain $\left(\sigma=K \varepsilon^{n}\right)$

$n$ : Strain-Hardening Exponent from Power Law Fit of True Stress versus True Strain $\left(\sigma=K \varepsilon^{n}\right)$.

IG Fracture: $\%$ of fracture surface that has an intergranular (IG) fracture appearance from SEM imaging.

N/A: Not Applicable

?. Problem or mistake in measurement.

NYD: No Yield point Detected. 
Table 5. Summary of Mechanical, Testing, and Fractographic Properties for 50\% Cold-Worked $316 S S$.

\begin{tabular}{|c|c|c|c|c|c|c|c|c|c|c|c|c|c|c|c|c|}
\hline $\mathbf{A} / \mathbf{G} \#$ & Run \# & $\begin{array}{l}\text { Cold } \\
\text { Work }\end{array}$ & $\begin{array}{c}\text { Specimen } \\
\text { Type }\end{array}$ & $\begin{array}{c}\text { Strain } \\
\text { Rate }\end{array}$ & $\begin{array}{c}\text { Test } \\
\text { Temp. }\end{array}$ & $0.2 \% Y S$ & UTS & $\mathbf{U E}$ & $\mathbf{T E}$ & $\begin{array}{c}\text { TE } \\
\text { (scribes) }\end{array}$ & $\begin{array}{c}\text { Failure } \\
\text { Time }\end{array}$ & $\mathbf{R A}$ & $\begin{array}{c}\text { Plastic } \\
R\end{array}$ & $\mathbf{K}$ & $n$ & $\begin{array}{c}\text { IG } \\
\text { Fracture }\end{array}$ \\
\hline & & $(\%)$ & $(\mathrm{U}$ or $\mathrm{N})$ & $\left(\sec ^{-1}\right)$ & $\left({ }^{\circ} \mathrm{C}\right)$ & $(\mathrm{MPa})$ & $(\mathrm{MPa})$ & $(\%)$ & $(\%)$ & $(\%)$ & (minutes) & $(\%)$ & & $(\mathrm{MPa})$ & & $(\%)$ \\
\hline $620 \mathrm{~F} 4$ & $\mathrm{~A} 013$ & 50 & $\mathrm{U}$ & $10^{-3}$ & 400 & 794.4 & 817.8 & 0.5 & 2.3 & 2.0 & 1.22 & 16.6 & 0.54 & 158.4 & 0.042 & 0 \\
\hline 620F5 & A012 & 50 & $\mathrm{U}$ & $10^{-3}$ & 500 & 757.1 & 778.3 & 0.5 & 1.8 & 3.1 & 1.22 & 14.1 & 0.48 & 143.2 & 0.037 & 0 \\
\hline $620 \mathrm{C} 3$ & A016 & 50 & $\mathrm{~N}$ & $10^{-3}$ & 400 & NYD & 872.9 & 0.0 & 0.0 & 0.0 & 0.7 & 6.9 & N/A & $\mathrm{N} / \mathrm{A}$ & N/A & 0 \\
\hline 620C6 & A017 & 50 & $\mathrm{~N}$ & $10^{-3}$ & 500 & NYD & 911.0 & 0.0 & 0.0 & 1.3 & 0.68 & 7.9 & N/A & $\mathrm{N} / \mathrm{A}$ & $\mathrm{N} / \mathrm{A}$ & 0 \\
\hline $620 \mathrm{C} 1$ & A032 & 50 & $\mathrm{U}$ & $10^{-5}$ & 280 & 854.2 & 858.4 & 0.2 & 1.8 & 0.0 & 81.4 & 17.2 & 0.60 & 154.4 & 0.027 & 0 \\
\hline $620 \mathrm{C} 2$ & $\mathrm{~A} 035$ & 50 & $\mathrm{U}$ & $10^{-5}$ & 350 & 822.2 & 845.1 & 0.4 & 1.2 & 0.7 & 81.8 & 12.8 & 0.95 & 159.0 & 0.040 & 0 \\
\hline 620F1 & A041 & 50 & $\mathrm{U}(25 \%)$ & $10^{-5}$ & 350 & 762.0 & $\mathrm{~N} / \mathrm{A}$ & $\mathrm{N} / \mathrm{A}$ & 0.4 & 1.2 & N/A & N/A & N/A & $\mathrm{N} / \mathrm{A}$ & $\mathrm{N} / \mathrm{A}$ & $\mathrm{N} / \mathrm{A}$ \\
\hline $620 \mathrm{~F} 2$ & A019 & 50 & $\mathrm{U}$ & $10^{-5}$ & 400 & 800.0 & 822.5 & 0.6 & 1.6 & 2.5 & 82.3 & 12.8 & 0.52 & 137.8 & 0.011 & 0 \\
\hline $620 \mathrm{~F} 3$ & $\mathrm{~A} 020$ & 50 & $\mathrm{U}$ & $10^{-5}$ & 500 & 718.5 & 737.7 & 0.6 & 2.4 & 0.0 & 87.7 & 23.9 & 0.27 & 117.2 & 0.001 & 0 \\
\hline $620 \mathrm{C} 4$ & $\mathrm{~A} 025$ & 50 & $\mathrm{~N}$ & $10^{-5}$ & 400 & NYD & 952.6 & 0.0 & 0.0 & 0.6 & 57.6 & 4.1 & N/A & $\mathrm{N} / \mathrm{A}$ & N/A & 0 \\
\hline $620 \mathrm{C} 7$ & $\mathrm{~A} 024$ & 50 & $\mathrm{~N}$ & $10^{-5}$ & 500 & NYD & 806.1 & 0.1 & 0.1 & 0.0 & 52.8 & 13.4 & N/A & N/A & N/A & 0 \\
\hline $620 \mathrm{C5}$ & B005 & 50 & $\mathrm{~N}$ & $10^{-7}$ & 400 & NYD & 926.7 & 0.1 & 0.1 & 1.3 & 3340 & 13.3 & $\mathrm{~N} / \mathrm{A}$ & $\mathrm{N} / \mathrm{A}$ & $\mathrm{N} / \mathrm{A}$ & 0 \\
\hline $620 \mathrm{C} 8$ & $\mathrm{~A} 047$ & 50 & $\mathrm{~N}$ & $10^{-7}$ & 500 & 788.7 & 802.4 & 0.2 & 0.6 & 2.7 & 3218 & 13.7 & N/A & N/A & N/A & 0 \\
\hline 620F6 & & 50 & $\mathrm{U}$ & $? ?$ & $? ?$ & & & & & & & & & & & \\
\hline
\end{tabular}

A/G\#: material/specimen classification according to AGHCF Quality Assurance plan.

Specimen Type (U or N): U - Un-notched or N - Notched; percentage (\%) indicates interrupted test at \% plastic strain prior to necking or maximum load

$0.2 \%$ YS: For Notched specimens, denotes an "effective" engineering stress value at $0.2 \%$ plastic strain offset.

TE (scribes): Total Elongation as measured directly from scribe marks on the gauge section.

Failure Time: Time to failure for all tests including both elastic and plastic regimes.

RA: Reduction-in-Area.

Plastic $R$ : Plastic anisotropy parameter, $\mathrm{R}=[($ width strain) $/($ thickness strain $)]$

$K$ : Strength Coefficient from Power Law Fit of True Stress versus True Strain $\left(\sigma=K \varepsilon^{n}\right)$.

$n$ : Strain-Hardening Exponent from Power Law Fit of True Stress versus True Strain $\left(\sigma=K \varepsilon^{n}\right)$.

IG Fracture: \% of fracture surface that has an intergranular (IG) fracture appearance from SEM imaging.

N/A: Not Applicable

?: Problem or mistake in measurement.

NYD: No Yield point Detected.

??: Test conditions not se 


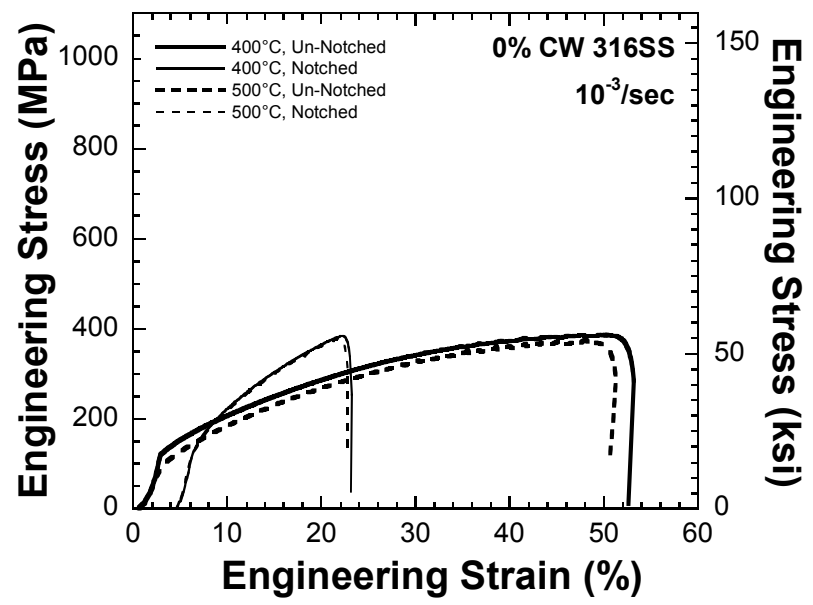

(a)

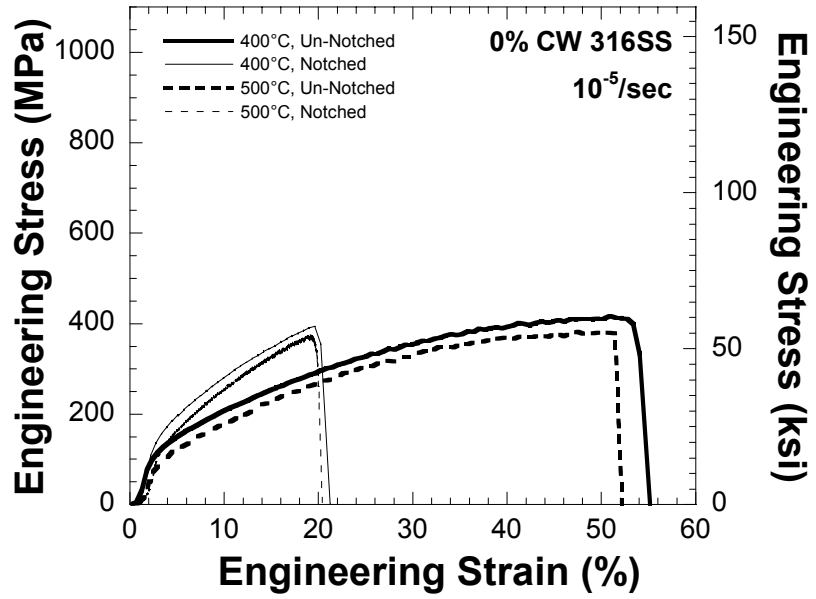

(b)

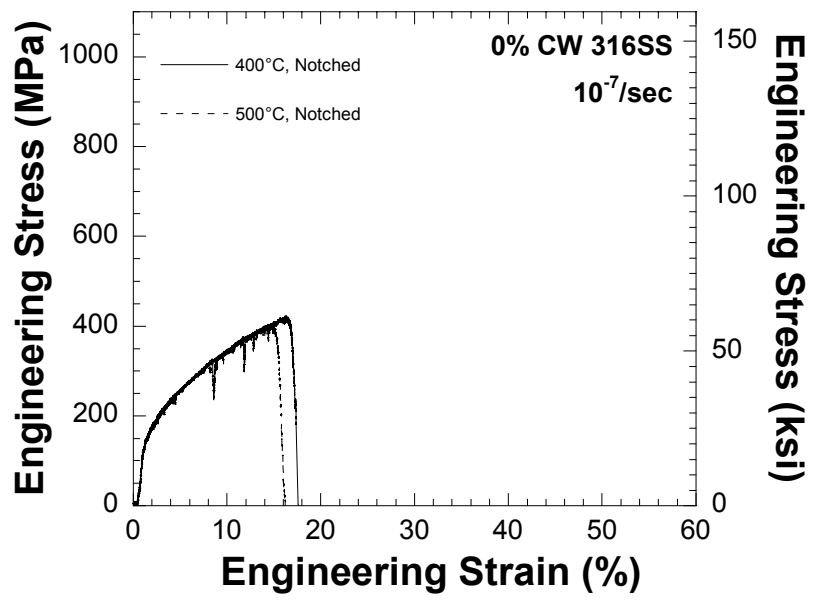

(c)

Figure 13. Engineering stress vs. strain responses for un-notched and notched (DENT design) $0 \% \mathrm{CW}$ specimens tested at strain rates of (a) $10^{-3}$, (b) $10^{-5}$, and (c) $10^{-7} \mathrm{sec}^{-1}$ and temperatures of 400 and $500^{\circ} \mathrm{C}$; note, all plots in Fig. 13, 14, and 15 have fixed stress range but the strain range of Fig. 13 differs from Fig. 14 and 15. 


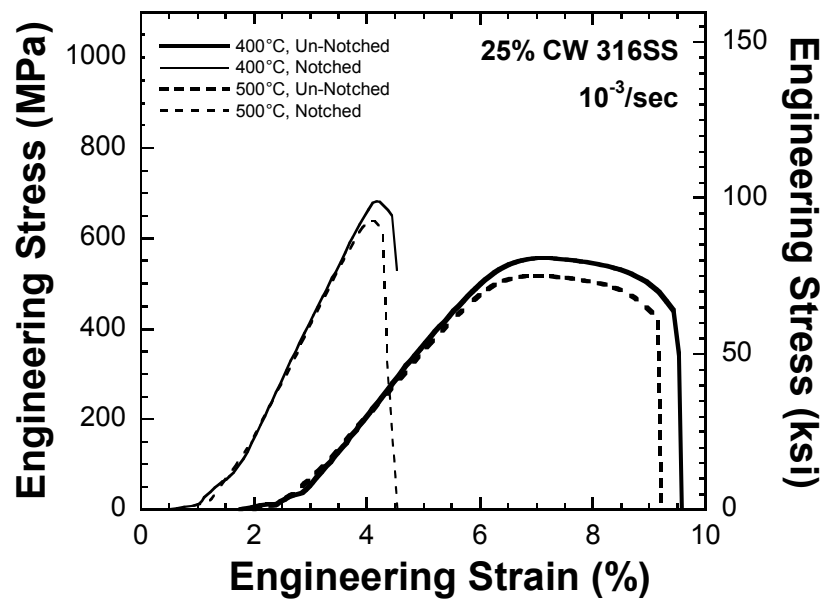

(a)

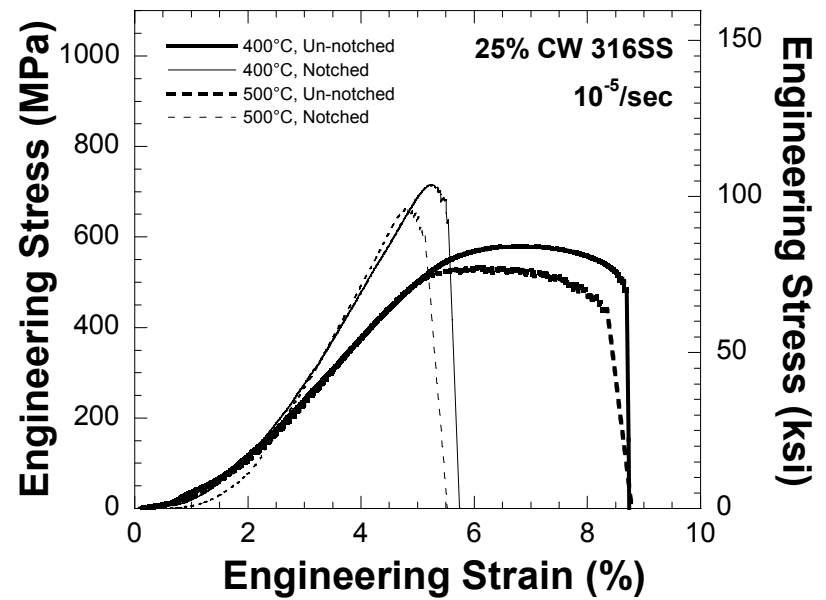

(b)

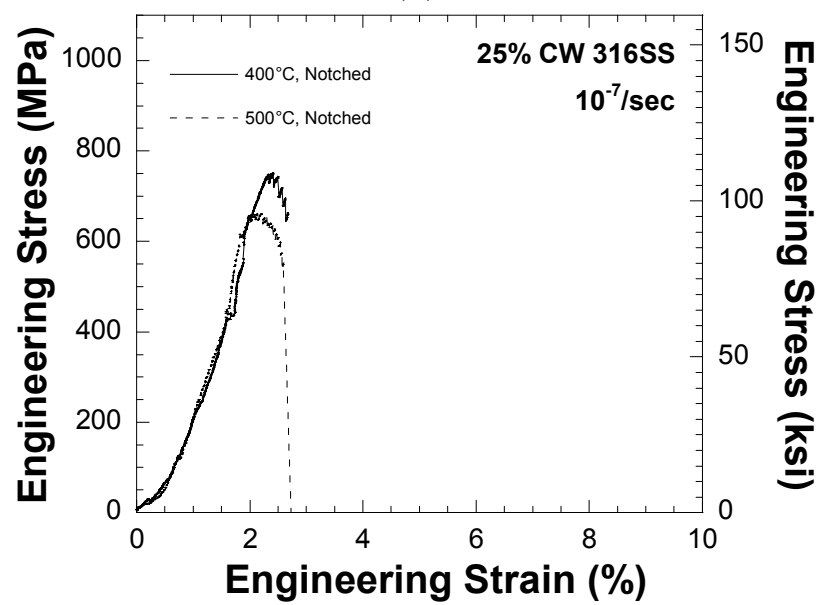

(c)

Figure 14. Engineering stress vs. strain responses for un-notched and notched (DENT design) $25 \% \mathrm{CW}$ specimens tested at strain rates of (a) $10^{-3}$, (b) $10^{-5}$, and (c) $10^{-7} \mathrm{sec}^{-1}$ and temperatures of 400 and $500^{\circ} \mathrm{C}$; note, all plots in Fig. 13, 14, and 15 have fixed stress range but the strain range of Fig. 13 differs from Fig. 14 and 15. 


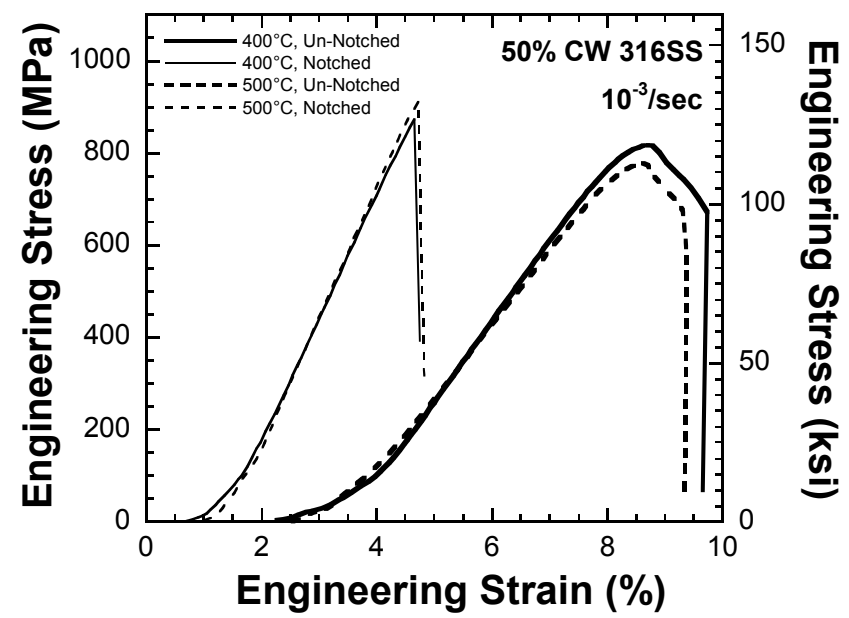

(a)

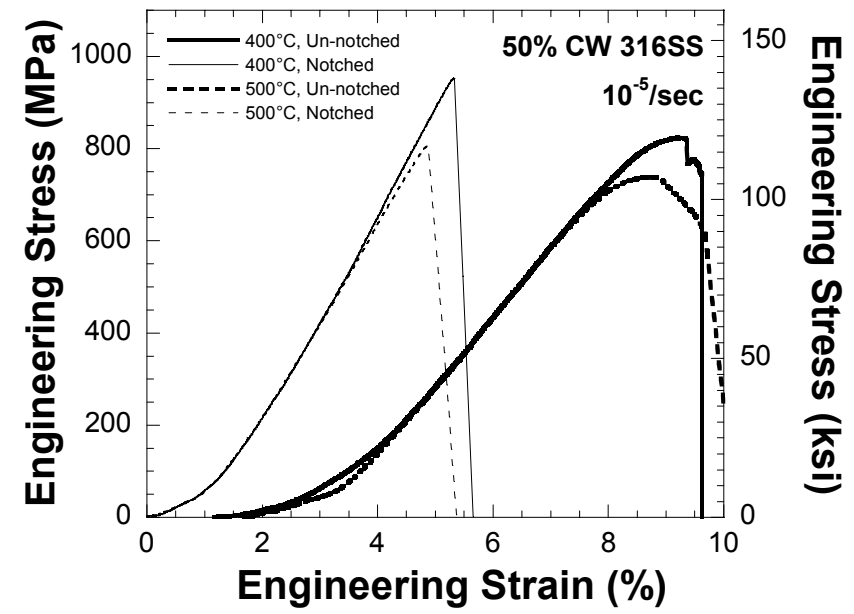

(b)

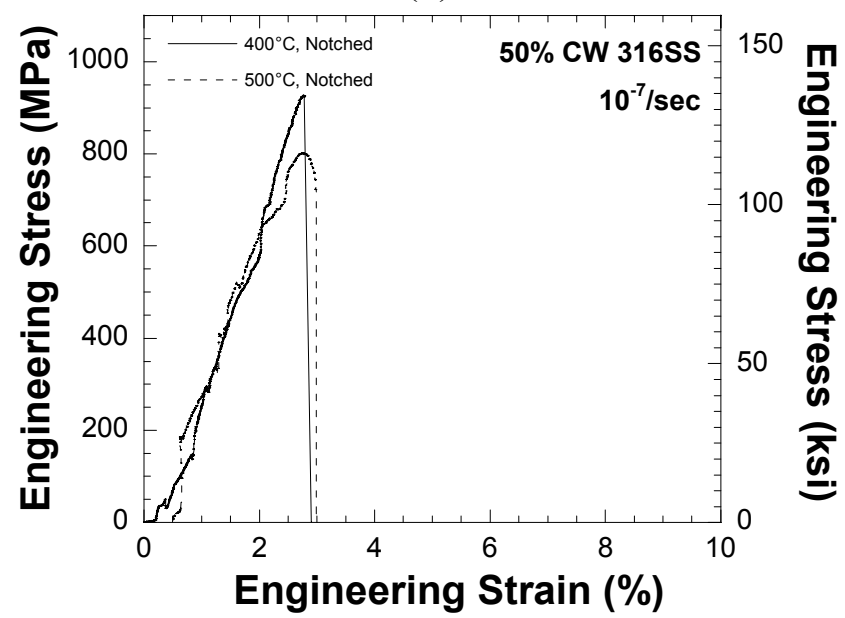

(c)

Figure 15. Engineering stress vs. strain responses for un-notched and notched (DENT design) $50 \% \mathrm{CW}$ specimens tested at strain rates of (a) $10^{-3}$, (b) $10^{-5}$, and (c) $10^{-7} \mathrm{sec}^{-1}$ and temperatures of 400 and $500^{\circ} \mathrm{C}$; note, all plots in Fig. 13, 14, and 15 have fixed stress range but the strain range of Fig. 13 differs from Fig. 14 and 15. 


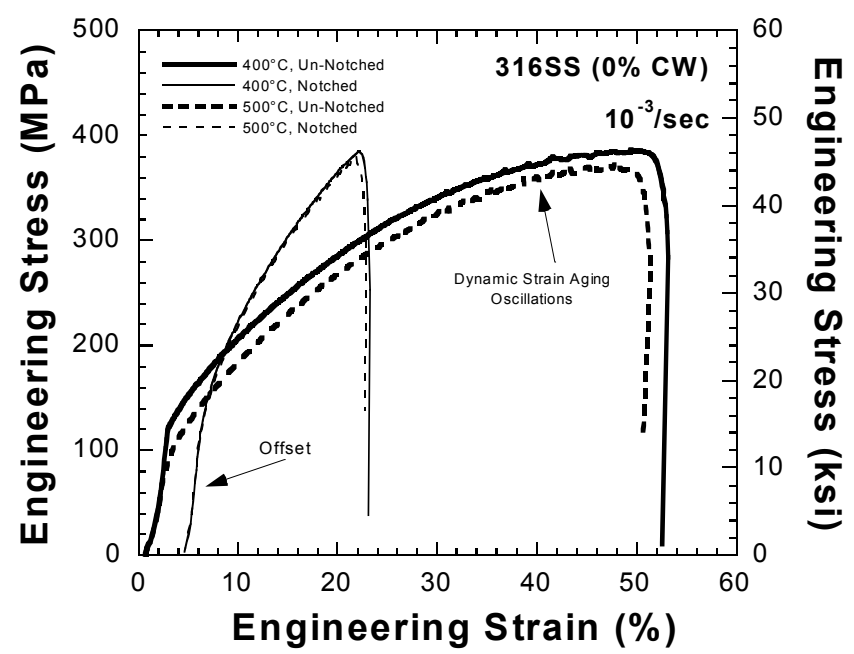

(a)

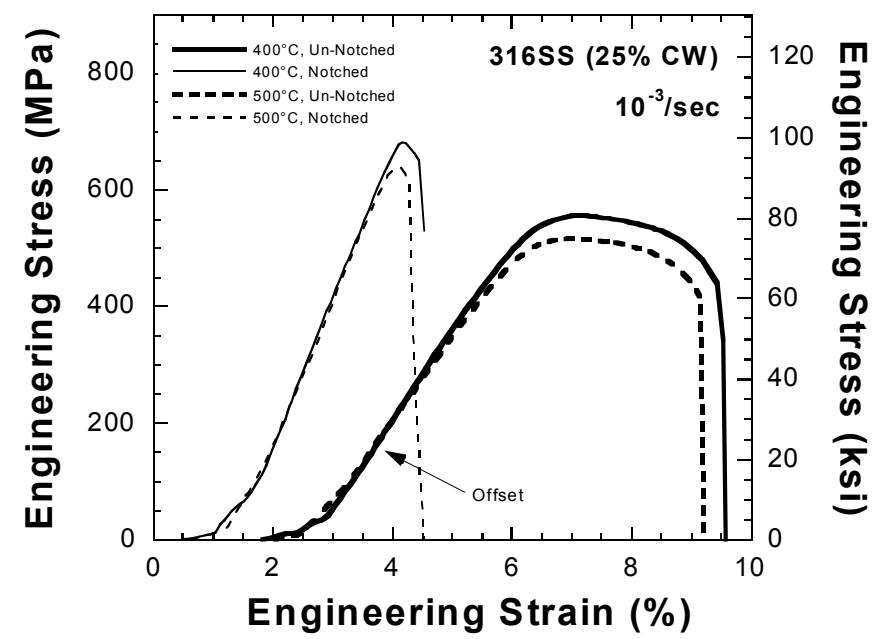

(b)



(c)

Figure 16. Engineering stress vs. engineering strain responses for notched and un-notched specimens at 400 and $500^{\circ} \mathrm{C}$ with (a) 0 , (b) 25 , and (c) $50 \%$ cold-work. 


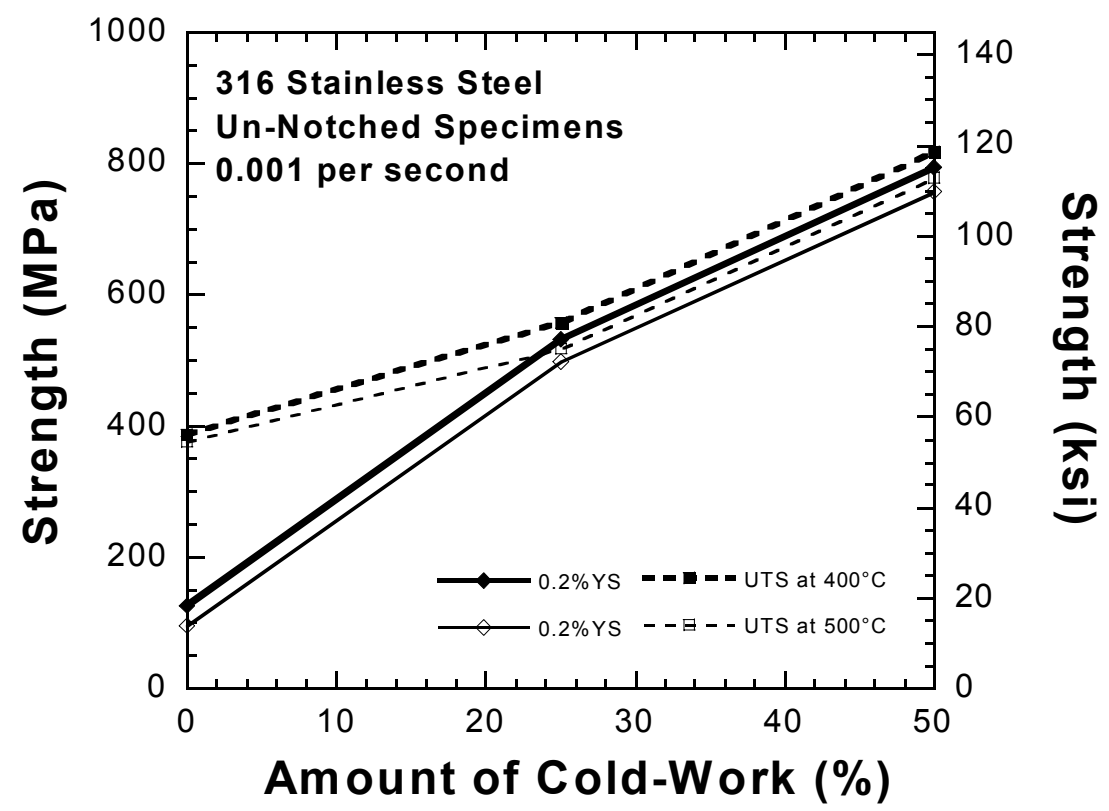

(a)

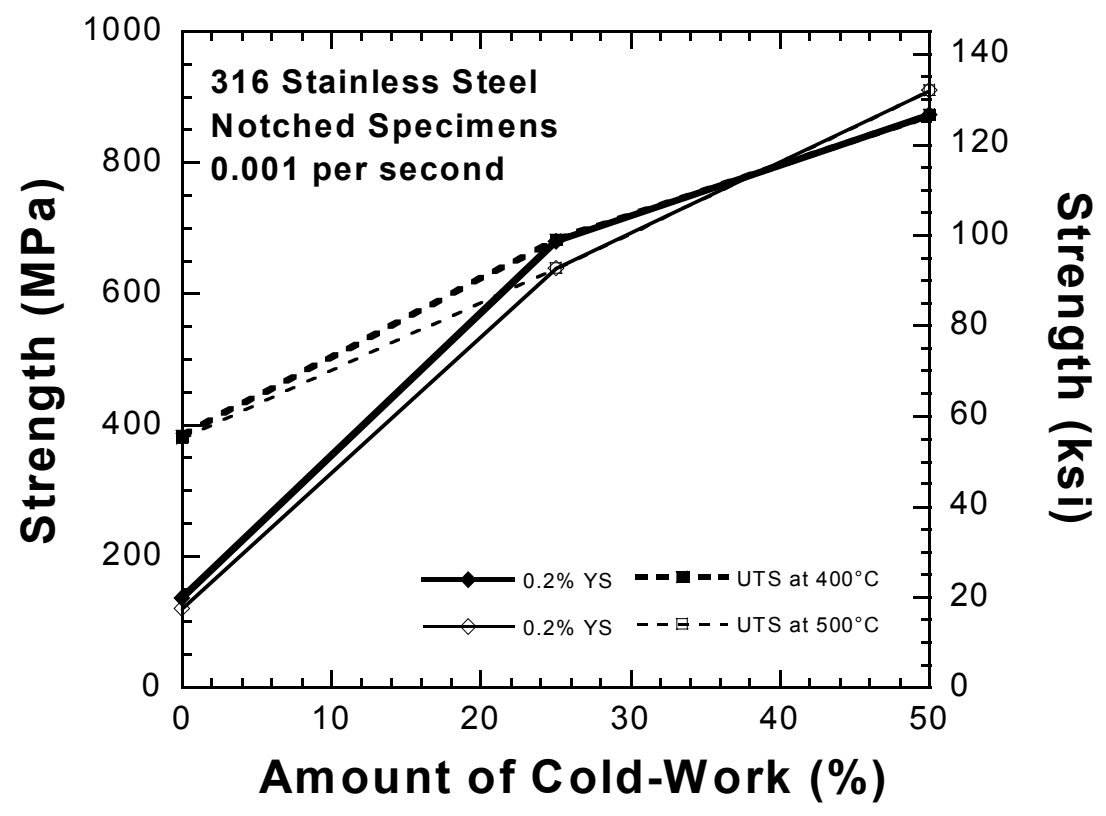

(b)

Figure 17. 0.2\% Yield Strength (YS) and Ultimate Tensile Strength (UTS) versus \%CW for (a) un-notched and (b) notched specimens tested at $0.001 / \mathrm{sec}$ and at 400 and $500^{\circ} \mathrm{C}$. 
effect of plastic constraint resulting from triaxial stresses ahead of the notch tip. Like that of the $0 \%$ cold-worked material, there appears to be a larger effect of temperature on yield and flow stress for un-notched specimens as compared to notched specimens. Highly cold-worked materials show little or no crack growth resistance as evident from the lack of plastic strain after yielding.

As expected, $0 \%$ cold-worked material has high strain-hardening capability and shows significant ductility under these test conditions. Figures 18 and 19 show elongation, and reduction-in-area (measured using microscope with $\mathrm{x}$, y stage and digital micrometers), and time-to-failure to support the strain-hardening characteristics of this material. Fracture profiles show significant through-thickness and width necking (as evident from the reduction-in-area measurement of Figure 18), non- $45^{\circ}$ shear fracture, and a plastic anisotropy value, $R=\left(\varepsilon_{\text {width }} / \varepsilon_{\text {thickness }}\right)$, of approximately 0.75 such that through-thickness slip is more easily accommodated than across the specimen width. In contrast, 25 and $50 \%$ cold-worked materials show significantly less ductility compared to $0 \%$ coldworked material. As seen in Figure 20, if we calculate the equivalent true stress-true strain curves and, using a Power Law fit, we find that the strain-hardening exponent, $n$, decreases significantly with increasing cold-work. This supports the Consideré Criterion that the $n$-value should be approximately equal to the uniform strain. The plastic anisotropy value, $R$, for 25 and $50 \%$ cold-worked materials is found to be roughly 0.45 and 0.5, respectively, suggesting that through-thickness slip is twice that along the width direction (note for an ideally isotropic material $R=1$ ). Note the $\mathrm{R}$ value in Figure 20 is the deviation from linearity and not the anisotropy value.

Also, as shown in Figure 20, there is a significant increase in strength with increasing cold-work. A major objective of testing highly cold-worked material is to approach the strength levels of irradiated stainless steels. Previous studies conducted at ANL of 316SS material irradiated in EBR-II reactor to a fluence between 2-40 dpa have shown yield and ultimate strengths not to exceed 700 and $775 \mathrm{MPa}$, respectively, when tested at $0.001 / \mathrm{sec}$ and $430^{\circ} \mathrm{C}$. Figure 17 shows comparable values of strength for the $50 \%$ cold-worked material at 400 and $500^{\circ} \mathrm{C}$. Likewise, a yield strength comparison of $25 \%$ cold-worked material is equivalent to that of $316 \mathrm{SS}$ irradiated to 10-15 dpa for temperatures between 400 and $500^{\circ} \mathrm{C}$ but the two materials are not comparable when considering ultimate tensile strengths. Total elongation results for 25 and $50 \%$ cold-worked materials are found to be slightly less than $4 \%$, which is less than $8 \%$ found for the irradiated $316 \mathrm{SS}$ results.

The effect of temperature on the strength of un-notched tensile specimens is shown in Figure 21 . As expected, both $0.2 \%$ yield strength and ultimate tensile strength decrease with increasing temperature. The amount of this decrease in strength appears to increase with greater cold work. Also, the strain-hardening behavior is significantly greater for $0 \% \mathrm{CW}$ material compared to 25 and $50 \% \mathrm{CW}$ materials, which is consistent with reduced ductility of heavily cold-worked materials. Additionally, the effect of strain-rate hardening on yield and ultimate tensile strength for un-notched and notched (DENT design) specimens was not readily apparent in this testing. 
For DENT specimens, the constraints of the two notches caused increased strength at lower strain-rates, as shown in Figure 22, as compared to un-notched specimens. Also, as compared to 


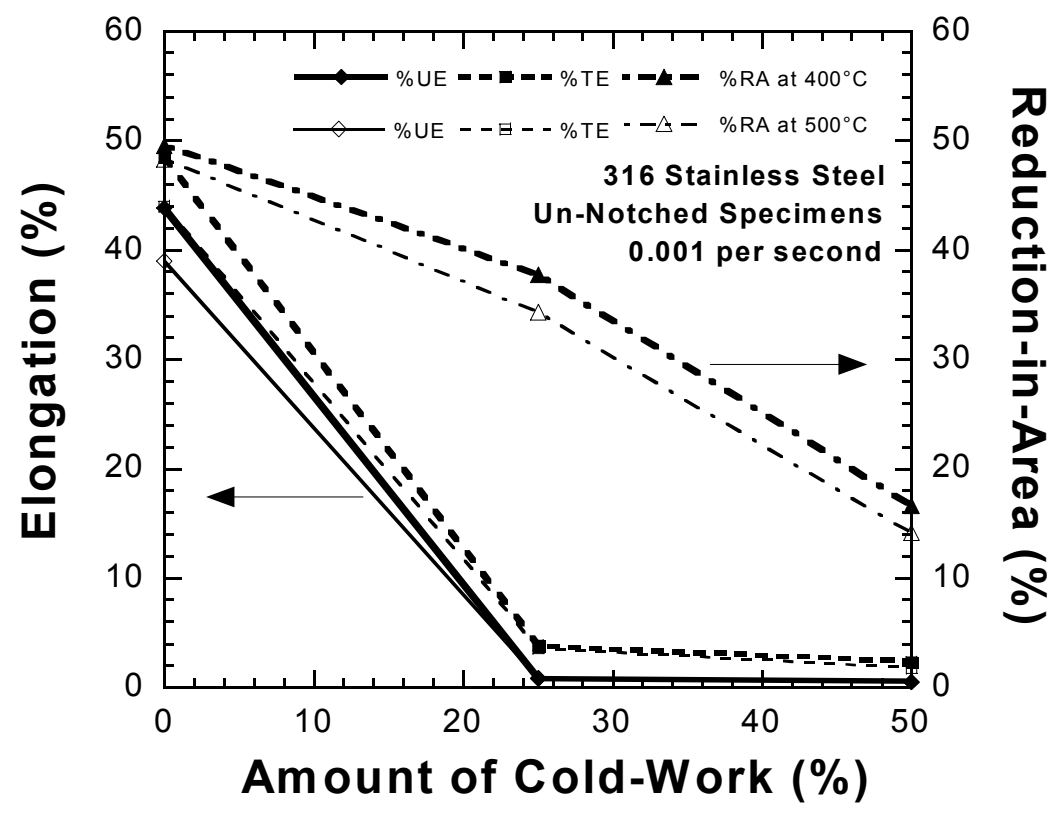

Figure 18. Uniform Elongation (\%UE), Total Elongation (\%TE), and Reduction-in-Area (\%RA) versus $\% \mathrm{CW}$ for un-notched specimens tested at $0.001 / \mathrm{sec}$ and at 400 and $500^{\circ} \mathrm{C}$.

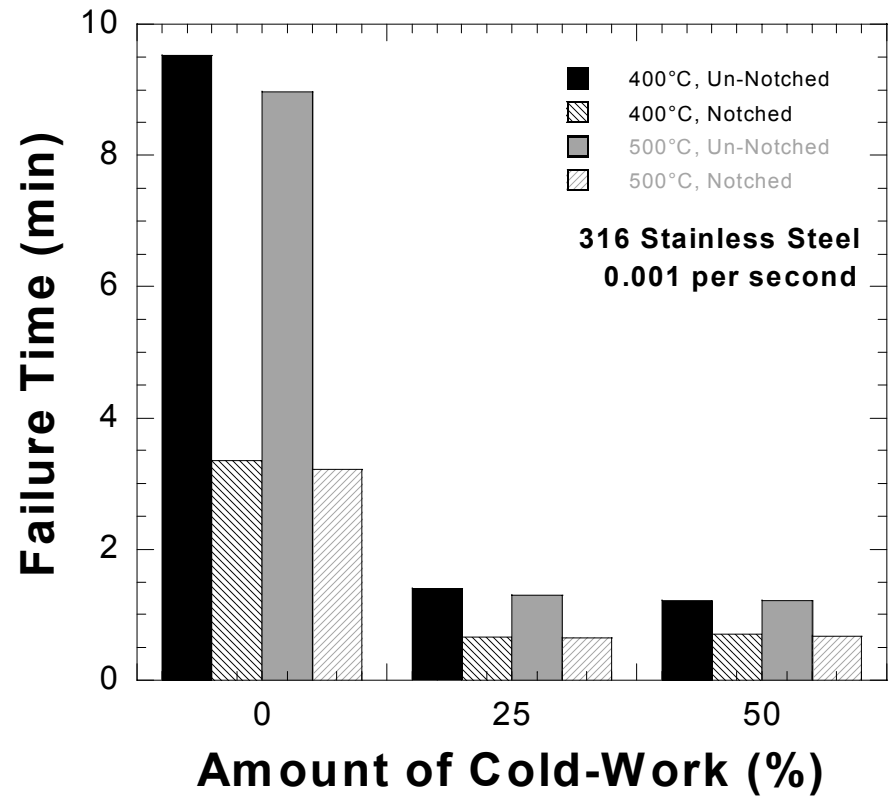

Figure 19. Failure time versus \% $\% W$ for notched and un-notched specimens tested at $0.001 /$ sec and at 400 and $500^{\circ} \mathrm{C}$. 


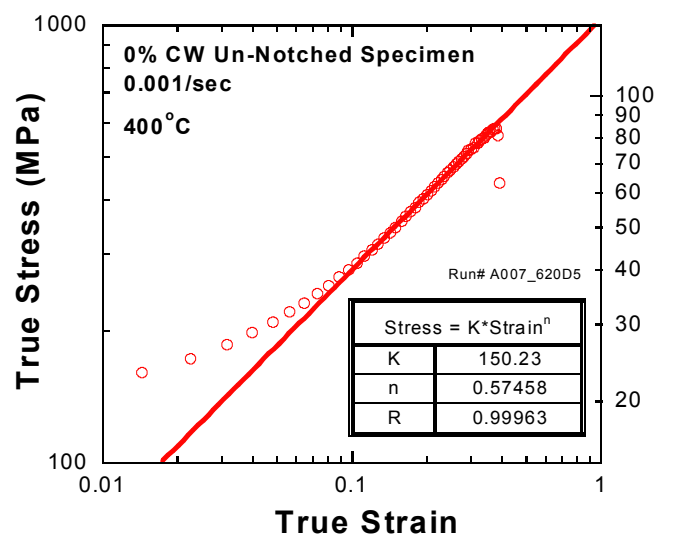

(a)

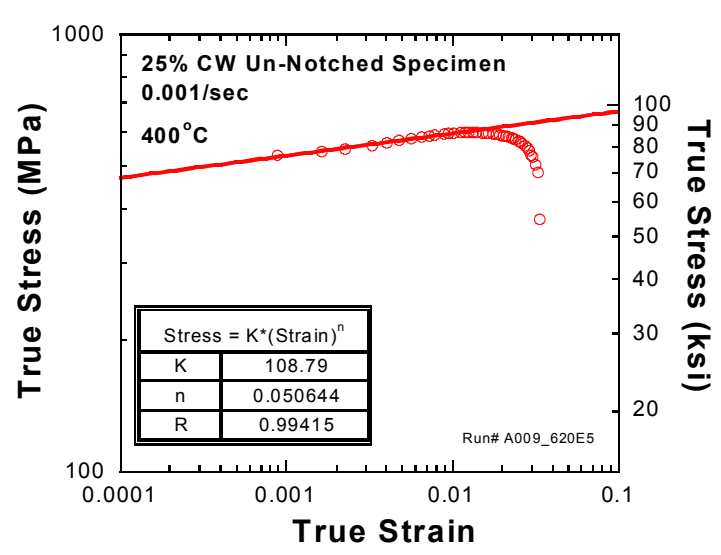

(c)

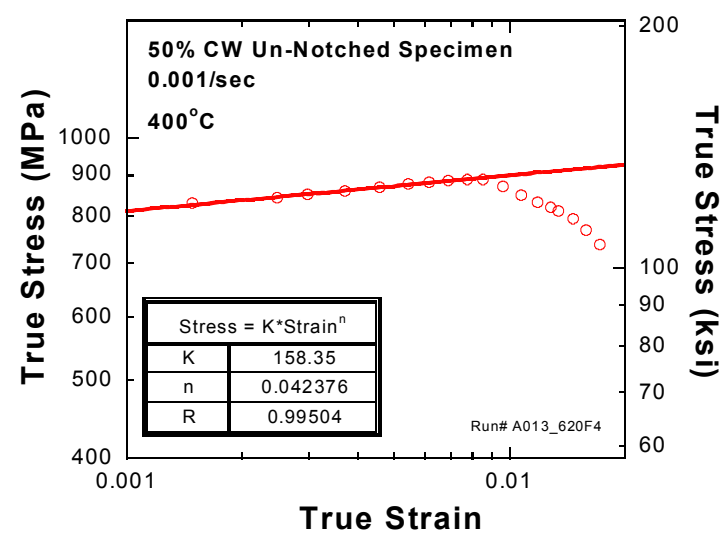

(e)

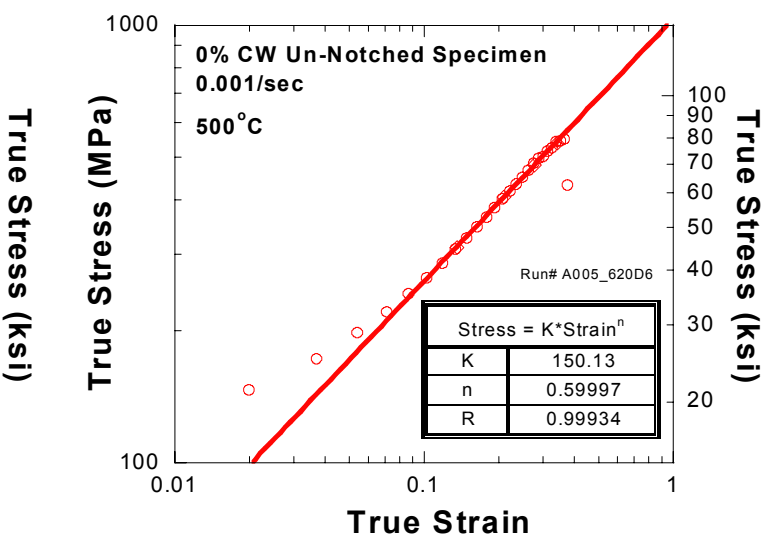

(b)

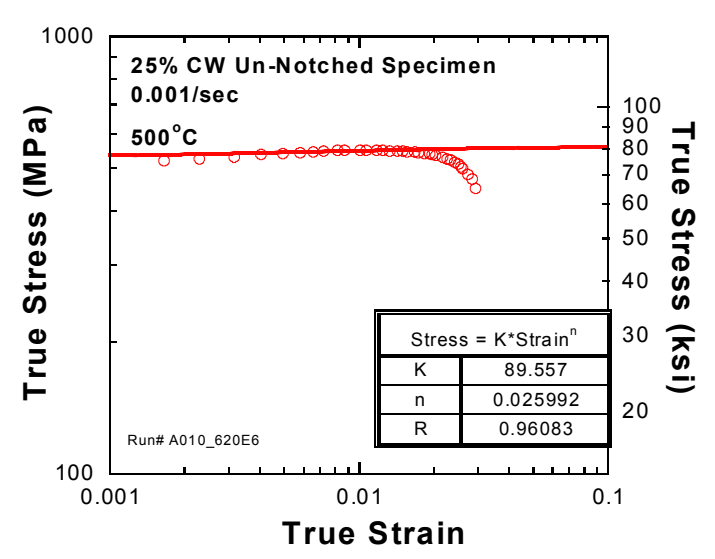

(d)

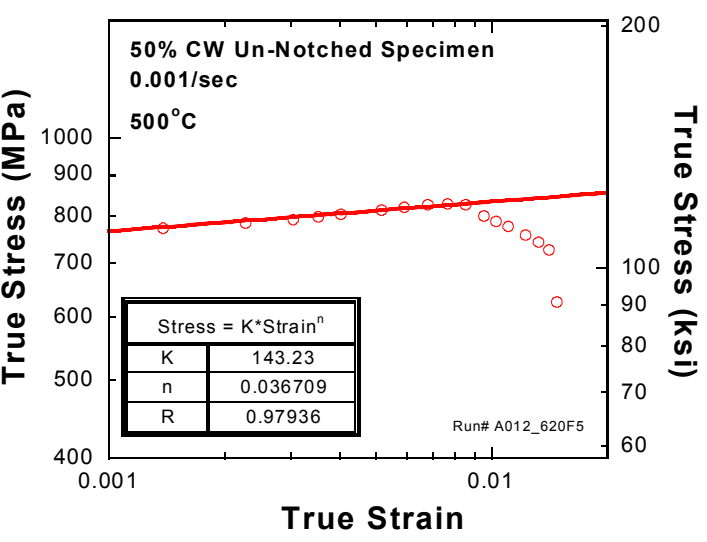

(f)

Figure 20. True stress vs. true strain plots with Power Law fits (s = Ken) for all un-notched specimens with (a), (b) $0 \%$, (c), (d) $25 \%$, and (e), (f) $50 \%$ cold-work at 400 and $500^{\circ} \mathrm{C}$, respectively; note, open circles represents experimental data and the line represents a Power Law fit. 


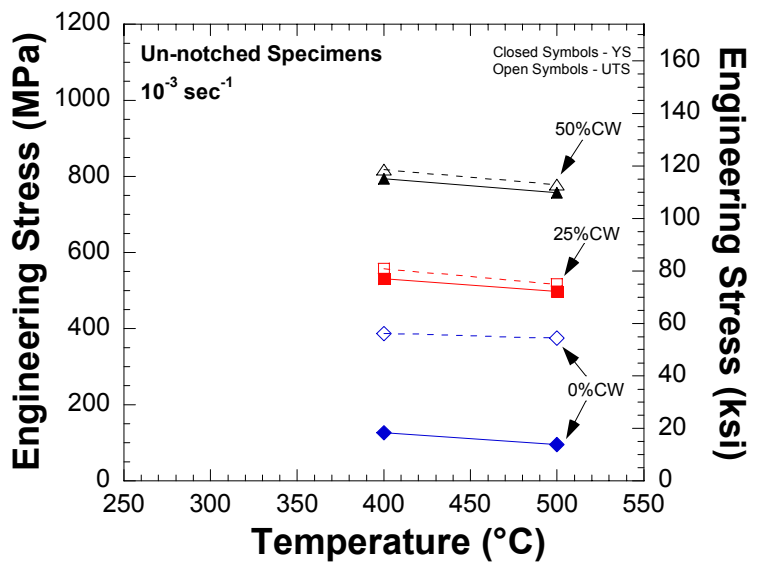

(a)

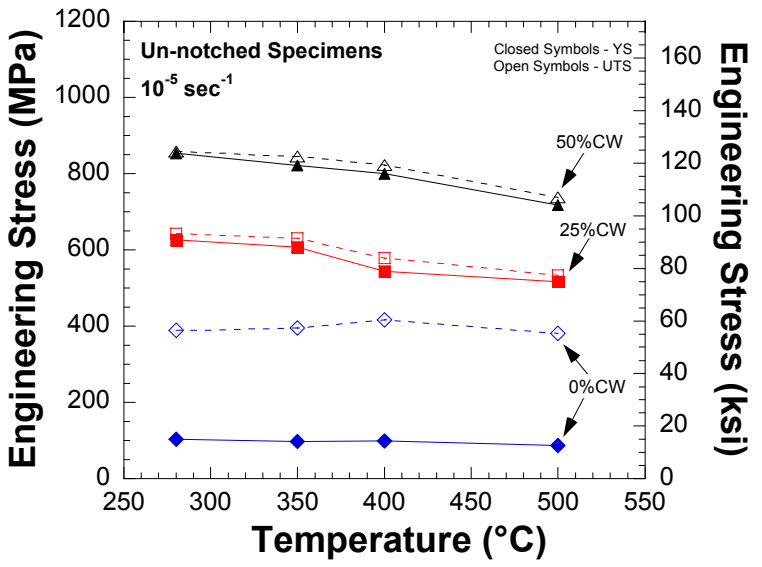

(b)

Figure 21. $0.2 \%$ yield and ultimate tensile strengths of un-notched specimen as a function of temperature at (a) $10^{-3}$ and (b) $10^{-5} \mathrm{sec}^{-1}$.

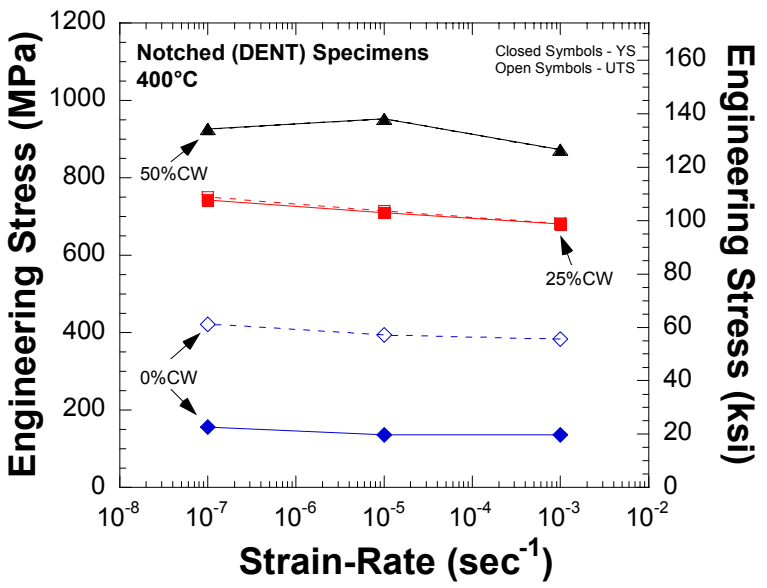

(a)

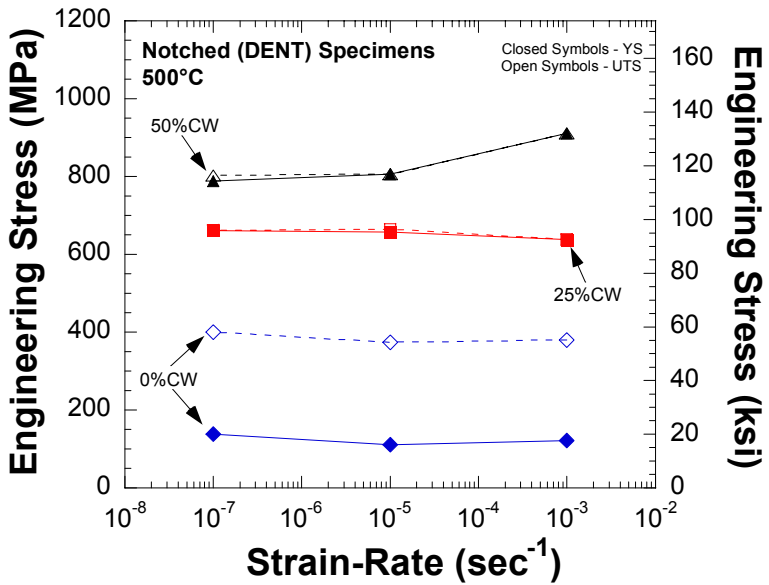

(b)

Figure 22. Semi-log plots of $0.2 \%$ yield and ultimate tensile strengths of notched specimen (DENT design) as a function of strain rate at (a) 400 and (b) $500^{\circ} \mathrm{C}$.

the un-notched specimens, the strengths of DENT specimens show a greater dependency of temperature but similar dependency of strain rate. This result is consistent with earlier work by Wire et. al [29] indicating that strain-rate effects were not observed at test temperatures similar to those used in this study (see figure 23). However at elevated temperature, yield strength decreases with decreasing strain-rate. 



\subsubsection{Fractography}

Fractographic examination using a scanning electron microscope (SEM) is presented in Figures 24 and 25 and indicates only transgranular, ductile fracture via mixed microvoid coalescence and shear regardless of level of material $\mathrm{CW}$, test conditions, and specimen designs. The low magnification fractographs of Figure 24 show significant throughthickness contraction for both 0 and $25 \% \mathrm{CW}$ material but little or no contraction for the $50 \% \mathrm{CW}$ material; this is reflected in the reduction-in-area data presented Figure 18. The high magnification fractographs of Figure 24 show mixed ductile fracture. At even higher magnifications as shown in Figure 25, slip plane development is observed in areas of shear-type fracture, which was observed in predominantly $50 \% \mathrm{CW}$ specimens.

\subsubsection{Finite Elemental Analysis}

Finite elemental analyses (FEA) of un-notched and notched specimen geometries have been conducted to determine the evolution of stress and strain with varying levels of cold-work. The results from FEA will help in understanding the fracture mechanisms, shear instability across the specimen thickness vs. crack growth from a notch-tip, as a function of strain-hardening exponent. Results of FEA are presented in Figure 26 for unnotched and notched geometries using $0 \% \mathrm{CW}$ mechanical properties. Figure 26(a) shows uniform stress in the gauge section of an un-notched specimen whereas Figure 26(b) shows stress concentration at the notch tips of a notched specimen.

Furthermore, due to the limitations in machining notched specimens from irradiated materials, FEA will help in the development of notch geometries that optimize stress concentrations in order to initiate a crack rather than plastic instability. Specifically, the in-cell EDM has a wire diameter of 0.004-inch, which will yield a notch-tip radius of approximately 0.0025 -inch, whereas the cold-worked specimens were machined with a notch-tip radius of approximately 0.0007 -inch using an out-of-cell milling machine. As part of the Fracture Mechanism study, the primary objective is to determine whether irradiated stainless steels fail by intergranular cracking outside of the water environment of reactors, therefore, sharp notch geometries are desirable.

\subsubsection{Specimen Design using FEA}

As reported above, tensile tests of $\mathrm{CW}$ material failed to produce cracking in an IG manner. We therefore employed finite element analysis (FEA) to examine why IG cracking does not occur prior to testing the valuable irradiated material. 


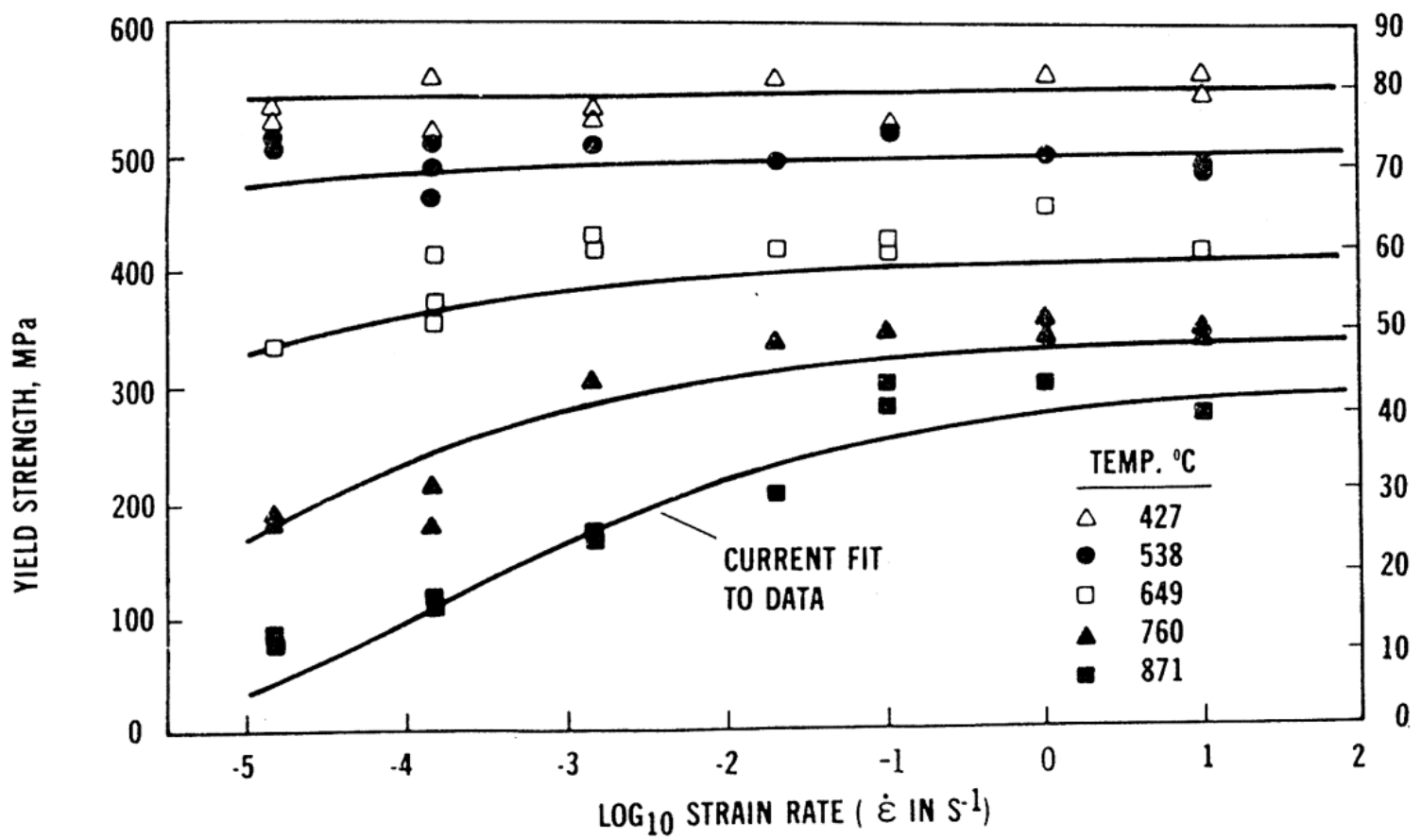

Figure 23. Plot of Yield strength as a function of temperature and Log strain rate. [28] 

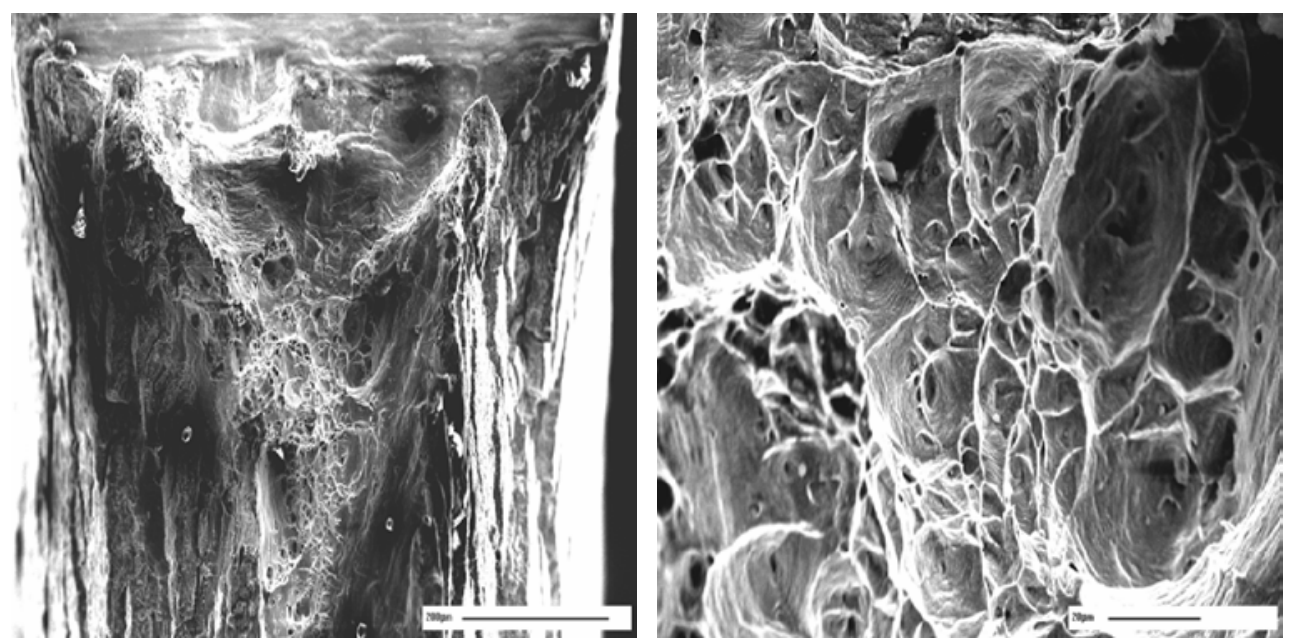

(a)
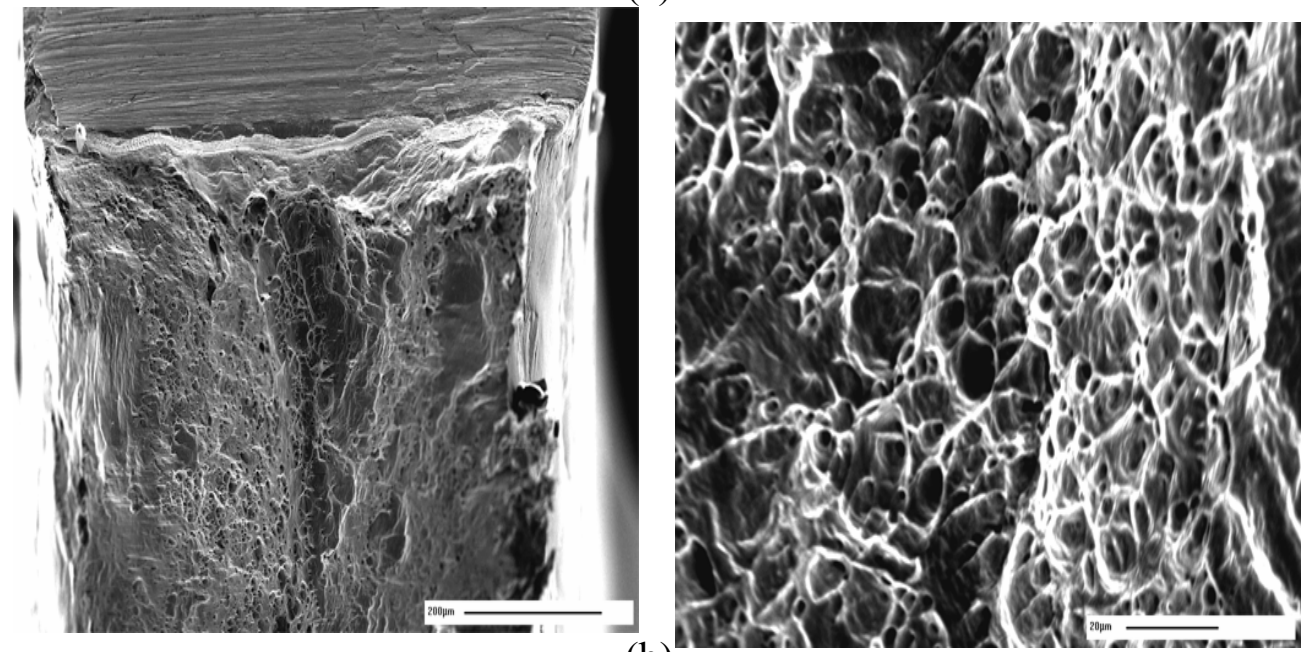

(b)
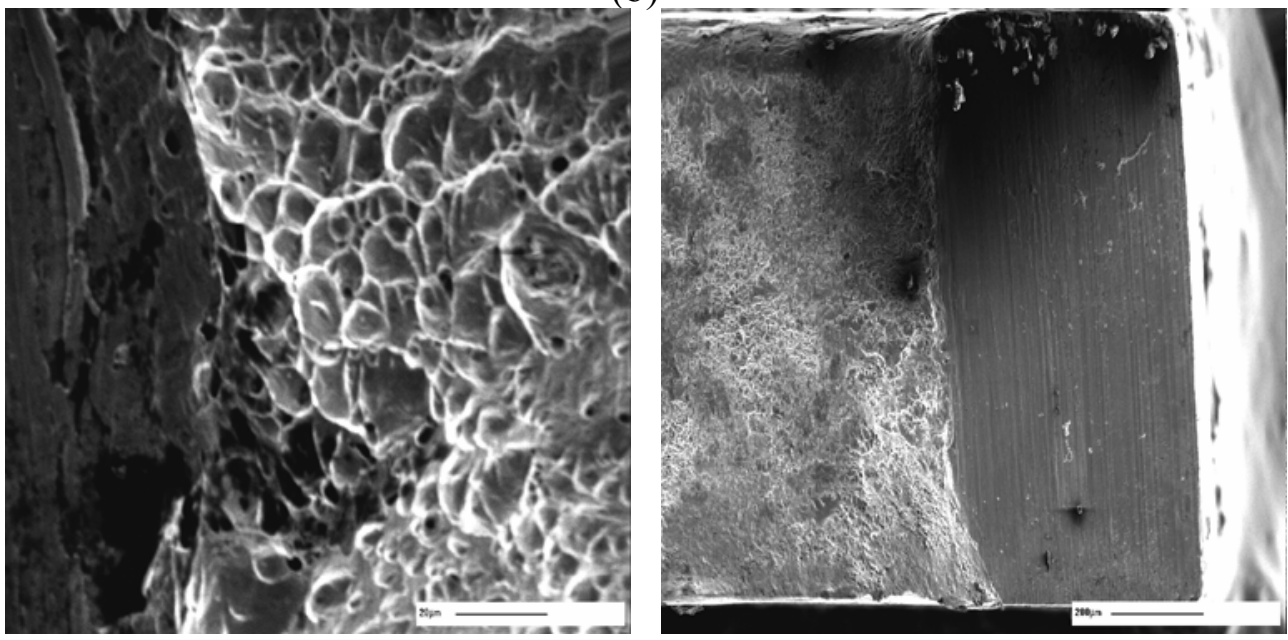

(c)

Figure 24. SEM fractographs at low $(\approx 150 X)$ and high $(\approx 1000 X)$ magnifications of failed DENT specimens (notch surfaces at top) fabricated from (a) 0 , (b) 25, and (c) $50 \%$ CW 316SS. 


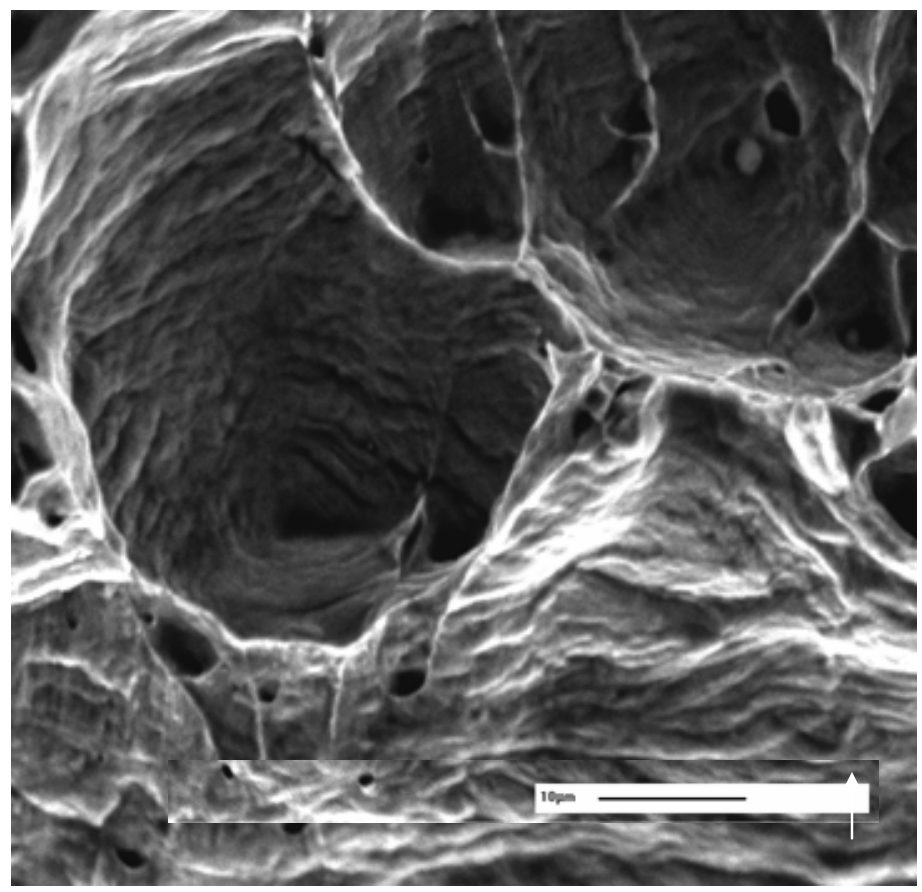

(a)



(b)

Figure 25. SEM fractograph of (a) 25 and (b) $50 \% \mathrm{CW}$ specimen showing mixed microvoid tearing and shear fracture; in the shear areas, evidence of slip planes are observed as indicated by white arrows. 


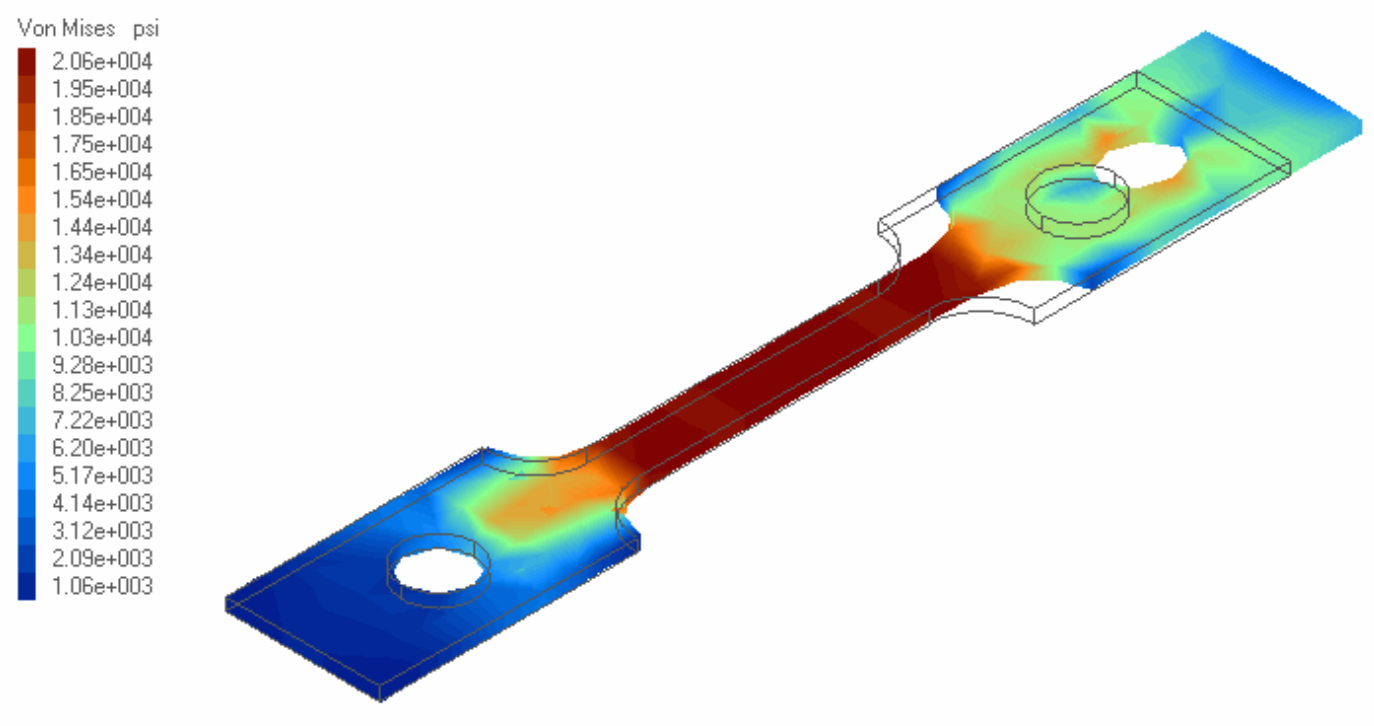

(a)

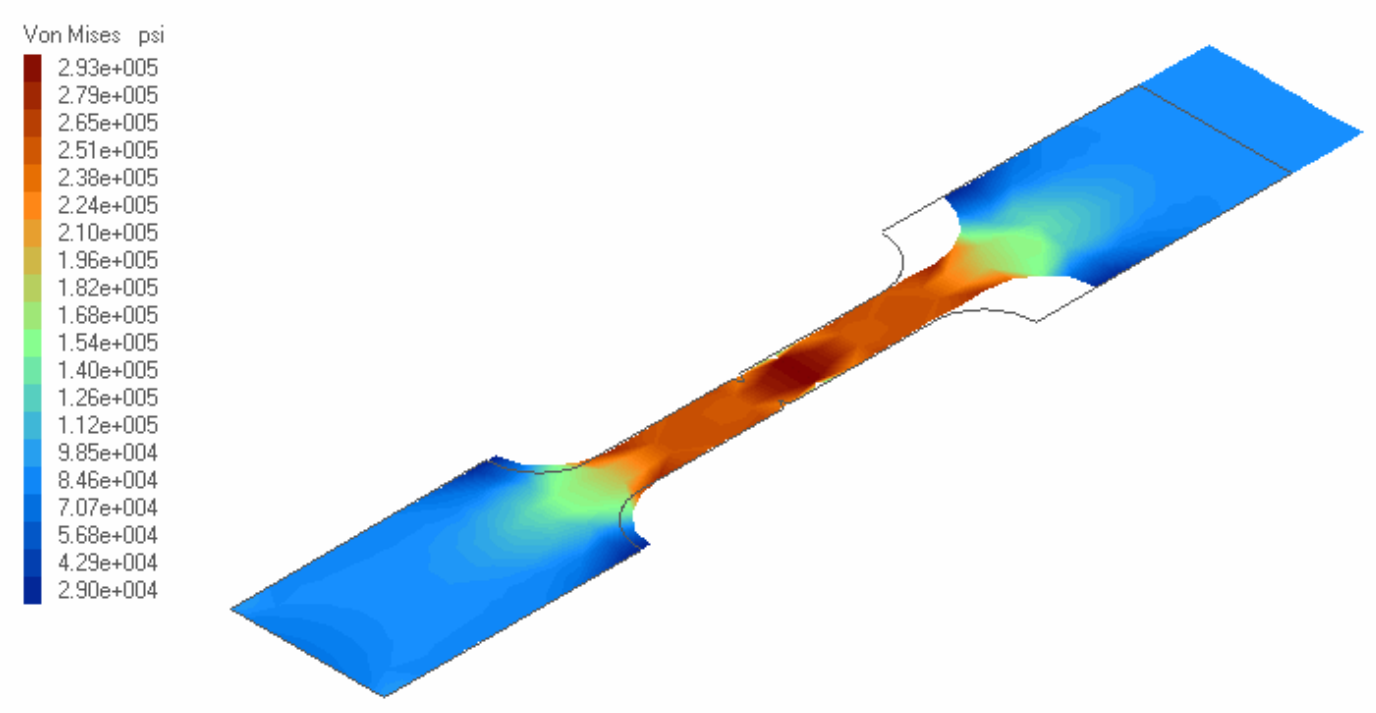

(b)

Figure 26. FEA results showing the stress distributions at the ultimate tensile stress (prior to plastic instability) using a (a) 3-dimensional (3D) geometry of an un-notched specimen and (b) 2-dimensional geometry of a notched specimen (note, in order to analyze the notch tips, smaller mesh sizes were needed such that a 3D analysis was not possible with the present software configuration) for $0 \% \mathrm{CW}$ material tested at $400^{\circ} \mathrm{C}$ and $10^{-3} / \mathrm{sec}^{-1}$; the solid lines indicate the original dimensions of the specimen. 
Based on the geometry of Figure 27 and using ASTM Standard E8-96a (Standard Test Methods for Tension Testing of Metallic Materials), we have investigated the various tensile specimens, both notched and un-notched, to determine the optimal design to investigate Mode I cracking of cold-worked and, later, irradiated stainless steels.

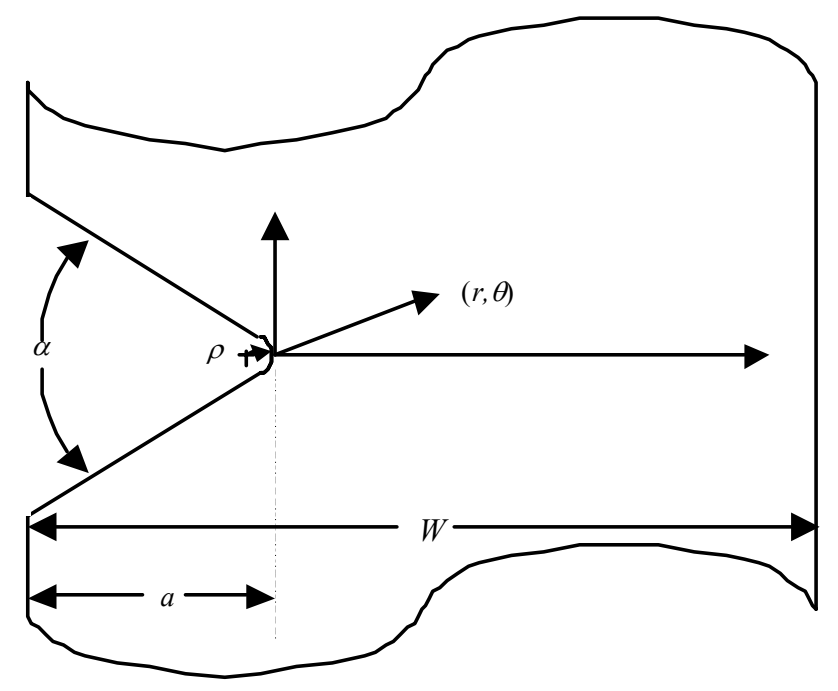

Figure 27. Geometric parameters of study for optimal notch design; a - notch angle, $\mathbf{r}$ notch-tip radius, polar coordinate system ( $r, q)$ ahead of notch-tip, a - notch depth, and W ligament width according to specimen centerline of symmetry.

Because the sheet materials of this study have a nominal thickness of $\leq 0.040$-inch $(\leq 1.02$ $\mathrm{mm}$ ), a plane-stress condition is produced. Under uniaxial tension of un-notched and double-notched specimens, fully oblique failure or near- $45^{\circ}$ through-thickness shear results. Ideally, introduction of a notch provides a stress concentration site that geometrically constrains plastic deformation by limiting through-thickness slip. This constraint effect is particularly important for testing thin sheet materials with low strainhardening behavior and at high temperatures. Therefore, it is essential that this notch design provide sufficient constraint to mitigate through-thickness slip and promote Mode I crack initiation and propagation. Pre-cracking of the specimen using fully tensile fatiguing $(R=\min$ load $/ \max$ load $=+0.1)$ will also assist in promoting Mode I cracking.

Criteria for optimal specimen design must account for hot-cell testing irradiated material (high strength and low strain-hardening behavior) and includes the following: (1) minimize ratio of plastic zone size ahead of notch-tip $\left(r_{p}\right)$ to remaining uncracked ligament ( $W-a)$ according to linear elastic fracture mechanics, (2) maximizing uncracked ligament $(W-a)$ to increase effect of the constraint but must consider maximum testing load of specimen, (3) minimizing notch-tip radius $(\rho)$ and/or fatigue pre-crack specimen to concentrate stresses at a sharp crack tip and promote Mode I crack, and (4) introduce asymmetric loading to concentrate stresses at notch tip by using a single-edge notch tensile (SENT) design rather than a symmetric double-edge notch tensile (DENT) design. 
Using finite elemental analysis (FEA), the elastic and plastic stress distributions ahead of the notch were determined based on a 3000 total mesh and mesh size of 0.005 -inch by 0.005 -inch; plastic stresses were determined using non-linear plastic behavior assuming a strain-hardening behavior fitted to the Power Law $\left(\sigma=K \varepsilon^{n}\right.$, where $\sigma$ is the true stress [MPa], $K$ is the strength coefficient [MPa], $\varepsilon$ is the true plastic strain [dimensionless], and $n$ is the strain-hardening exponent [dimensionless]). Figure 28 shows these plastic stress distributions in a reduced gauge section of the DENT specimen and two proposed SENT specimen designs, assuming a sharp notch $(\rho=0)$. Various $(a / W)$-ratios were investigated to optimize stress distributions according to the above criteria.

For the DENT specimen, significant overlap of stress and symmetric loading occurs due to the interaction of the two notches. These FEA results are consistent with our experimental results of DENT testing such that, regardless of level of cold-work (0-50\%), through-thickness slip is the dominant fracture mode resulting in near- $45^{\circ}$ shear. Whereas, the FEA results show that the SENT designs cause asymmetric loading and gradual decrease of stress in the ligament.

From these stress distributions, Figure 29 is a plot of the normalized stress (defined as the ratio of calculated stress-to-yield stress) versus the normalized distance ahead of the notch tip (defined as the ratio of distance ahead of notch tip-to-ligament width) for the DENT specimen and two proposed SENT specimen designs, as shown in Figure 30. More to the point, Figure 29 shows the stress ahead of the notch tip in the plane of the notch $(\theta=0$; see Figure 27) for the DENT specimen and proposed SENT specimen designs. We see that the gauge width of the DENT specimen, symmetric to the mid-line of the specimen $(W=0.059$-inch), is fully plastic (Normalized Stress $>1)$, resulting in a failure process dominated by plastic instability. In contrast, the SENT specimen designs show plastic behavior (again, Normalized Stress $>1$ ) for only a portion of the ligament. Furthermore, it is apparent that, as $(a / W)$ decreases, the amount of the ligament that is in the plastic regime decreases. Therefore, considering the loading requirements for specimens with large $W$, SENT specimens were fabricated from unirradiated, coldworked and 316SS materials and are proposed for the irradiated 316 SS samples. Figure 30 shows the different specimen designs of this FEA study with 26c and 26d showing the chosen SENT designs.

\subsubsection{Single Edge Notch Tensile Sample Testing}

Testing of the SENT specimens fabricated from 25 and $50 \% \mathrm{CW}$ material consisted of initial strain rates of $10^{-7} \mathrm{sec}^{-1}$ and $500^{\circ} \mathrm{C}$. Under these test conditions, the triaxial stress state ahead of an initiated crack locally induces a higher hydrostatic stress $(\approx 3$ times as compared to the far-field stress) and low crack-tip strain rates, which may increase the likelihood of grain boundary separation and on a macroscopic level, induce intergranular fracture in heavily $\mathrm{CW}$ materials. Because we are testing sheet materials, a stress state of plane stress is promoted due to the lack of lateral (or thickness) material constraints therefore portions or all of the remaining ligament may fail by plasticity-induced throughthickness shear. In fact, the SENT specimen fabricated from $50 \% \mathrm{CW}$ material failed by 
through-thickness shear instability whereas the $25 \% \mathrm{CW}$ specimen failed by Mode I crack growth under this quasi-static strain rate. 


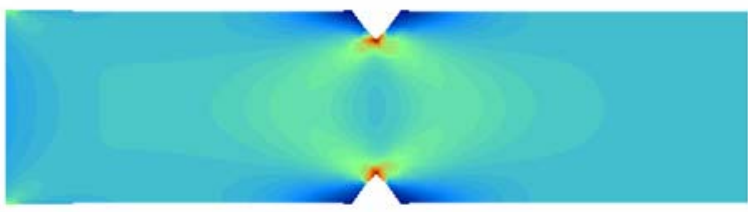

(a)

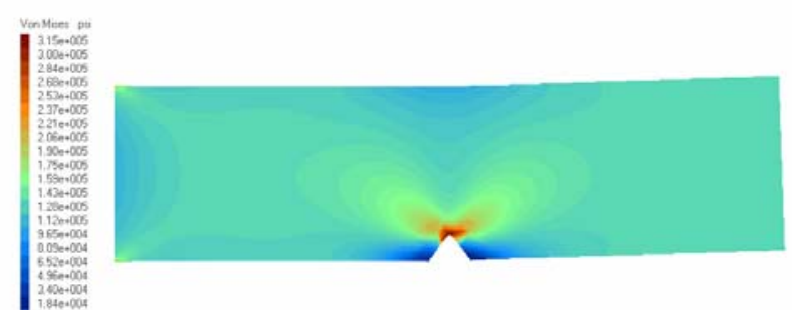

(b)

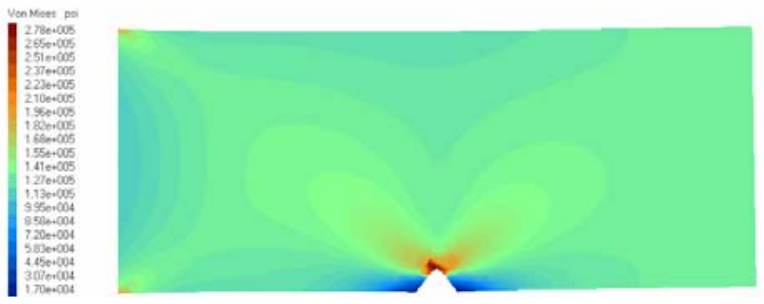

(c)

Figure 28. Stress distribution in the reduced gauge section containing a $60^{\circ}$-notch with fixed depth of 0.019-inch and fixed notch-tip radius of 0.000 -inch (sharp notch) for (a) DENT (a/W= 0.322), (b) SENT (a/W=0.161), and (c) SENT (a/W=0.091) specimen designs; note, extreme left edge in (a) and (b) has a vertical dimension of 0.118-inch whereas (c) is 0.210-inch.

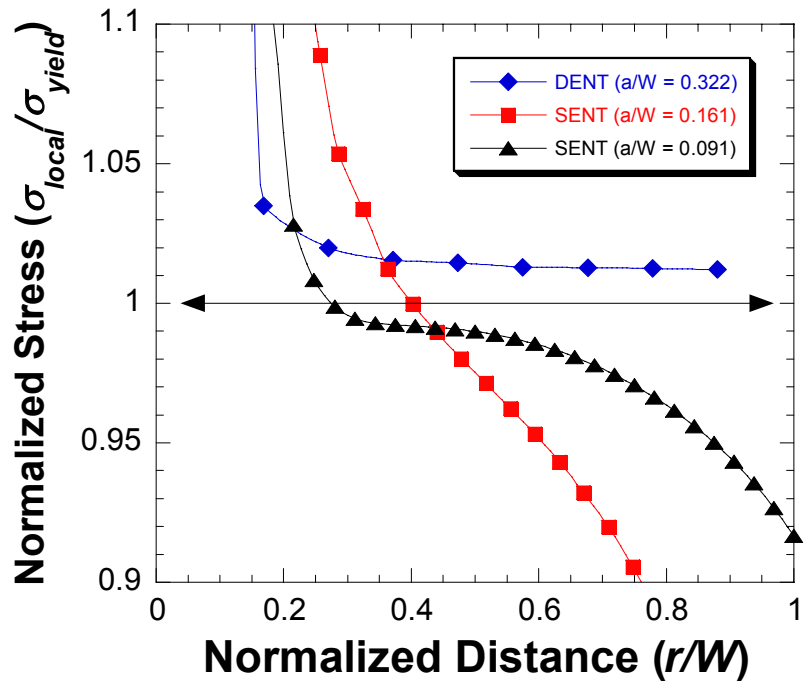

Figure 29. Normalized stress vs. distance ahead of the notch tip at $q=0$ for DENT and SENT specimen designs; notch depth (a) for all specimens is fixed at 0.019-inch. 


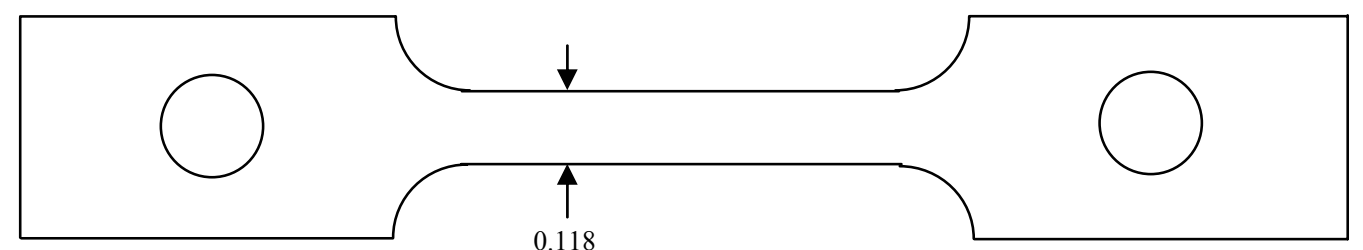

(a)

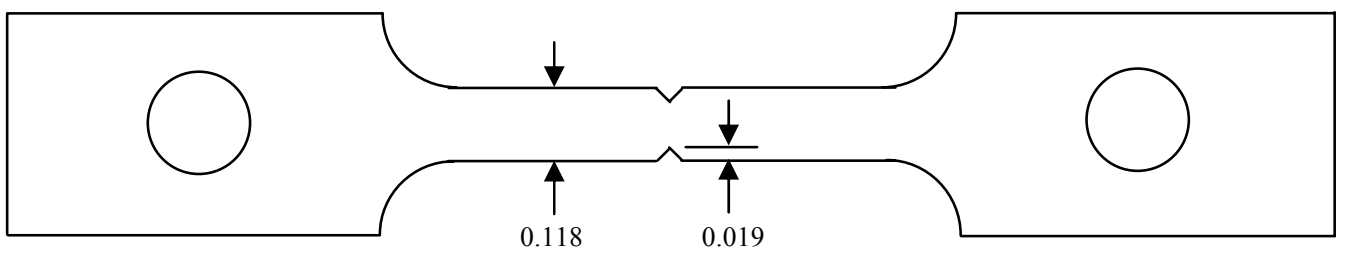

(b)

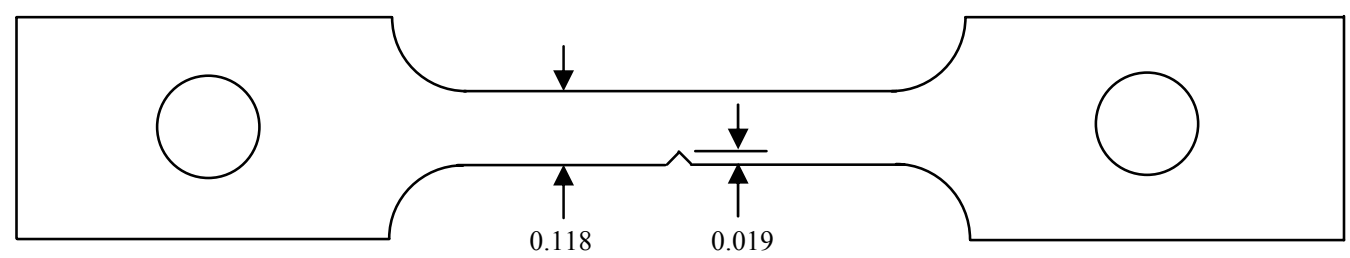

(c)

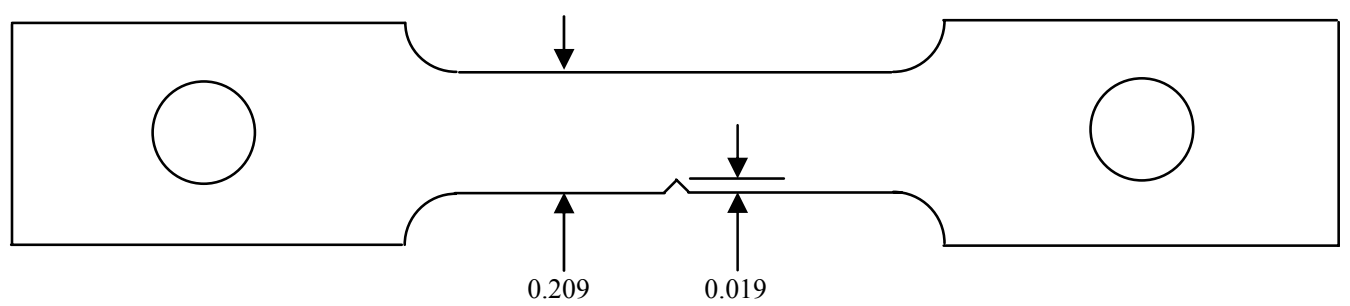

(d)

Figure 30. (a) Un-notched (a/W=0), (b) DENT (a/W=0.322), (c) SENT (a/W=0.161), and (d) SENT (a/W=0.091) specimen designs; all dimensions in inches; nominal gauge thickness and length are 0.0335 -inch and 0.75 -inch; notch angle (a) is $60^{\circ}$. 
Figure 31 shows the load-displacement responses of these two SENT specimens. The $50 \% \mathrm{CW}$ specimen shows classic linear-elastic and strain-hardening induced plasticity with failure dominated by through-thickness shear, as shown in Figure 32. More to the point, the $25 \% \mathrm{CW}$ SENT specimen shows linear elastic behavior followed by plastic discontinuities which represent a repetitive process involving plasticity-induced crack growth followed by crack blunting. After stopping the $25 \% \mathrm{CW}$ test prior to fracture, as shown in Figure 33, we observed Mode I crack growth across the specimen width, as predicted by our FEA study. ANL has the capability to induce a fatigue pre-crack in the SENT specimens prior to quasi-static loading; this would ensure Mode I crack initiation and growth such that the likelihood of intergranular fracture rather than plasticity-induced fracture may occur. However, in both cases of testing 25 and 50\% CW SENT specimens, intergranular fracture was not observed.

\subsection{Mechanical Testing on Irradiated Tensile Samples}

As mentioned previously, tensile tests were conducted on two irradiated 316 SS samples prior to activities in the hot cell being halted. The samples were irradated to doses of 14 and $25 \mathrm{dpa}$ at a temperatures of approximately $375^{\circ} \mathrm{C}$. The tensile tests were conducted at the irradiation temperature and a strain-rate of $1 \times 10^{-5} \mathrm{sec}^{-1}$ was employed. Figure 34 plots the engineering strain vs engineering stress for the two tests. The figure also contains the measured mechanical properties data. In order to get a more complete picture of the changes in mechanical properties, the results from these tests can be compared to results generated for similar EBR-II material tested in several other programs [2,3]. Both $12 \%$ and 20\% 316 stainless steel has been examined. Density measurements, tensile properties and microstructural characterization were carried out on the samples.

Tensile samples of the $20 \%$ cold-worked 316 were taken from material irradiated at temperatures between $371-385^{\circ} \mathrm{C}$ and tested at $\sim 370^{\circ} \mathrm{C}$. A full description of sample preparation, test, and analysis steps can be found in references [3, 30-32]. The strain rate for $20 \%$ cold-worked tensile tests was $4 \times 10^{-5} / \mathrm{s}$. The strain rate for the $12 \%$ cold-worked samples was $1 \times 10^{-3} / \mathrm{s}$. At these temperatures, the difference in strain rates between the $12 \%$ and $20 \%$ cold-worked tests is not expected to significantly change the measured mechanical properties (see Figure 23)[28].

The yield strength as a function of irradiation dose is shown in Figure 35. The yield strength increases most rapidly for the $12 \%$ cold-worked 316 irradiated and tested at lower $\left(\sim 380^{\circ} \mathrm{C}\right)$ temperature. The majority of the increase in yield strength appears to occur over approximately the first $10 \mathrm{dpa}$ of irradiation. The increase in yield strength as a function of dose is similar for the $12 \%$ cold-worked 316 irradiated and tested at higher temperature $\left(\sim 430^{\circ} \mathrm{C}\right)$ and for the $20 \%$ cold-worked 316 . For these two conditions, the increase in yield strength occurs more slowly as a function of irradiation dose. For the $12 \%$ cold-worked 316 irradiated at $\sim 430^{\circ} \mathrm{C}$, there is a fairly large scatter in the measured yield strength at any specific dose. The ultimate tensile strength (not shown) follows similar trends as the yield strength for all three conditions. 


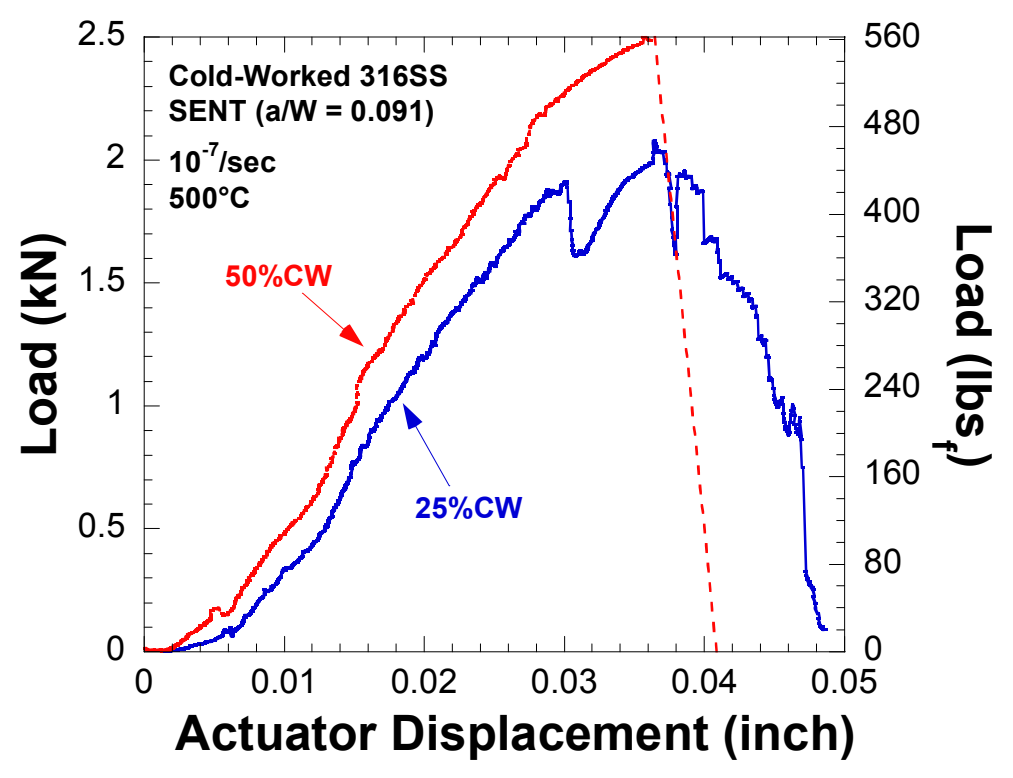

Figure 31. Load vs. actuator displacement responses for SENT specimens fabricated from 25 and $50 \% \mathrm{CW}$ materials.
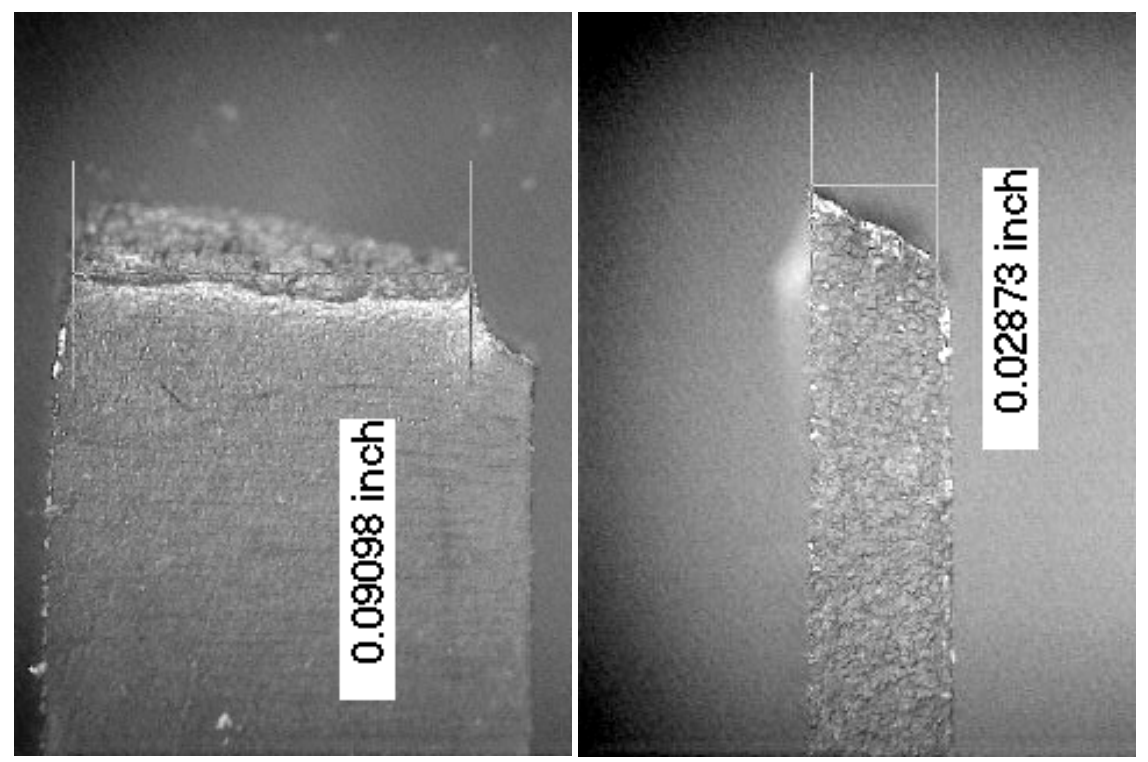

Figure 32. Stereoscopic images of post-test SENT specimen fabricated from $50 \%$ CW material showing through-thickness shear fracture on a near $-45^{\circ}$ plane from the principal stress direction. 


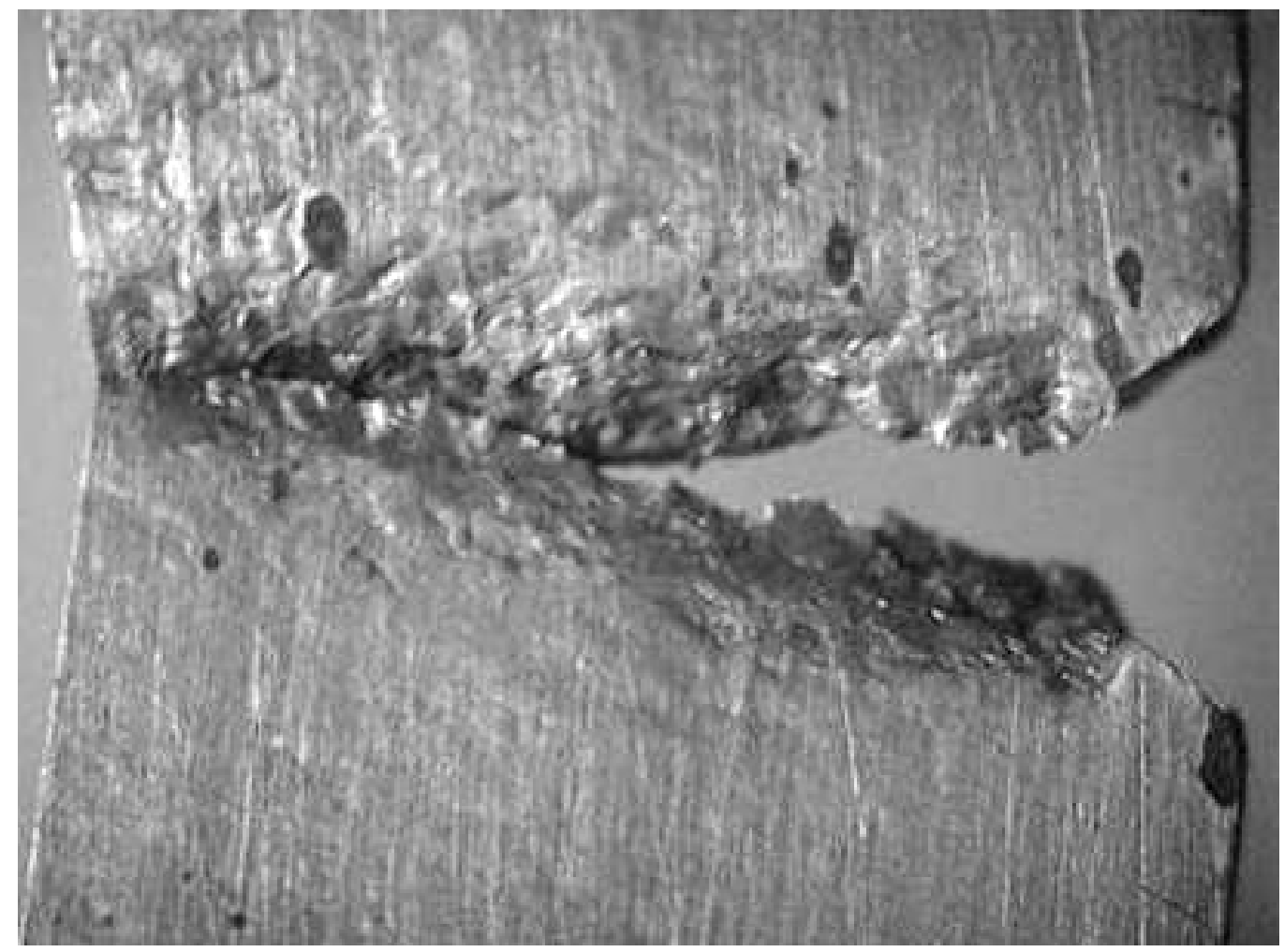

Figure 33. Stereoscopic images of SENT specimen fabricated from $25 \% \mathrm{CW}$ material prior to fracture showing plane-stress Mode I crack growth. 


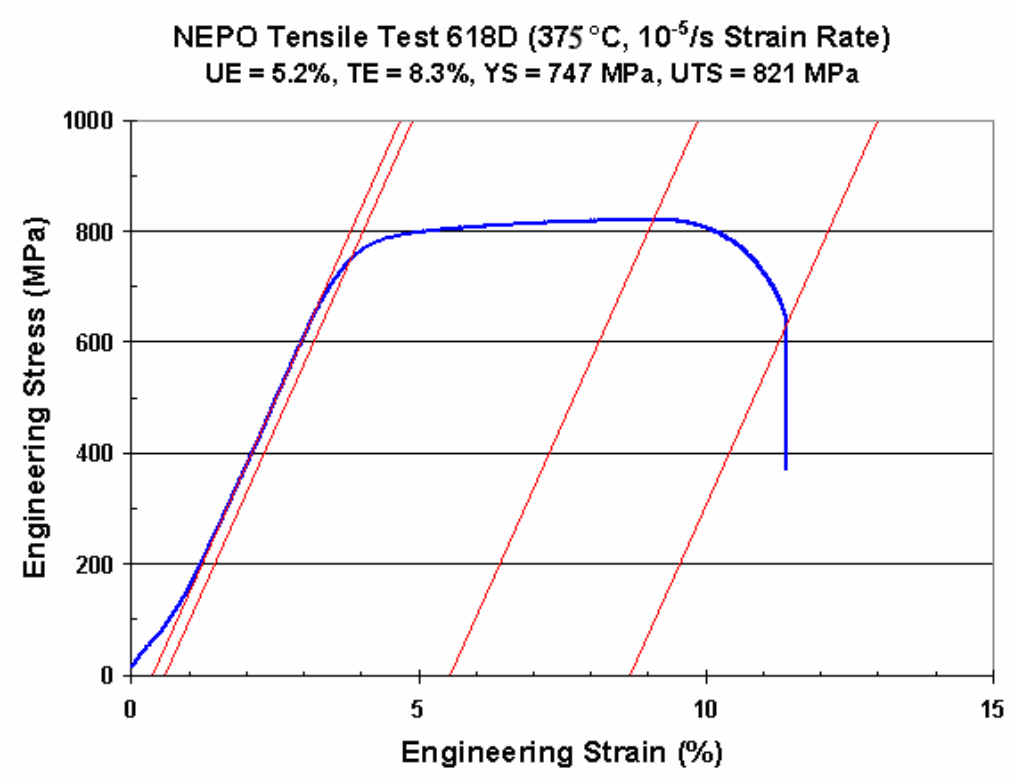

a)

NEPO Tensile Test618E (25 dpa, $375^{\circ} \mathrm{C}, 10^{-5} / \mathrm{s}$ Strain Rate) $\mathrm{UE}=3.7 \%, \mathrm{TE}=6.7 \%, \mathrm{YS}=755 \mathrm{MPa}$, UTS $=828 \mathrm{MPa}$

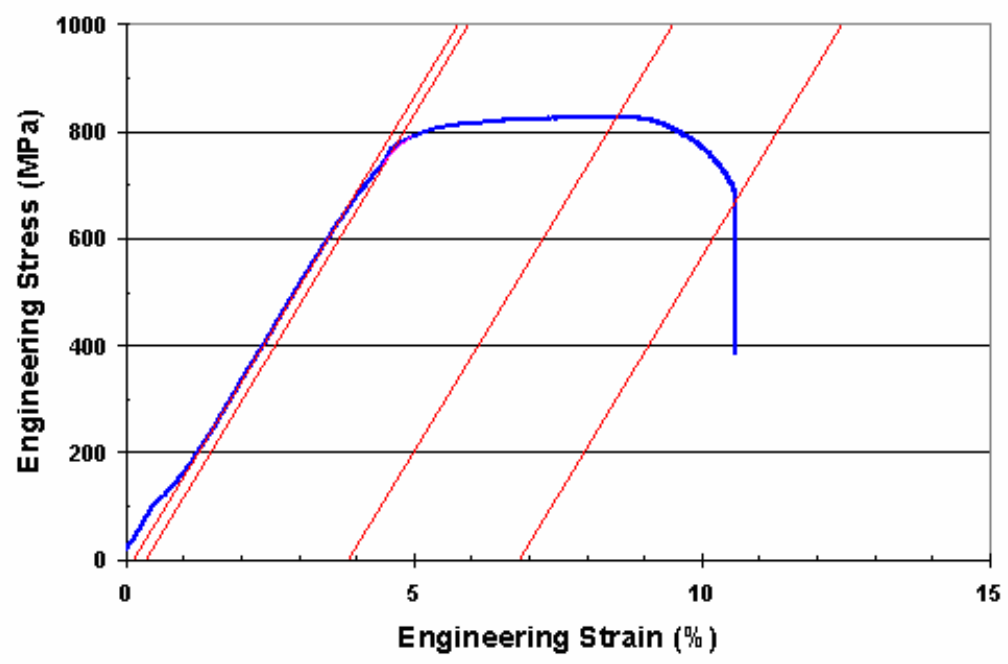

b)

Figure 34. Stress-strain curves for 316 samples tested at $\sim 375^{\circ} \mathrm{C}$ and following irradiation at a) $14 \mathrm{dpa}$ and b) $25 \mathrm{dpa}$. Tensile properties data are also listed. UE is uniform elongation, TE is total elongation, YS is yield strength and UTS is the ultimate tensile strength. 


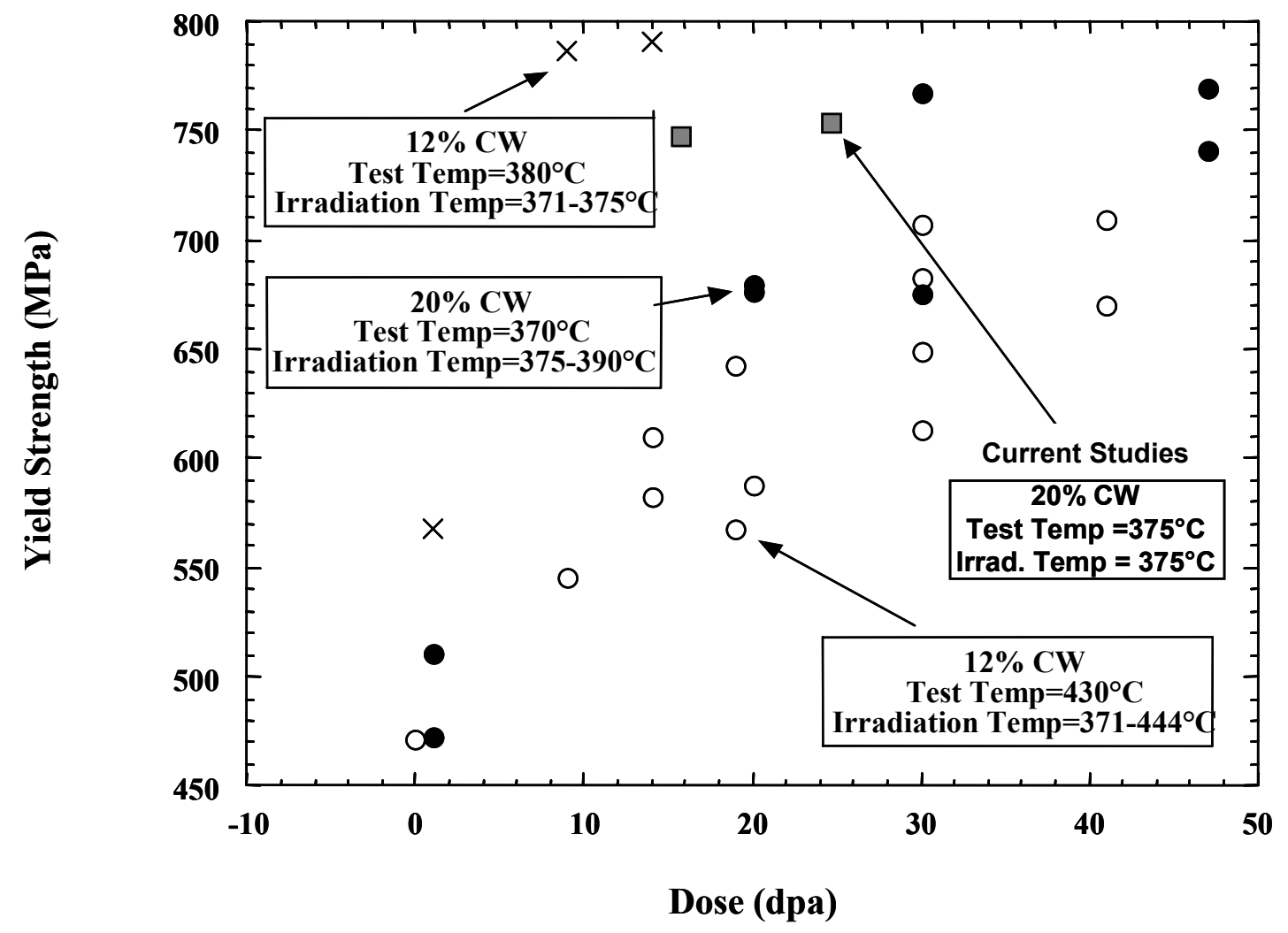

Figure 35. Yield Strength for EBR-II 316 stainless steel. Filled squares represent most recently conducted tests.

The ductility, as measured by the total elongation to failure, is presented in Figure 36. The total elongation for the $12 \%$ cold-worked 316 irradiated and tested at lower $\left(\sim 380^{\circ} \mathrm{C}\right)$ temperature decreases rapidly over the first $10 \mathrm{dpa}$. A similar effect occurs for the $20 \%$ cold-worked 316. At the highest dpa achieved for the 20\% cold-worked 316 (47 dpa), the total elongation at failure is around $2 \%$, which is quite low. The decrease in total elongation as a function of dose is the slowest for the $12 \%$ cold-worked 316 irradiated and tested at higher temperature $\left(\sim 430^{\circ} \mathrm{C}\right)$.

A measure of the ability to work harden is given by $\left(1-\frac{\sigma_{y}}{\sigma_{u}}\right)$, where $\sigma_{y}$ is the yield strength and $\sigma_{\mathrm{u}}$ is the ultimate tensile strength. As the material hardens, the yield strength approaches the ultimate tensile strength. This quantity is plotted as a function of dose in Figure 37. Figure 37 includes data for the 12\% cold-worked 316 irradiated and tested at lower $\left(\sim 380^{\circ} \mathrm{C}\right)$ temperature, the $12 \%$ cold-worked 316 irradiated and tested at higher $\left(\sim 430^{\circ} \mathrm{C}\right)$ temperature, and the $20 \%$ cold-worked 316 . In addition, data from Fish et al., [33] on the hardening of 20\% cold-worked 316 irradiated at high dose rate in row 2 of EBR-II is included in Figure 37. The 12\% cold-worked 316 irradiated and tested at 
lower $\left(\sim 380^{\circ} \mathrm{C}\right)$ temperature and the $20 \%$ cold-worked 316 irradiated at high dose rate (from Fish et al.) harden the fastest. At high dose, it appears all of the 




Figure 36. Total Elongation for EBR-II 316 stainless steel. Filled squares represent most recently conducted tests.

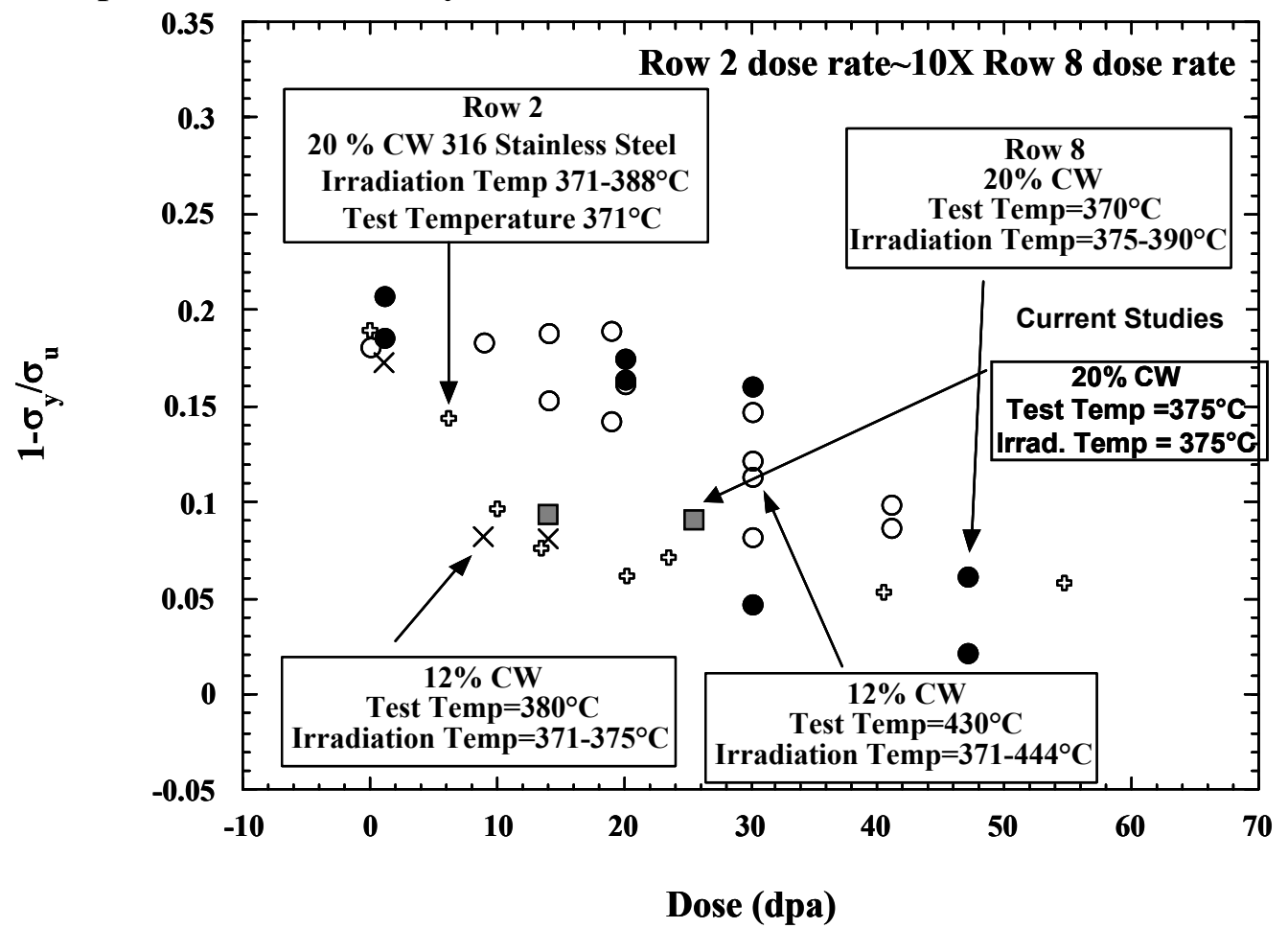

Figure 37. Hardening for EBR-II 316 stainless steel 
alloys approach a similar hardening value of around 0.05 (where the yield strength is $\sim 95 \%$ of the ultimate tensile strength).

The low total elongation of the $20 \%$ cold-worked samples tested in this study correlates with a change in fracture mode. Posttest fractography was performed on two representative samples of the $20 \%$ cold-worked material at doses of 30 and 47 dpa using a scanning electron microscope. Necking of the gauge section in the 30 dpa specimen is evident, but for the higher-dose specimen, necking is almost imperceptible. This is consistent with the measured elongation data, which showed further reduction of ductility during irradiation from 30 to $47 \mathrm{dpa}$. Because necking constitutes a sizable fraction of the gauge deformation after the maximum load (uniform elongation) is attained prior to fracture, it reflects to a large extent the difference between the uniform and total elongation.

Fracture in the $20 \%$ cold-worked specimen irradiated to 30 dpa is mainly ductile but with local regions of mixed-mode failure. The ductile fracture, illustrated in (Figure 38), consists mainly of dimples and microvoids. Among the dimples, there are facet features that suggest flow localization and slip band decohesion. The 30 dpa sample has limited areas with mixed mode fracture (not shown) where some failure appears as a transgranular shear along active slip planes. The side surface of the 30 dpa specimen shows steps from the tensile deformation; such features are typically associated with dislocation channeling in material.

The fracture surface of the higher-exposure 47 dpa specimen displays significantly more brittle features, as shown in Figure 39. The fracture consists of mainly small facets and slip bands that suggest cleavage fracture. Dimples and microvoids are far less abundant than in the lower-exposure $30 \mathrm{dpa}$ specimen. Noticeable steps are also found on the side surfaces of the specimens.

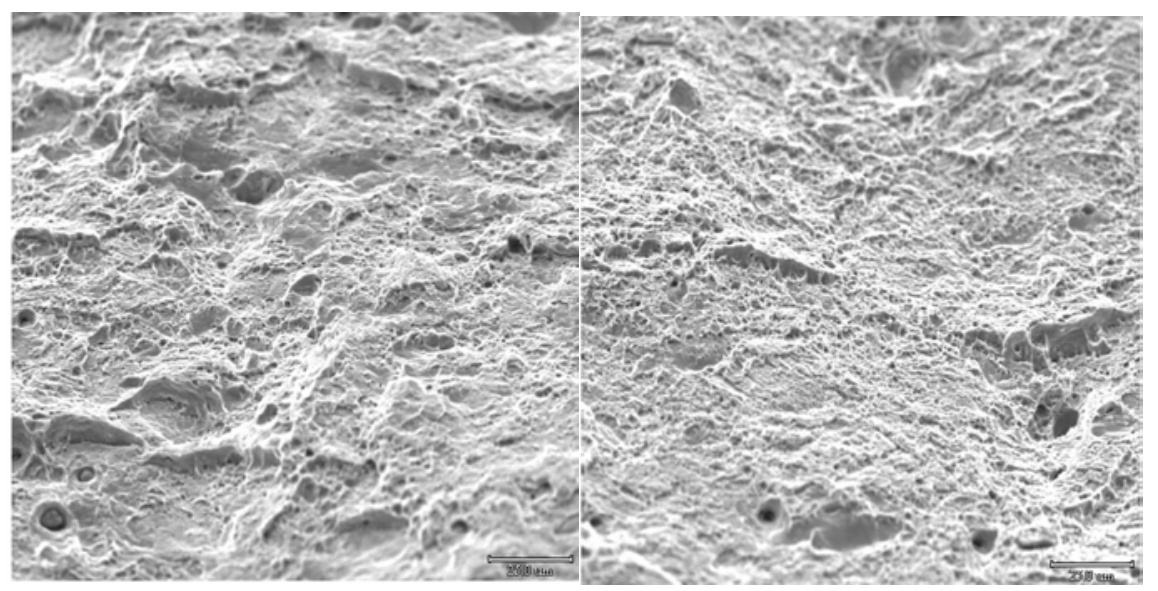

Figure 38. Areas of fracture surface in $20 \%$ cold-worked 316 irradiated to 30 dpa showing ductile dimples mixed with facets 


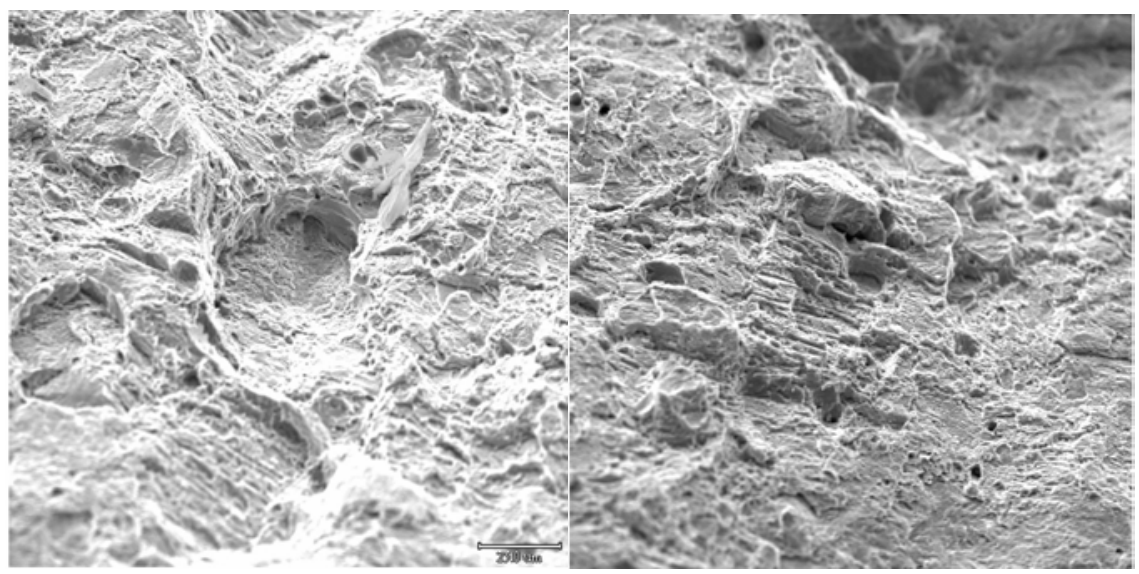

Figure 39. Areas of fracture surface in $20 \%$ cold-worked 316 irradiated to 47 dpa showing a faceted surface.

Post-tensile test fractography was also performed on $12 \%$ cold-worked samples. Fractography was performed on samples irradiated to doses from 19-41 dpa at temperatures of $417-435^{\circ} \mathrm{C}$ to elucidate the fracture mode and to determine the crosssectional reduction-in-areas. Frontal view of the fracture tips revealed necking of the gauge section in both the thickness and width directions. Similar necking deformation was seen in the other three specimens examined in the SEM. The relatively high reduction-in-areas, $27 \%$ for a $30 \mathrm{dpa} / 425^{\circ} \mathrm{C}$ sample and $36 \%$ for samples irradiated to 19 $\mathrm{dpa} / 435^{\circ} \mathrm{C}, 30 \mathrm{dpa} / 425^{\circ} \mathrm{C}$, and $41 \mathrm{dpa} / 417^{\circ} \mathrm{C}$, agree with the substantial elongations for $12 \%$ cold-worked 316 irradiated $\sim 430^{\circ} \mathrm{C}$. Further corroborating the observation that the material after the irradiation was still ductile, the SEM fractography confirmed that the fracture consisted of exclusively ductile dimples and microvoids in all four specimens. No channel facets or other brittle features were present in any of the surfaces examined.

\subsubsection{Summary of Tests on Irradiated Materials}

Mechanical properties and associated microstructural changes were measured on coldworked AISI 316 stainless steel irradiated under low dose rate conditions both in this and two previous studies. Both $12 \%$ and $20 \%$ cold-worked conditions were examined. Although the yield strength for each condition approached similar values with increasing dose, the rate of increase in strength differed with cold-work and irradiation temperature. The $12 \%$ cold-worked steel irradiated and tested at lower temperature $\left(\sim 380^{\circ} \mathrm{C}\right)$ had the fastest rate of strength increase. Differences in elongation were also noted. The $12 \%$ cold-worked steel irradiated and tested at lower temperature $\left(\sim 380^{\circ} \mathrm{C}\right)$ and the $20 \%$ coldworked 316 had the fastest rate of decrease in total elongation. The total elongation for the $20 \%$ cold-worked stainless steel reached $2 \%$ at $47 \mathrm{dpa}$, a low value. At this high dose and low elongation, the fracture was starting to transition from ductile to a more channeled fracture. The data on 316 stainless steel indicates degradation due to swelling and changes in mechanical properties. 


\subsection{Shear Punch Testing}

During the second year of the project, work began at ANL-W to establish the capability to perform shear punch mechanical tests on small (3 $\mathrm{mm}$ in diameter) discs. Although the original project scope produced at the beginning of the project in 2000 did not include shear punch as a small sample test technique, the strong advice of the project advisory board was to include shear punch in the test matrix. Therefore, when the year 2 test plan was put together, shear punch was added. This required the additional use of resources to establish this capability by adding fixtures to an existing tensile machine and modifying laboratory procedures for conducting tests on irradiated samples. As stated earlier, the shear punch testing capability has been established but the project was terminated prior to the planned completion of the testing workscope. 


\subsection{Microstructural Evaluation}

\subsection{Analysis of Work Hardened Microstructure in Unirradiated 316 SS}

The following section details results of a transmission electron microscopy (TEM) study to analyze the deformation microstructure that develops in unirradiated 316 SS following the initial cold work to levels of 25 and 50\%. In addition, a solution-annealed sample was analyzed for comparison.

Low magnification images of the samples are provided in Figure 40. Because of the complex nature of the dislocation structures in the cold-worked alloys, quantification of the microstructure could only be carried out in the thin regions near the foil edge. In the alloy which had been solution annealed, an extremely low dislocation density was observed. There was also evidence that the dislocations were highly mobile indicated by faint traces along the surface of the sample where the oxide film has been disrupted by the passage of dislocations along the slip planes. Because of the loss of dislocations to the surface, the bulk dislocation density in the solution annealed alloys can be expected to be higher than that observed in the prepared TEM thin foils. In the cold-worked materials, this should not be as great a problem due to dislocation entanglements locking the dislocations into place and preventing their motion to the foil surface.

Two images taken of the 25 and 50 percent cold-worked alloys are presented in Figure 41. The images were taken under WBDF conditions near the foil edge. For the purpose of counting, the defects were separated into two categories. In the first category, all the extended dislocations, stacking faults and microtwins were placed. This was done because there is strong evidence that the genesis of the microtwins is from the stacking faults that form early in the deformation process [34]. The second category of defects referred to as segments, includes all of the non-extended dislocation segments and small dislocation debris which appears similar to black spot damage in irradiated material. This may be the result of interaction of dislocations on different slip plans forming kinks or jogs and the cutting of the dislocations to form the small segments. For both levels of cold work, there is an increased density of extended dislocations, stacking faults and twins. The density of microtwins increased substantially between 25 and $50 \%$ coldworked levels, while the combined density of faults and twins decreased slightly. In addition the density of dislocation segments actually decreased in going from 25 to $50 \%$ cold-work. This may be a result of the non-uniform nature of deformation in polycrystalline materials in combination with an attainment of a saturation dislocation density by $25 \%$ cold-work. At this point the stress to generate twins becomes less than the stress for the operation of additional dislocation sources; as a result, twinning becomes the primary mode of deformation. Quantitative results describing the microstructural features found are listed in Table 6.

\subsubsection{Post-Tensile Test TEM of Cold-Worked 316}

Selected gauge section samples from the cold-worked 316 SS tensile bars were examined in the transmission electron microscope following testing. Figure 42 provides 
micrographs of two of the samples following an interrupted test to $25 \%$ strain. In Figure $42 \mathrm{a}$, the $0 \% \mathrm{CW}$ (SA) exhibits 


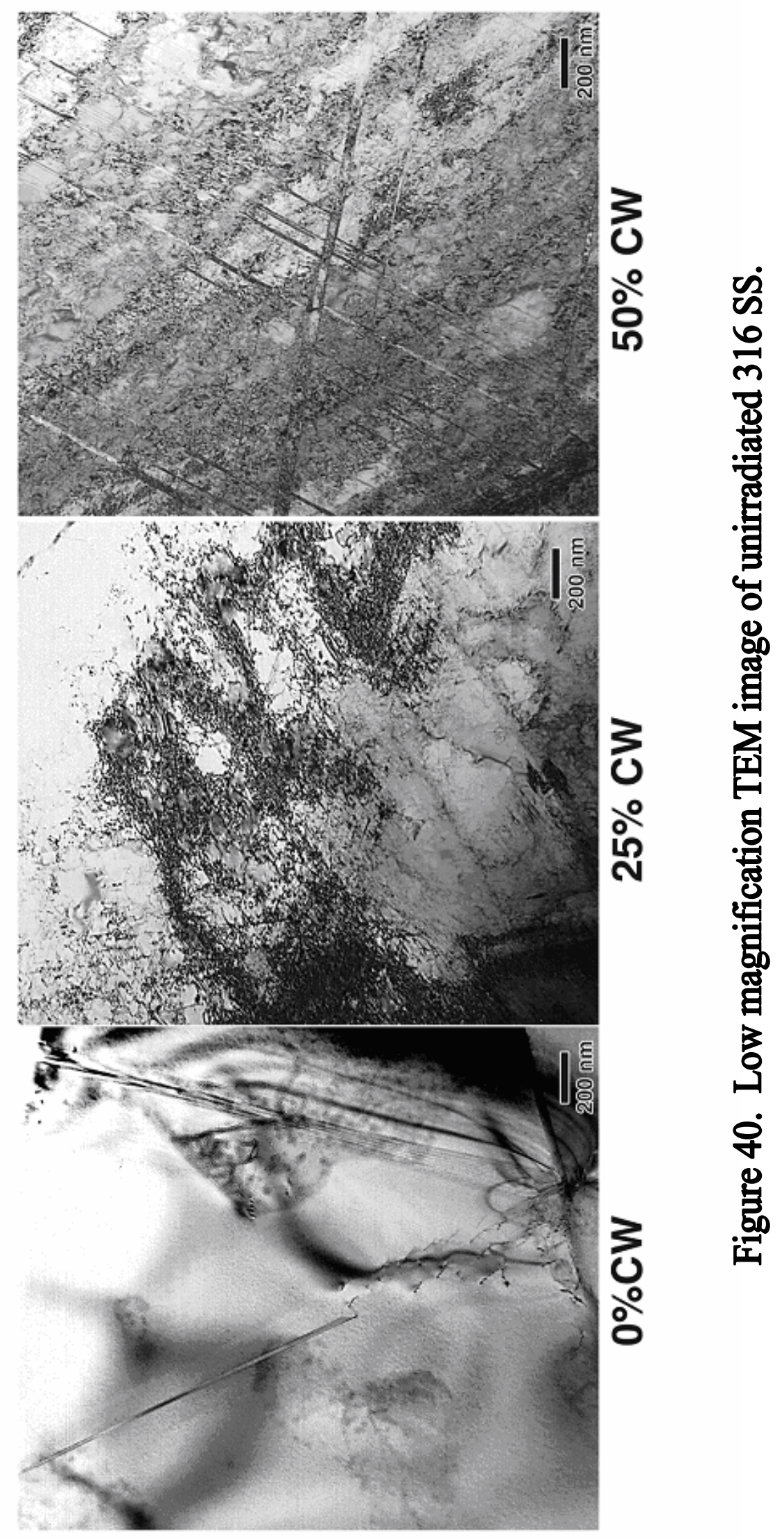



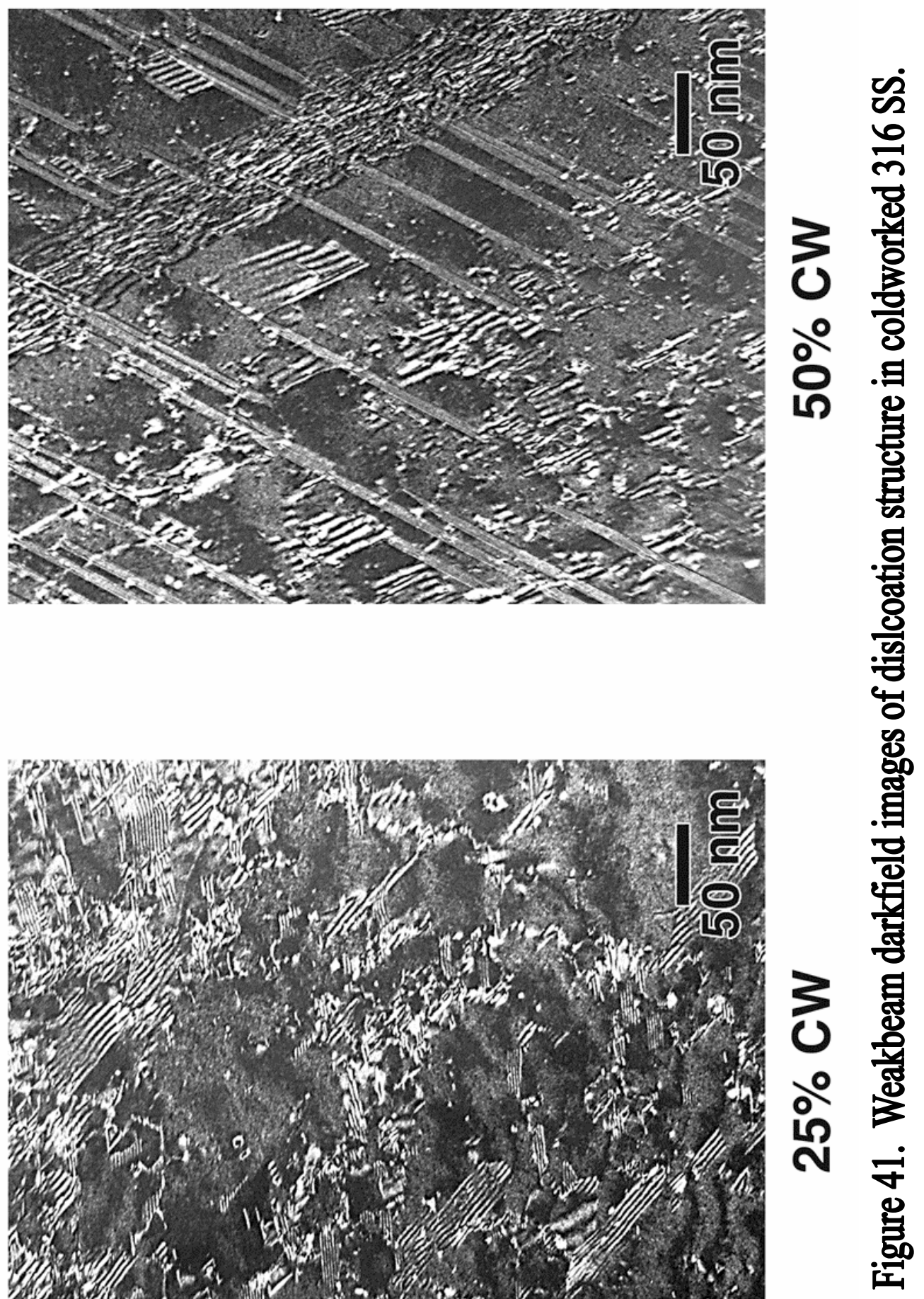
Table 6. Dislocation Densities in the Cold-worked 316 SS.

\begin{tabular}{|l|l|l|l|}
\hline & \multicolumn{3}{|l|}{ Dislocation Density $\left(\mathbf{1} / \mathbf{c m}^{-2}\right)$} \\
\hline Cold Work Level & Segments & Extended/Twins & Total \\
\hline $0 \%$ & $1.9 \times 10^{12}$ & $5.0 \times 10^{11}$ & $2.4 \times 10^{12}$ \\
\hline $25 \%$ & $6.7 \times 10^{15}$ & $2.6 \times 10^{15}$ & $9.3 \times 10^{15}$ \\
\hline $50 \%$ & $3.9 \times 10^{15}$ & $1.9 \times 10^{15}$ & $5.7 \times 10^{15}$ \\
\hline
\end{tabular}

substantial extended stacking fault and microtwin formation following $25 \%$ strain. The network dislocation density appears to be considerably lower in the SA tensile sample strained $25 \%$ uniaxially compared to the previously examined $25 \%$ cold-rolled 316 SS samples. The micrograph of the $25 \%$ cold-rolled sample following $25 \%$ uniaxial tensile strain shown in Figure $42 \mathrm{~b}$ also exhibits evidence of increased twin density along with the rearrangement of network dislocation into lower energy dislocation arrays. Dislocation rearrangement during plastic deformation occurs to reduce the overall stored strain energy of the dislocation network structures.

\subsection{Microstructural Analysis of Irradiated Coldworked 316 SS}

The defect microstructures of the 3 irradiated CW 316 SS samples (7, 30 and 32 dpa) were examined and quantified in the TEM. Table 7 lists the irradiation conditions and defect parameters for the voids and dislocations. The final column is the amount of swelling due to the formation of cavities and is calculated from the following equation:

$$
\frac{\Delta V}{V}=\frac{(4 / 3) \pi R^{3} N}{1-(4 / 3) \pi R^{3} N}
$$

where $\mathrm{R}$ is the void radius and $\mathrm{N}$ is the density. The actual amount of bulk swelling may be different than this value due to the evolving dislocation structure and the formation of the high density of second phase precipitates, however, the low level of void swelling in all of the samples examined (7, 30 and $32 \mathrm{dpa}$ ) suggests the hex duct material has not yet reached the $1 \% /$ dpa steady-state level of swelling commonly cited for austenitic stainless steel [35]. The substantial difference in swelling between the 30 and 32 dpa samples ( 2 times) is not expected, however the swelling uncertainty (based on the data spread) for the 32 dpa sample is substantially larger.

Both bubbles and large faceted voids are observed to form in the irradiated CW 316 SS. The sample irradiated to only $7 \mathrm{dpa}$ had a low density of cavities, consequently, the calculated swelling is extremely low and the expected contribution to hardening from these cavities should be limited. As the bubbles grow with dose, they transition into voids as indicated by the faceted nature of the void surfaces. These facets form along the low energy atomic planes to conserve surface energy. Figure 43 is a BF TEM image of the 3 samples taken under void contrast 




a)

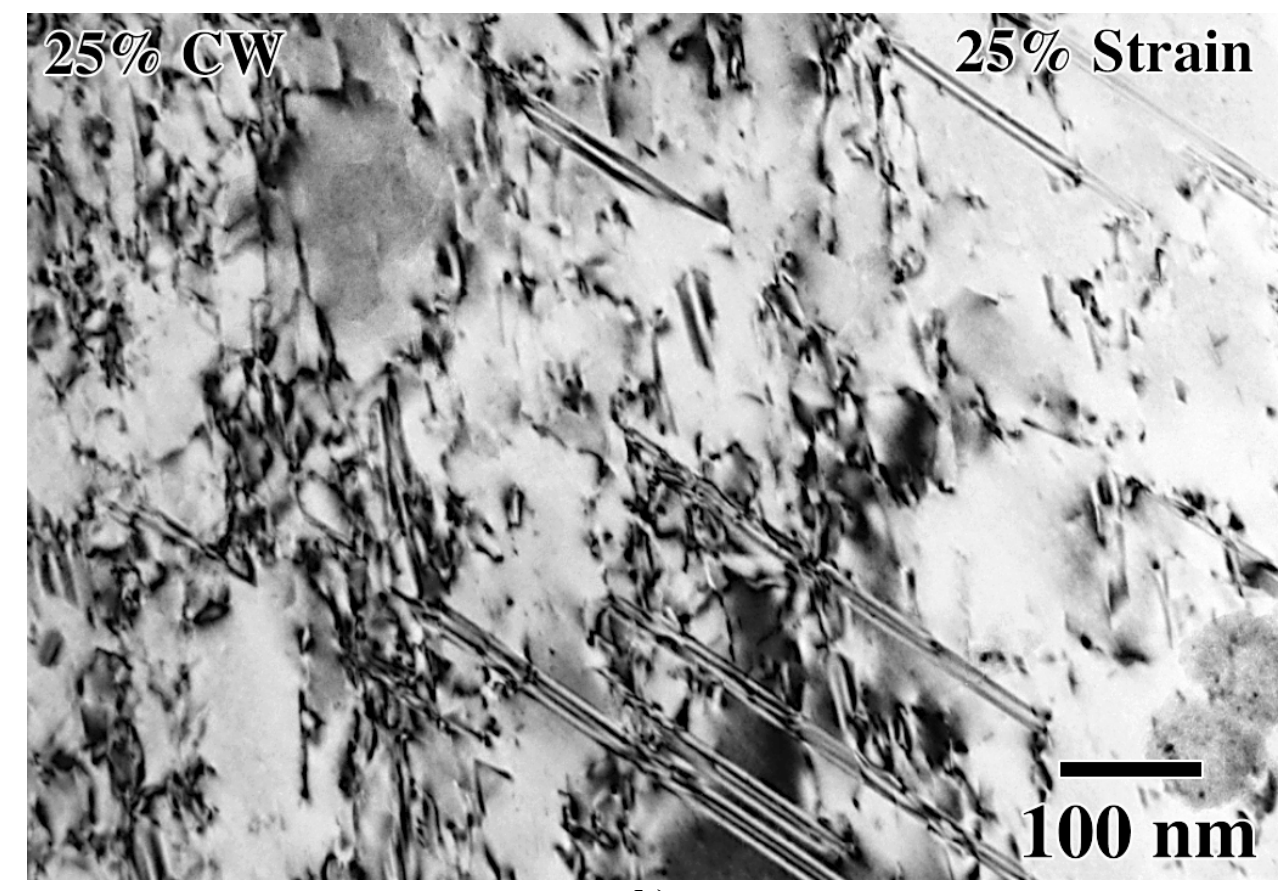

b)

Figure 42. TEM micrographs of $316 \mathrm{SS}$ following $25 \%$ strain in uniaxial tension a) $0 \% \mathrm{CW}$ (SA) b) $25 \%$ cold work 
Table 7 Void and dislocation sizes and densities for the EBR-II 316 SS TEM samples.

\begin{tabular}{|c|c|c|c|c|c|c|}
\hline \multicolumn{4}{|c|}{ Dislocations } & \multicolumn{3}{|c|}{ Voids } \\
\hline & \multicolumn{2}{|c|}{ Faulted } & \multirow{2}{*}{$\frac{\text { Network }}{\text { Density }\left(\mathrm{m}^{-2}\right)}$} & & & \\
\hline Sample & $\begin{array}{l}\text { Avg. Size } \\
\text { (nm)/range }\end{array}$ & Density $\left(\mathrm{m}^{-3}\right)$ & & $\begin{array}{l}\text { Avg. Size } \\
(\mathrm{nm}) / \text { range }\end{array}$ & Density $\left(\mathrm{m}^{-3}\right)$ & $\begin{array}{c}\text { Swelling } \\
(\%)\end{array}$ \\
\hline $\begin{array}{c}\text { SD4 } \\
7 \mathrm{dpa}, \\
373 \mathrm{C}\end{array}$ & $\begin{array}{c}29.6 / \\
11.5-55.8\end{array}$ & $6.4 \pm 2.1 \times 10^{21}$ & $3.2 \pm 0.8 \times 10^{15}$ & $\begin{array}{c}6.9 / \\
1.9-13.0\end{array}$ & $3.4 \pm 1.3 \times 10^{19}$ & $0.001 \pm 0.001$ \\
\hline $\begin{array}{c}\text { SD5 } \\
30 \text { dpa, } \\
379 \mathrm{C}\end{array}$ & $\begin{array}{c}26.4 / \\
12.3-36.7\end{array}$ & $5.2 \pm 1.7 \times 10^{21}$ & $3.9 \pm 1.0 \times 10^{15}$ & $\begin{array}{c}11.6 / \\
3.2-23.0\end{array}$ & $3.5 \pm 0.2 \times 10^{21}$ & $0.30 \pm 0.03$ \\
\hline $\begin{array}{c}\text { SD3 } \\
32 \text { dpa, } \\
380 \mathrm{C}\end{array}$ & $\begin{array}{c}19.4 / \\
9.0-29.9\end{array}$ & $8.3 \pm 1.3 \times 10^{21}$ & $8.1 \pm 1.0 \times 10^{15}$ & $\begin{array}{c}11.9 / \\
3.9-25.5\end{array}$ & $6.9 \pm 1.8 \times 10^{21}$ & $0.61 \pm 0.25$ \\
\hline
\end{tabular}

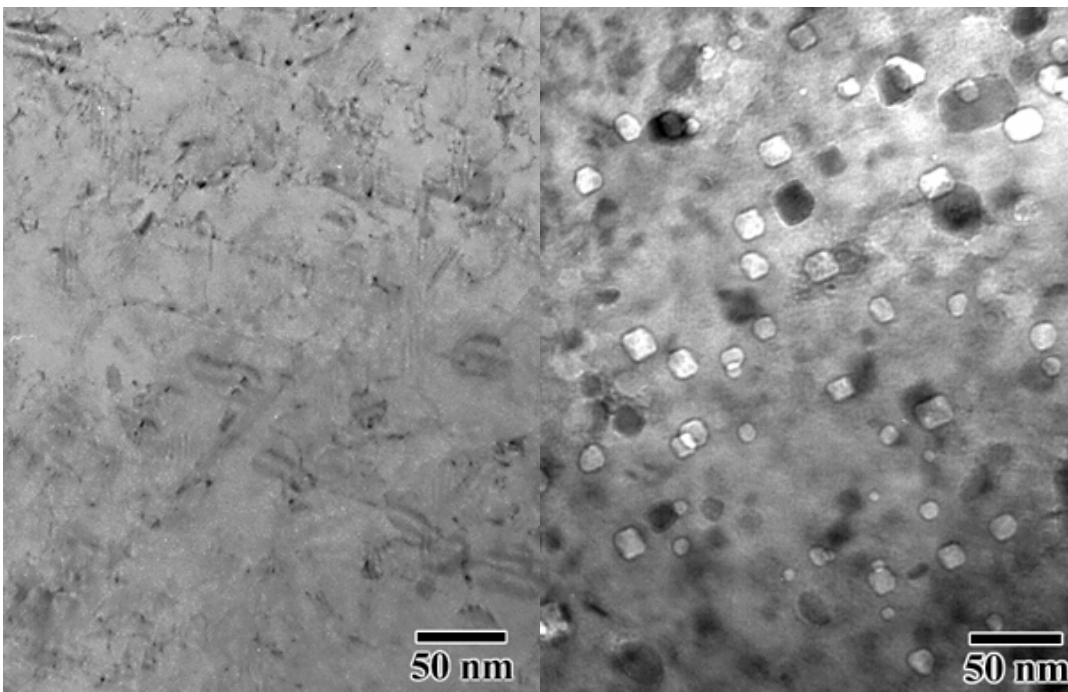

a) b)

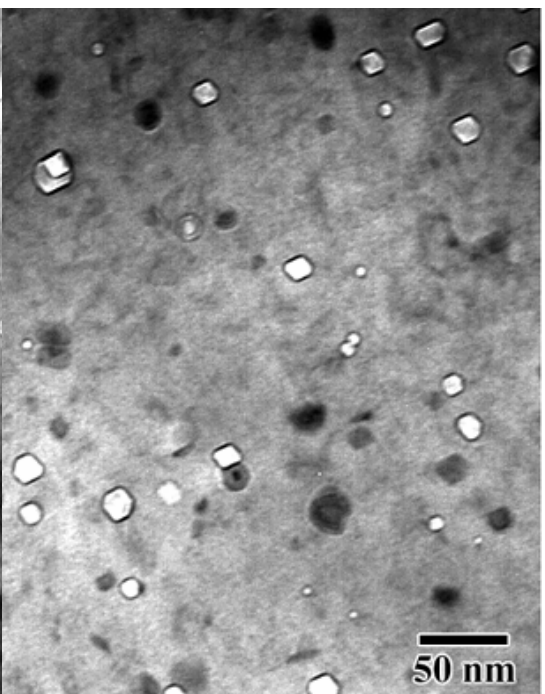

c)

Figure 43. Void contrast TEM images of the $316 \mathrm{SS}$ hex duct samples, a) $7 \mathrm{dpa}, 373^{\circ} \mathrm{C}$, b) $30 \mathrm{dpa}, 379^{\circ} \mathrm{C}$ and c) $32 \mathrm{dpa}, 380^{\circ} \mathrm{C}$. 
imaging conditions.. The larger voids will act as strong obstacles to plastic deformation as discussed in the next section.

The dislocation microstructures consist of both faulted loops (exhibiting fringe contrast in the TEM image) and dense tangles of perfect dislocations typically referred to as network dislocations. Because 316 SS has a low stacking fault energy, there is a complete absence of perfect dislocation loops. Figure 44 is a representative BF TEM image of the sample irradiated to $30 \mathrm{dpa}$ at $379^{\circ} \mathrm{C}$. The dislocation network density and the density and size of the faulted loops does not change significantly between 7 and 30 dpa. However, the 32 dpa sample has both a higher density of loops and network dislocations, although the average loop diameter is lower.

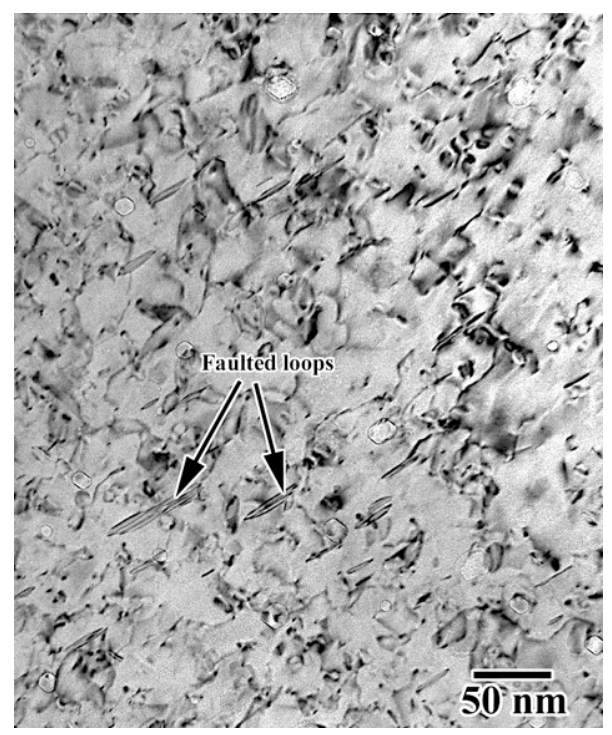

Figure 44. Representative bright field TEM micrograph taken in dislocation contrast illustrating the defect structure that develops in the 316 SS hexagonal duct following irradiation to $30 \mathrm{dpa}$ at $379^{\circ} \mathrm{C}$.

One explanation for the increase in network density along with a decrease in average faulted loop diameter is that as the faulted loop density increases and the loops grow to a critical size, they will unfault. The mobile perfect loops will then interact and form the dense tangles of network dislocations. Because the larger loops are being eliminated, the average loop size will decrease.

Size and density parameters for the precipitates observed in the 3 samples examined are provided in Table 8. Local composition variations in the hex duct may be partly responsible for the significant difference in precipitate density between the 30 and 32 dpa samples. Studies show that precipitate formation in irradiated stainless steel can be either radiation -induced or radiation enhanced [36]. Radiation-induced precipitates are not observed in thermally aged samples, while radiation-enhanced precipitates will form thermally but at a much slower rate. Earlier studies on similar stainless steel indicate the majority of the precipitates in the EBR-II 316 SS are Cr-rich 
Table 8. Precipitate size and densities for the 3 TEM samples examined.

\begin{tabular}{|l|l|l|}
\hline Sample ID & Precipitate Size $(\mathbf{n m}) /$ range & Precipitate density, $\mathbf{~}^{-3}$ \\
\hline SD4, 7 dpa, 373C & negligible precipitates & negligible precipitates \\
\hline SD5, 30 dpa, 379C & $16.7 /(6.64-38.7)$ & $1.4 \pm 0.2 \times 10^{21}$ \\
\hline SD3, 32 dpa, 380C & $19.5 /(7.7-47.8)$ & $7.4 \pm 0.7 \times 10^{21}$ \\
\hline
\end{tabular}

carbides such as $\mathrm{M}_{23} \mathrm{C}_{6}$ and $\mathrm{M}_{6} \mathrm{C}$ [37]. Both of these precipitate types can be observed in thermally aged samples, although their compositions are slightly different. Formation of precipitates during irradiation will also promote hardening.

\subsection{Microstructure Analysis of Irradiated Solution Annealed 304}

Microstructural examination was also carried out on 3 samples of solution annealed 304 SS. The irradiation conditions for each of the samples along with the results from the characterization are listed in Table 9. Void contrast TEM micrographs of the 3 samples examined are shown in Figure 45. A high density of voids and precipitates were observed in all three samples. In comparison to the $7 \mathrm{dpa}$ sample of 316, which exhibited no voids and precipitates, the 304 sample irradiated to 11 dpa exhibited substantial void and precipitate formation. Although the average void size did not increase substantially with dose, the density of voids increased substantially leading to a significant increase in the calculated bulk swelling. The precipitates observed were not explicitly identified in this study, but are believed to be $\mathrm{M}_{23} \mathrm{C}_{6}$ based on results from similar samples in other studies.

Table 9. Void and dislocation sizes and densities for the EBR-II Solution annealed 304 SS TEM samples.

\begin{tabular}{|c|c|c|c|c|c|}
\hline \multicolumn{3}{|c|}{ Dislocations } & \multicolumn{3}{c|}{ Voids } \\
\hline & \multicolumn{2}{|c|}{ Faulted } & \multicolumn{3}{c|}{} \\
\hline Sample & $\begin{array}{c}\text { Avg. Size } \\
(\mathrm{nm})\end{array}$ & Density $\left(\mathrm{m}^{-3}\right)$ & $\begin{array}{c}\text { Avg. Size } \\
(\mathrm{nm})\end{array}$ & Density $\left(\mathrm{m}^{-3}\right)$ & $\begin{array}{c}\text { Swelling } \\
\%\end{array}$ \\
\hline $\begin{array}{c}\text { UD4 } \\
11 \mathrm{dpa}, \\
373 \mathrm{C}\end{array}$ & 30.2 & $6.9 \pm 2.4 \times 10^{21}$ & $14.9 \pm 5.0$ & $7.5 \pm 1.8 \times 10^{20}$ & $0.13 \pm 0.17$ \\
\hline $\begin{array}{c}\text { UD3 } \\
15.5 \mathrm{dpa}, \\
380 \mathrm{C}\end{array}$ & Not Meas. & Not Meas. & $13.5 \pm 4.0$ & $1.2 \pm 1.2 \times 10^{21}$ & $0.15 \pm 0.25$ \\
\hline $\begin{array}{c}\text { SD5 } \\
21.5 \mathrm{dpa}, \\
384 \mathrm{C}\end{array}$ & 40.5 & $9.6 \pm 1.8 \times 10^{20}$ & $11.9 \pm 4.1$ & $4.6 \pm 0.9 \times 10^{21}$ & $0.41 \pm 0.06$ \\
\hline
\end{tabular}

The faulted dislocation loop density was measured in the lowest and highest dose samples. Loop density in the intermediate dose sample was not measured due to the poor quality of the TEM 
sample preventing clear imaging of the loops. The density of faulted loops actually decreases with increasing dose, however the temperature for the higher dose sample is also greater possibly accounting for the decrease in loop density and increase in size. Unlike the coldworked 316, the solution annealed 304 does not have a pre-existing dislocation structure. As a result the initial softening phase will be absent and the material will harden in the early stages of irradiation. The increase in swelling rate will also tend to increase the rate of hardening in the 304.

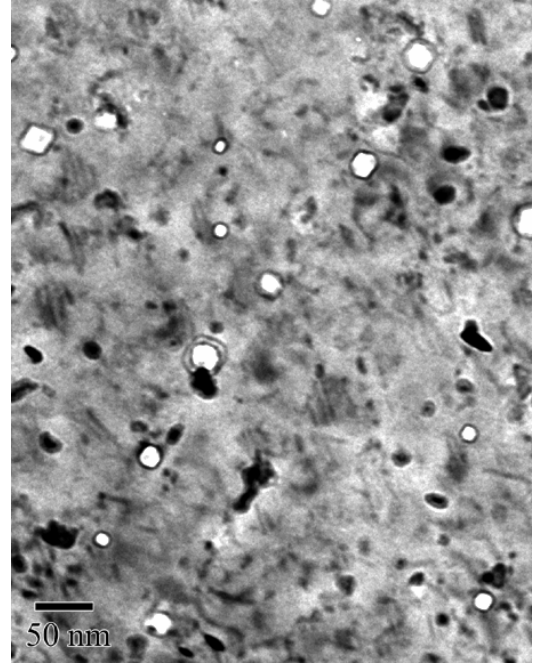

a)

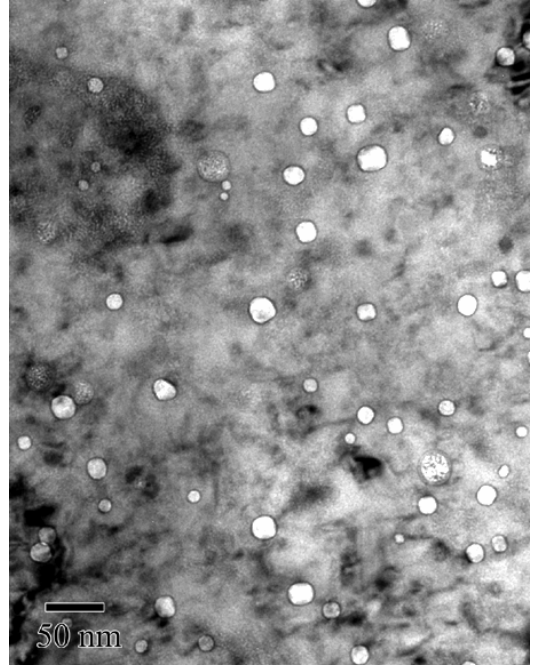

b)

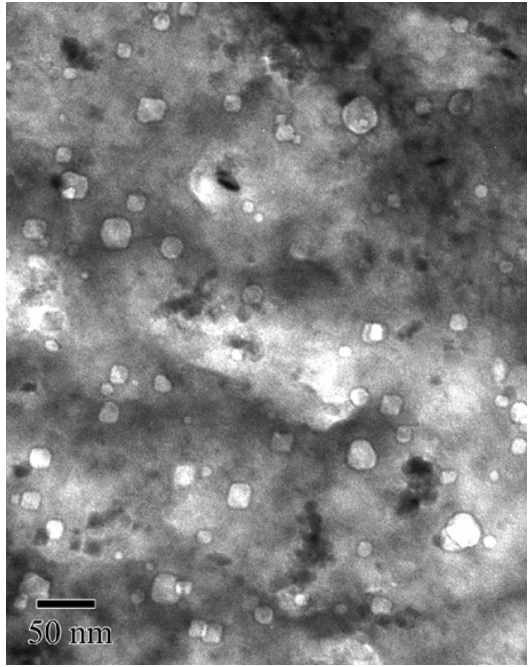

c)

Figure 45. TEM micrographs of solution annealed $304 \mathrm{SS}$ irradiated to a) 11 dpa b) 15.5 dpa and c) 21.5 dpa. 


\subsection{Deformation Modeling}

\subsection{Cold-Worked Materials Constitutive Modeling}

The flow stress constitutive relation to be used for the cold-worked austenitic stainless steels will separately considers the yield stress $\sigma_{\mathrm{y}}$ and the hardening component $\sigma_{\mathrm{pl}}$ as:

$$
\sigma(\varepsilon, d \varepsilon / d t, T)=\sigma_{y}(d \varepsilon / d t, T)+\sigma_{p l}(\varepsilon, d \varepsilon / d t, T)
$$

where $t=$ time, $\varepsilon=$ strain and $T=$ test temperature. The strain hardening behavior can be modeled within a Kocks description [1] of dislocation density evolution with plastic strain that includes terms accounting for dislocation storage and annihilation. Thus, the hardening component of the flow stress is described by:

$$
\sigma_{p l}=M \alpha G b \sqrt{\rho}
$$

where $M$ is the Taylor factor, $\alpha$ describes the strength of the dislocation interactions, $G$ is the shear modulus, $b$ is the Burgers vector and $\rho$ is the dislocation density. The strain dependence of the hardening component of the flow stress is then determined from the evolution of dislocation density with plastic strain, accounted for within the framework of the Kocks model, such that

$$
\frac{d \rho}{d \varepsilon}=M\left(c_{1} \sqrt{\rho}-c_{2} \rho\right)
$$

eq. 5

The coefficients, $\mathrm{c}_{1}$ and $\mathrm{c}_{2}$, describe dislocation generation and annihilation, respectively and are obtained by fitting the strain hardening rate, $\mathrm{d} \sigma_{\mathrm{pl}} / \mathrm{d} \varepsilon_{\mathrm{p}}$, from the experimental true stress-true strain data. Thus,

$$
\frac{\mathrm{d} \sigma_{\mathrm{pl}}}{\mathrm{d} \varepsilon_{\mathrm{p}}}=\frac{\mathrm{M}^{3} \alpha^{2} \mathrm{G}^{2} \mathrm{~b}^{2} \mathrm{c}_{1}}{2 \sigma_{\mathrm{pl}}}-\frac{\mathrm{Mc}_{2} \sigma_{\mathrm{pl}}}{2}
$$

This analysis assumes a homogeneous distribution of dislocation density and may require modification in the case of heterogeneous deformation, twinning or non-homogeneous dislocation density evolution.

Phase one modeling work focused on developing fits to the strain hardening rate of 0,25 and $50 \%$ cold-worked stainless steel tested at 400 and $500^{\circ} \mathrm{C}$ with strain-rates of $10^{-3}$ and $10^{-5} \mathrm{~s}^{-1}$. Figures 46 and 47 plot the plastic strain-hardening rate, $\mathrm{d} \sigma_{\mathrm{pl}} / \mathrm{d} \varepsilon_{\mathrm{p}}$, for the 0,25 and $50 \%$ coldworked steel at 400 and $500^{\circ} \mathrm{C}$ respectively. As expected, $\mathrm{c}_{1}$ decreases and $\mathrm{c}_{2}$ increases with increasing cold-work/dislocation density. Tensile test results were input into the model for tests conducted at $10^{-5} \mathrm{~s}^{-1}$ and $350^{\circ} \mathrm{C}$, and are similar to results reported earlier on samples tested at a strain rate of $10^{-3} \mathrm{~s}^{-1}$. These results are presented in Figure 48 which shows the stain hardening rate plotted against strain. The figure indicates that the strain hardening rate increases with cold work level, similar to the $10^{-3} \mathrm{~s}^{-1}$ results. The plot in Figure 49 indicates how $\mathrm{c}_{1}$ and $\mathrm{c}_{2}$ change 
with respect to cold-work level and temperature. The figure suggests the dislocation generation rate decreases with increasing cold-work, while the annihilation rate increases with increasing cold-work level. Temperature appears to increase the dislocation generation rate for the higher cold-work levels, while it appears temperature does not significantly influence the dislocation annihilation rate over the range tested.

\subsection{Modeling Framework For Irradiated Steels}

In the second year of this program the deformation model was expanded to irradiated materials using large deformation crystal plasticity which predicts the stress-strain behavior of the irradiated steels.

The model calculates the effective plastic strain rate via Orowan's equation:

$$
\frac{\mathrm{d} \vec{\varepsilon}_{\mathrm{p}}}{\mathrm{dt}}=\rho_{\mathrm{d}} \mathrm{b} \overrightarrow{\mathrm{v}}_{\mathrm{d}}
$$

Where $\rho_{d}$ - dislocation density, $b$ is the Burgers vector, and $V_{d}$ is the average dislocation velocity The dislocation density evolves by:

$$
\frac{d \rho_{d}}{d t}=\left(\frac{2}{b d_{d}}-\rho_{d} \frac{R}{2 b}\right) \frac{d \vec{\varepsilon}_{p}}{d t}
$$

Where $d_{d}$ is the dislocation loop size and $R_{c}$ is the capture radius.

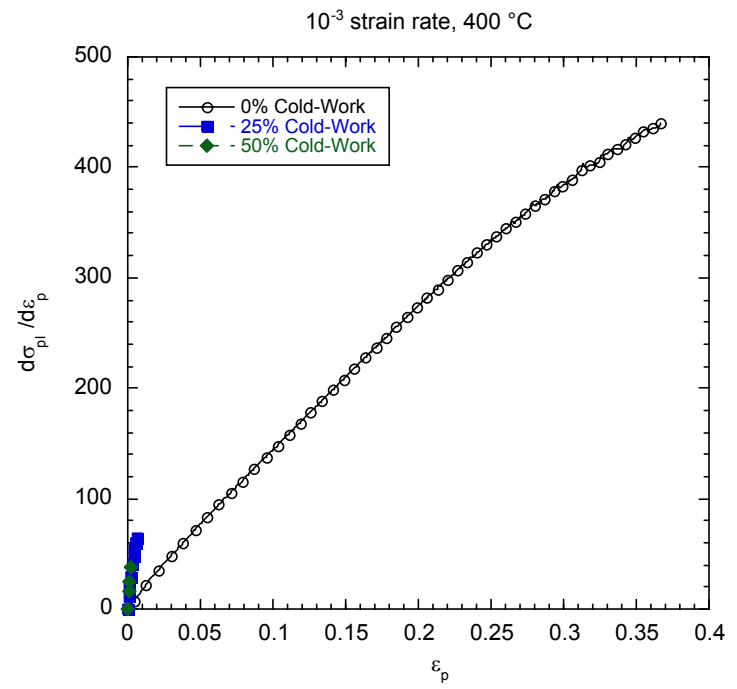

Figure 46. Strain-hardening rate data and fits for 0,25 and $50 \%$ cold-worked stainless steel, tested at $400^{\circ} \mathrm{C}$ and a strain-rate of $10^{-3} \mathrm{~s}^{-1}$. 


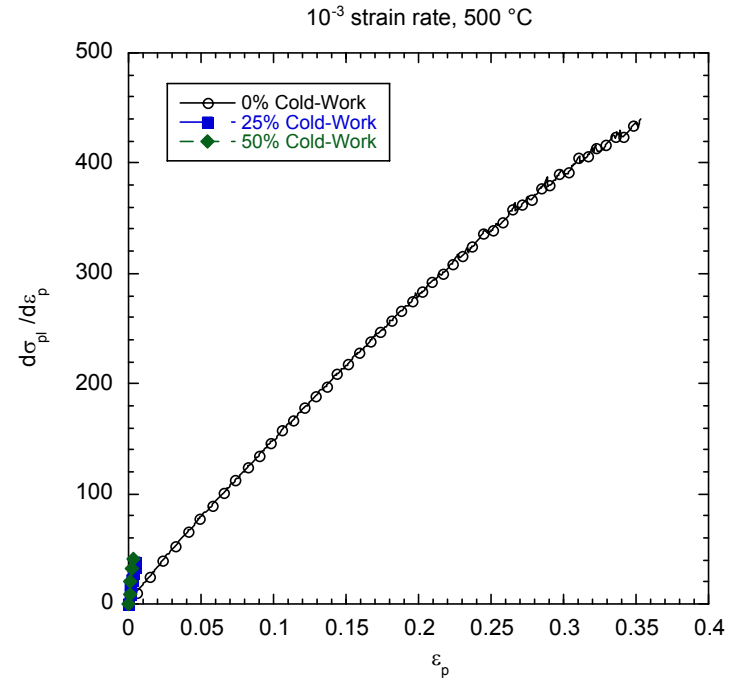

Figure 47. Strain-hardening rate data and fits for 0,25 and $50 \%$ cold-worked stainless steel, tested at $500^{\circ} \mathrm{C}$ and a strain-rate of $10^{-3} \mathrm{~s}^{-1}$.

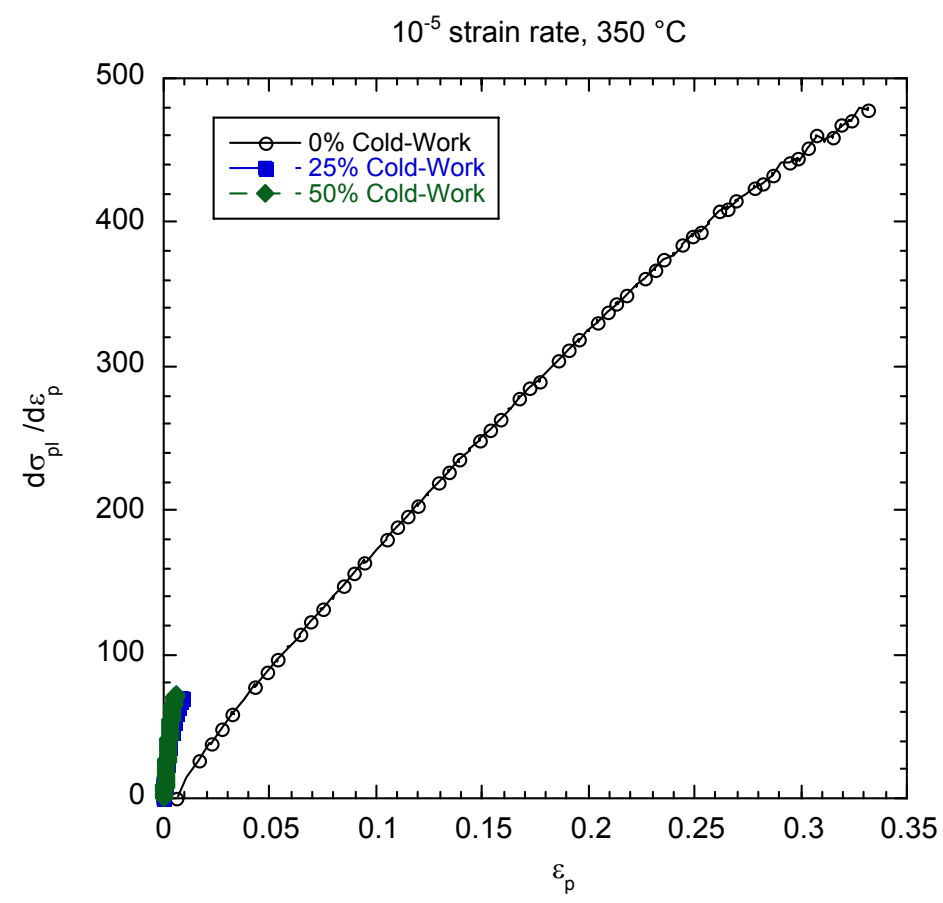

Figure 48. Modeling of the incremental flow stress or strain-hardening rate and fitting to tensile data to determine $c_{1}$ defect generation $c_{2}$ : defect annihilation constants, assuming a homogeneous defect distribution. 




Dislocation generation decreases $\mathrm{w} / \% \mathrm{CW}$

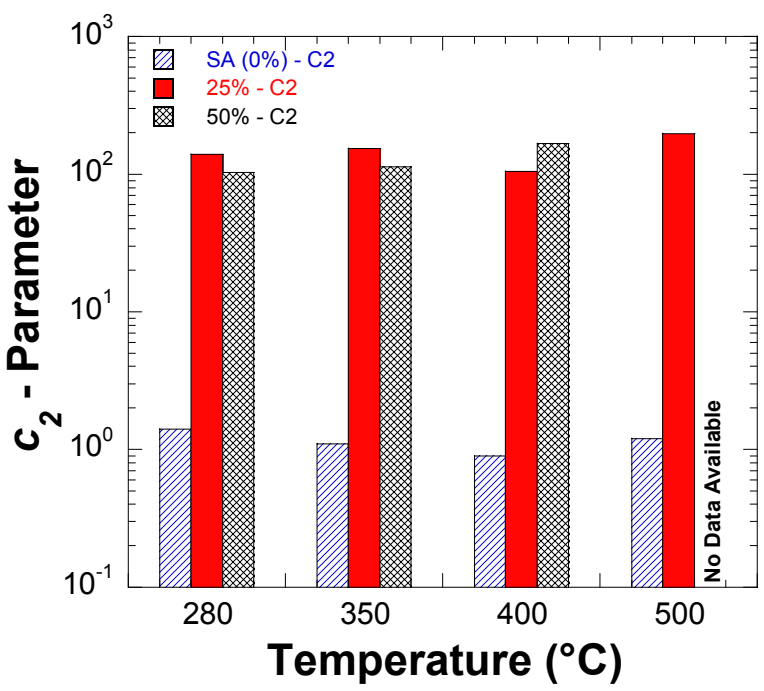

Dislocation annihilation increases $\mathrm{w} / \% \mathrm{CW}$

Figure 49. Influence of test temperature and cold-work level on model constants $c_{1}$ and $c_{2}$.

The dislocation velocity is given by:

$$
\vec{v}_{d}=v_{o}\left(\frac{\vec{\sigma}}{\mu b \sqrt{\alpha \rho_{d}+\beta N_{v} d}}\right)^{1 / m}
$$

where $N_{v}$ is the radiation defect cluster number density, $d$ is the radiation defect cluster size and $\beta$ is the strengthening coefficient.

The model does a good job of predicting the expected general stress-strain behavior of irradiated stainless steel. Figure 50 shows the calculated stress-strain behavior as a function of increasing defect density. Similar to the observed behavior in irradiated stainless steel, the model predicts increased yield strength, the appearance of a yield point, and decreased work hardening. 


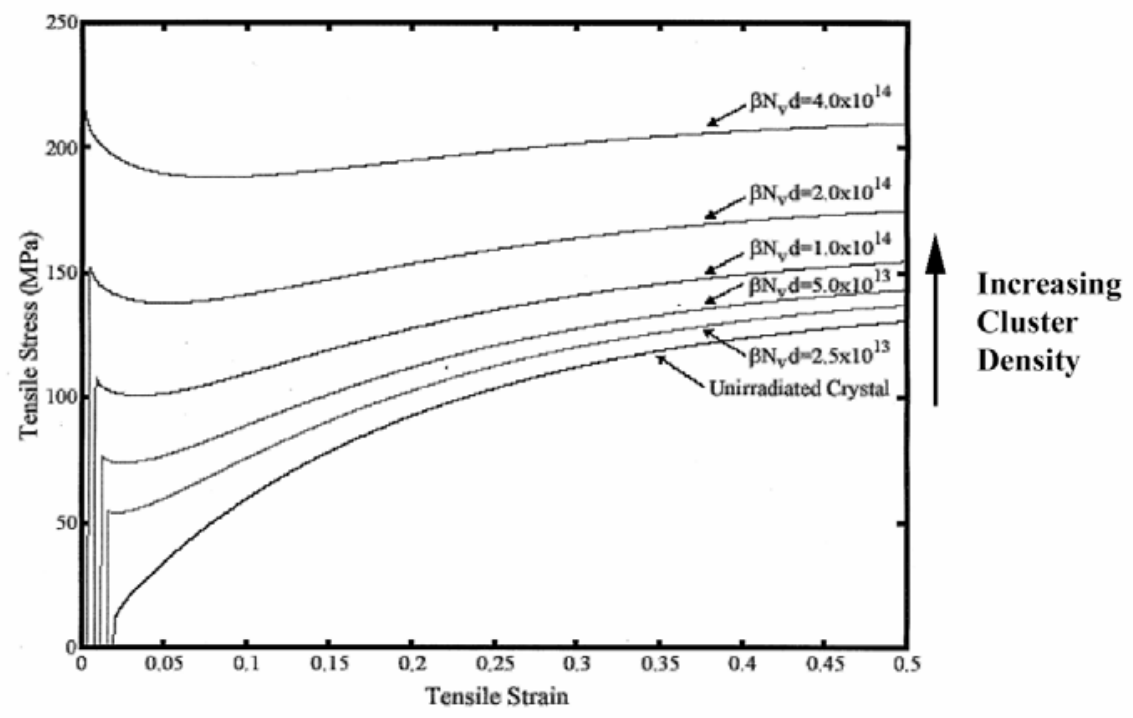

Figure 50. Predicted stress-strain behavior as a function of defect density
(increasing radiation damage).

Concerns were raised in the advisory committee on the applicability of the radiation model to predicting behavior in stainless steel irradiated under LWR conditions. As a result modeling efforts were expanded to consider various other models as described in the next two sections.

\subsection{Dispersed Barrier Modeling}

The initial effect of radiation damage in $\mathrm{CW}$ material may be to cause a strength decrease as dislocation networks are "annealed out" by an influx of point defects. However, as the radiation damage builds up, the evolution of the defect microstructure significantly affects material deformation behavior. The observed increase in strength and loss of uniform ductility is a direct result of the increase in obstacle density. These obstacles both inhibit the operation of dislocation sources and impede the movement of line dislocations.

A variety of models have been proposed to describe the increased resistance to dislocation motion through a spectrum of obstacles such as defects produced during irradiation. Long-range interactions between loops and dislocations are negligible as the interaction force decreases as a function of $1 / R^{2}$ where $R$ is the distance from the loop [38]. Thus, only those defects within a radius of $2 \mathrm{r}$ (diameter of the defect) will contribute substantially to interaction force. One can approximate the expected increase in yield strength $\left(\sigma_{y}\right)$ due to radiation hardening by discrete obstacles such as dislocation loops, voids and precipitates as:

$$
\Delta \sigma_{y}=M \alpha \mu b \sqrt{N d}
$$

eq. 10

where $\alpha$ is a constant related to the strength of the obstacle ( $\alpha=1$ for voids, 0.33 for precipitates and loops and 0.11 for network dislocations[15]), $\mu$ is the shear modulus, $b$ is the magnitude of the Burgers vector, $\mathrm{N}$ is the obstacle density and $\mathrm{d}$ is the obstacle diameter. Hardening due to the dislocation network can be approximated by: 


$$
\Delta \sigma_{y}=M \alpha \mu b \sqrt{\rho_{d}}
$$

where $\rho_{\mathrm{d}}$ is the dislocation network density. In both instances, $\mathrm{M}$ is a factor relating the shear stress on the slip plane in a single crystal to the tensile stress necessary to activate slip in a polycrystal. This value has been shown to be 3 [39]. Each of the obstacle types will provide an increment of strengthening and the net effect is calculated using a superposition law of the form:

$$
\Delta \sigma_{t o t}=+\Delta \sigma_{L R} \sqrt{\sum_{i}\left(\Delta \sigma_{S R, i}\right)^{2}}
$$

where $\Delta \sigma_{\text {tot }}$ is the total change in yield stress, $\Delta \sigma_{\mathrm{LR}}$ is the change due to long range barriers (network dislocations) and $\Delta \sigma_{\mathrm{SR}, \mathrm{i}}$ is the change due to the $\mathrm{i}$ 'th short range obstacle (loops, voids, precipitates). Using the defect parameter values given in tables 7 and 8, the incremental hardening as a function of dose is plotted in Figure 51 for the irradiated CW 316 SS. At the lower dose, the network dislocations provided the greatest increment of strengthening, however as the voids, loops and precipitate population builds up, they become the greater contributors to hardening. It is important to note that the relatively high density of larger voids that form at higher dose in the EBR-II materials are not likely to form under typical PWR conditions. Temperature has a strong influence on void growth rate, and the EBR-II materials are at the upper temperature bound of PWR conditions. Voids that do form in PWR components will likely be significantly smaller. Since large voids have the strongest obstacle strength, hardening in irradiated PWR components should be less substantial.

When the obstacle density becomes high enough, there may be a transition in deformation behavior from a more homogeneous planar glide mode to localized twin deformation or 


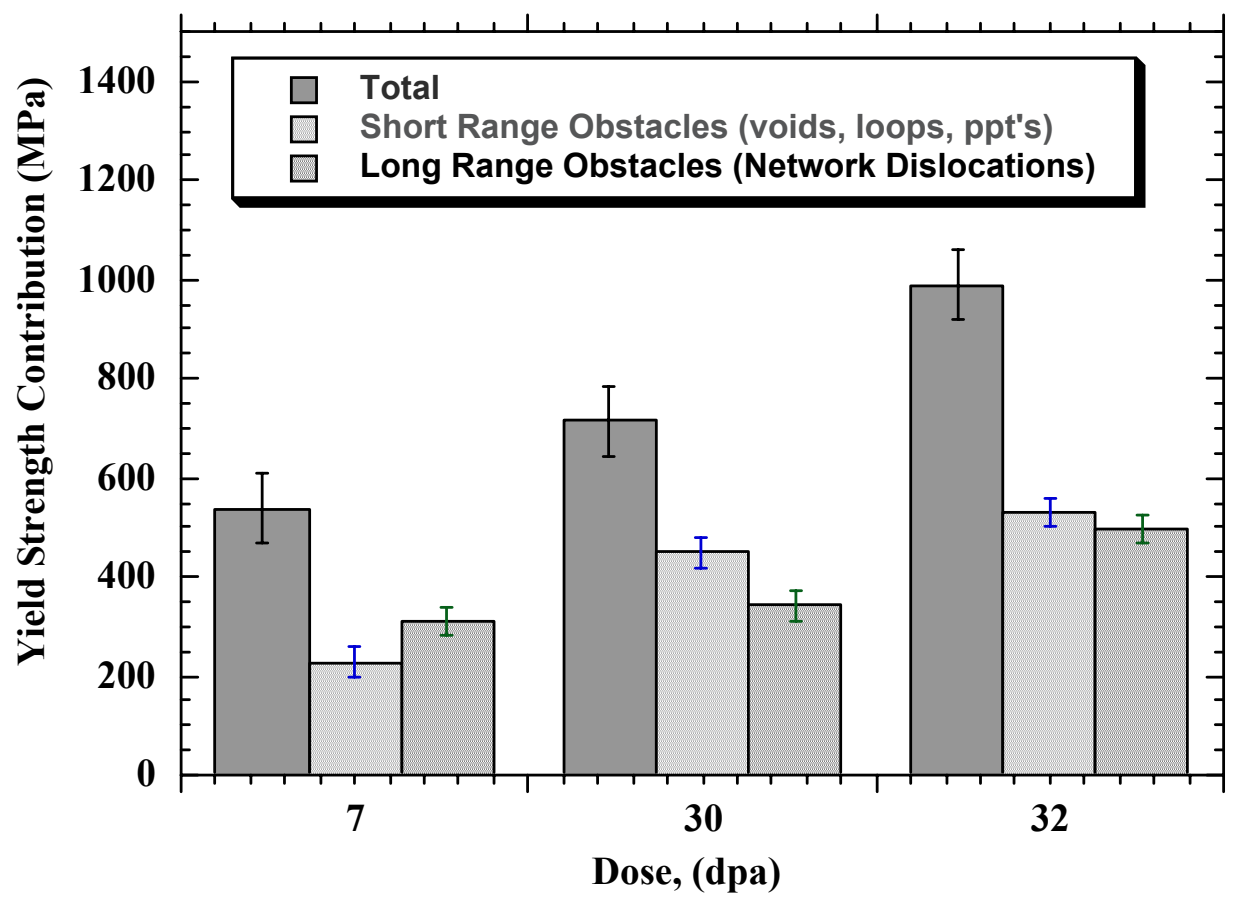

Figure 51. Calculated yield strength contributions from various obstacles quantified in the TEM microstructure based on the dispersed barrier hardening model.

dislocation channeling. Dislocation channeling is a process whereby glide dislocations traverse the grains and remove the radiation produced dislocation structure in a narrow band or channel along the slip plane of the dislocation. Both twins and channels tend to initiate at regions of stress concentration. Channel formation in materials is associated with decreased work hardening and a dramatic reduction in the uniform elongation. The formation of dislocation channels appears to be more likely at higher temperatures or lower strain rates [40]. The significance of this localization of the deformation is that if the matrix is hardened compared to the grain boundaries and a large amount of shear is introduced where a dislocation intersects the boundary, the likelihood of a crack initiating at this point is increased. This is consistent with the change in fracture behavior observed in the EBR-II 316 SS material irradiated to 47 dpa (see Figure 39). However, such a high dose is not expected for PWR materials at the higher temperatures and lower dose behavior is more representative (see Figure 4).

\subsection{Mechanical Properties Correlations using Equation of State}

To complement the development of constitutive relationships based on fundamental material parameters the applicability of mechanical properties correlations were considered. These correlations were initially developed for unirradiated metals [41] and further expanded to stainless steels irradiated in the breeder reactor program $[29,33]$ where, in anticipation of 
possible off-normal or transient reactor events, it was desired to predict alloy mechanical behavior over a range of temperatures and strain-rates from a limited data set. The correlations involve the application of an empirical equation of state to calculate a structure or "hardness" parameter that is independent of material history and related only to the alloy "hardness" as represented by its flow stress as a function of strain-rate and temperature. For purposes of the correlations, it is assumed that alloy hardness derived from cold-working and irradiation are equivalent and thus structure parameter values obtained from coldworked material can be used in predicting flow behavior of the irradiated material where, due to the expense of testing, there is a limited data. The structure parameter, $\sigma^{*}$, is defined as follows :[33].

$$
\log _{10}\left(\frac{\sigma^{*}}{\sigma}\right)=A\left[\frac{\left\{\sigma^{*} /\left(E / E_{0}\right)\right\}^{M}}{\varepsilon \exp \left(Q / R T_{K}\right)}\right]^{\lambda}
$$

where

$\sigma=$ yield strength $(0.2$ percent offset $)$

$\mathrm{T}_{\mathrm{k}}=$ test temperature (absolute temperature)

$\dot{\varepsilon}=$ strain rate $\left(\mathrm{s}^{-1}\right)$

$\sigma^{*}=$ structure parameter which describes the "hardness state" of the material

$\mathrm{E}=$ Young's modulus at $\mathrm{T}_{\mathrm{k}}$

$\mathrm{E}_{0}=$ Young's modulus at $310.8 \mathrm{~K}$

$\mathrm{Q}=0.355 \mathrm{MJ} / \mathrm{mole}$

$\mathrm{R}=8.32 \mathrm{~J} /($ mole $\mathrm{K})$

$\mathrm{A}=0.263(\mathrm{MPa})^{-1.26}(\mathrm{~s})^{-0.28}$

$\mathrm{M}=4.5$

$\lambda=0.28$

A, Q, M and $\lambda$ are constants determined from experimental data for 316 stainless steel. A plot the yield stress vs $\log$ of the strain-rate at a temperature of $600^{\circ} \mathrm{C}$ for various structure parameter values is provided in Figure 52. The structure parameter becomes equal the yield strength at high strain-rate and/or at lower temperatures. The main application of the structure parameter calculations in the breeder reactor program was to calculate the high temperature $\left(\mathrm{T}>500^{\circ} \mathrm{C}\right)$ transient strength from low temperature data. The usefulness of these correlations at temperatures lower than $400^{\circ} \mathrm{C}$ under steady state conditions is somewhat limited. There is potential to modify the correlations to specific areas of interest to aging phenomena in LWR internals, however this task could not be performed within the resources and time frame of the current project. The initial intention of this project was to test samples at $10^{-3}, 10^{-5}$ and $10^{-7} \mathrm{~s}^{-1}$ strain rates, the data from which could then be compared to structure parameter calculations. However due to the previously mentioned difficulties in testing, test were conducted only at a strain rate of $10^{-5} \mathrm{~s}^{-1}$. At the lower temperatures and higher strain rates that the experimental tests were performed, the calculated structure parameter was, as expected, equivalent to the yield strength. 


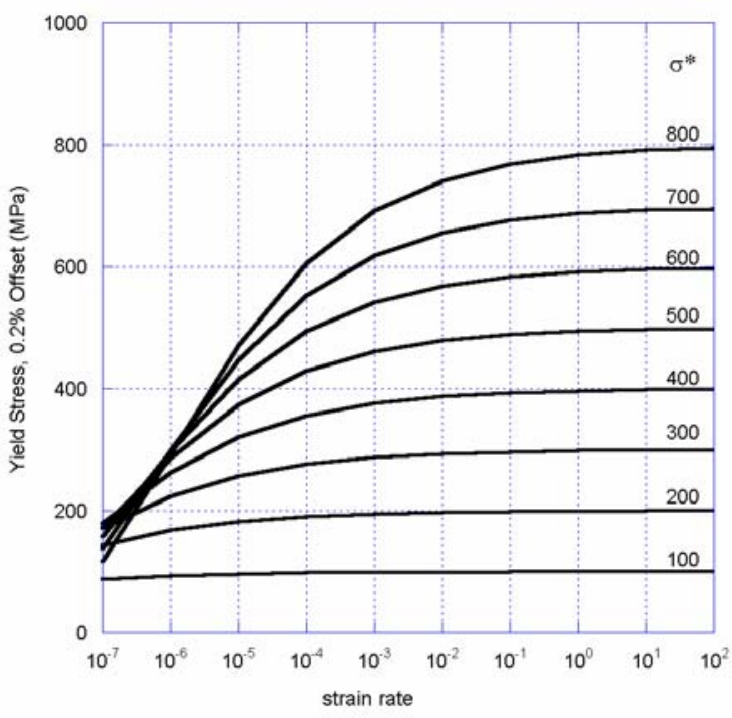

Figure 52. Calculated yield strength as a function of strain-rate and for various structure parameters. Note that at higher strain rates the structure parameter is insensitive to strain rate. 


\subsection{Conclusions}

The results of this study indicate that austenitic stainless steel will not fail intergranularly due to work hardening alone, and that either radiation damage and/or a corrosive environment are required to induce intergranular failure. The tensile behavior of 0,25 and $50 \% \mathrm{CW} 316 \mathrm{SS}$ steel was studied over a range of temperatures and strain rates. Both un-notched and double edge notched samples were tested. The greatest work hardening rate was observed for the $0 \% \mathrm{CW}$ sample. Yield and UTS was observed to decrease as a function of increasing temperature and decreasing strain rate (Figures 17 and 18). All samples tested failed to fracture intergranularly. Finite element methods were employed to design a single edge notched tensile (SENT) samples that provided increased plastic constraints with a greater likelihood of fracturing along the grain boundaries. The SENT samples also failed to fracture intergranularly.

Mechanical properties changes were measured on cold-worked AISI 316 stainless steel irradiated under low dose rate conditions both in this and two previous studies. Both $12 \%$ and $20 \%$ coldworked conditions were examined. Although the yield strength for each condition approached similar values with increasing dose, the rate of increase in strength differed with cold-work and irradiation temperature. The $12 \%$ cold-worked steel irradiated and tested at lower temperature $\left(\sim 380^{\circ} \mathrm{C}\right)$ had the fastest rate of strength increase. Differences in elongation were also noted. The $12 \%$ cold-worked steel irradiated and tested at lower temperature $\left(\sim 380^{\circ} \mathrm{C}\right)$ and the $20 \%$ coldworked 316 had the fastest rate of decrease in total elongation. The total elongation for the $20 \%$ cold-worked stainless steel reached $2 \%$ at $47 \mathrm{dpa}$, a low value. At this high dose and low elongation, the fracture was starting to transition from ductile to a more channeled fracture. The high dose necessary to initiate brittle channel type fraction suggests doses observed in PWR may not be substantial enough to cause such changes in deformation behavior.

TEM indicated that dense networks of extended dislocations form in the $316 \mathrm{SS}$ with increasing cold-work and these networks evolve into arrays of microtwins with increasing strain. The planar nature of the deformation microstructure and the development of twinning are believed to be responsible for the significant work hardening in austenitic SS.

TEM of irradiated solution annealed 304 and coldworked 316 SS revealed the formation of large densities of precipitates and voids with increasing radiation exposure. While no voids or precipitates were observed in the $316 \mathrm{SS}$ irradiated to $7 \mathrm{dpa}$, a sample of 304 irradiated to $11 \mathrm{dpa}$ had a relatively high density of voids. Overall, the swelling level for all of the samples was less than $1 \%$ indicating they were still in the transient swelling regime.

A baseline for the deformation model has been developed that successfully charts material stress strain behavior. The model indicates that the dislocation generation rate decreases with increasing cold-work, while the annihilation rate increases with increasing cold-work level. Temperature appears to increase the dislocation generation rate for the higher cold-work levels, while it appears temperature does not significantly influence the dislocation annihilation rate over the range tested.

A model developed to predict deformation behavior in irradiated material based on crystal plasticity predicted the general trends observed in tensile tests, including increased yield strength, the appearance of a yield point, and decreased work hardening. 
Dispersed barrier modeling suggests that large voids will contribute the most to embrittlement of reactor materials. If such large voids do not form under PWR conditions, then embrittlement will be less severe.

Finally an equation of state correlation was evaluated for application to studying aging behavior in irradiated LWR components. The correlations were specifically developed for predicting higher temperature behavior in breeder reactor components and may not be directly applicable to LWR parameters. Further work in developing the correlations for LWR aging behavior may be beneficial. 


\section{References}

1. U.F. Kocks, ASME J. Eng. Mater. Tech. 98 (1976) 76.

2. T. R. Allen, H. Tsai, R. S. Daum, D. L. Porter, J. I. Cole, T. Yoshitake, N. Akasaka, T. Donomae, S. Mizuta, J. Ohta, K. Dohi, and H. Kusanagi "Effects of Irradiation on the Swelling and Mechanical Properties of 316 Stainless Steel" Submitted to 11th International Conference on Environmental Degradation in Nuclear Power Systems-Water Reactors, (2003) submitted.

3. T. R. Allen, H. Tsai, J. I. Cole, J. Ohta, K. Dohi, H. Kusanagi,., "Properties of $20 \%$ ColdWorked 316 Stainless Steel Irradiated at Low Dose Rate," Effects of Radiation on Materials, ASTM STP 1447, ASTM International, West Conshohocken, PA, 2003. in press.

4. Bruemmer, S. M., Simonen, E. P., Scott, P. M., Andresen, P. L., Was, G. S., and Nelson, J. L., "Radiation-induced material changes and susceptibility to intergranular failure of light-waterreactor core internals", Journal of Nuclear Materials, Volume 274, 1999 pp. 299-314.

5. 1999 Cooperative IASCC Research (CIR) Program 1999 Annual Summary.

6. P. Scott, Framatome, Private communication.

7. R. E. Schramm and P. R. Read, Met. Trans., 6A (1975) 1345.

8. D. L. Douglass, G. Thomas and W. R. Roser, Corr., 20 (1964) $15 \mathrm{t}$.

9. F. Lecroisey and A. Pineau, in 14th Colloque de Metallurgie, CEN Saclay (1971).

10. I. Tamura, T. Maki, Trans. ISIJ, 10 (1970) 163.

11. B. Thomas, Met. Corr. Ind., 44 (1968) 405.

12. B. Bay, N. Hansen, D. A. Hughes and D. Kuhlman-Wilsdorf, Acta Met., 40 (1992) 205.

13. J. A. Venables, J. Phys. Chem. Solids, 25 (1964) 693.

14. J. A. Venables, Phil. Mag., 6 (1961) 379.

15. G. E. Lucas, Journ. Nucl. Mater., 206 (1993) 287.

16. M. Grossbeck and L Mansur, Mater. Sci. Forum 97-99 (1992) 808.

17. G. S. Was, S. M. Bruemmer, Journ. Nucl. Mater., 216 (1994) 326.

18. G. R. Odette and G. E. Lucas, J. Nucl. Mater., 179-181 (1991) 572.

19. G. R. Odette and G. Lucas, J. Nucl. Mater., 191-194 (1992) 50.

20. G. Johnson et al., ASTM-STP-725 (1981) 393.

21. J. J. Holmes and J. L. Straalsund, in Radiat. Eff. in Breeder Reactor Structural Mater., AIME (1977) 727.

22. J. M. Dupouoy, ibid 69, p. 83.

23. E. E. Bloom, W. R. Martin, J. O. Stiegler and J. R. Weir, J. Nucl. Mat., 22 (1967) p. 68

24. W.R. Martin and J.R. Weir, ASTM Tech. Publ. 380 (1965) 251.

25. J.J. Holmes, R.E. Robbins, J.L. Brimhall and B. Mastel, Acta Met., 16 (1968) 955.

26. E. P. Simonen and S. M. Bruemmer (1995). "Kinetic Evaluation of Intergranular Fracture in Austenitic Stainless Steels", Seventh International Conference on Environmental Degradation of Materials in Nuclear Power Systems-Water Reactors, NACE International, pp.1081-1092.

27. D. B. Williams and C. B. Carter, in Transmission Electron Microcopy: A Textbook for Materials Science (Plenum Press, New York, 1996)) p. 321.

28. G. Schoeck, J. App. Phys., 33 (1962) pp. 1745-1747

29. Wire, G. L., "State Variable Description of 316 Stainless Steel Postirradiation Mechanical Properties," Effects of Radiation on Materials: Tenth Conference, ASTM STP 725, D. Kramer, H. R. Brager, and J. S. Perrin, Eds., American society for Testing and Materials, p. 375. 
30. T.Yoshitake, T.Donomae, S.Mizuta, H.Tsai, Robert V. Strain, T.R.Allen, and J.I.Cole, "Tensile Properties of $12 \%$ Cold-Worked 316 Stainless Steel Irradiated at EBR-II Reactor with Lower Dose Rate Conditions to High Fluence," Effects of Radiation on Materials: $20^{\text {th }}$ International Symposium, ASTM STP 1405, S. T. Rosinski, M. L. Grossbeck, T. R. Allen, and A. S. Kumar, Eds., American Society for Testing and Materials, West Conshohocken, PA 2002, p. 469.

31. T. R. Allen, J. I. Cole, H. Tsai, S. Ukai, S. Mizuta, and T. Yoshitake, The Effect of Low Dose Rate Irradiation on the Swelling of 12\% Cold-Worked 316 Stainless Steel, Proceedings of the Ninth International Symposium on Environmental Degradation of Materials in Nuclear Power Systems-Water Reactors, , S. Bruemmer, P. Ford, G,. Was Eds., Newport Beach, CA, TMS, Warrendale, PA, (August 1999), p.1035.

32. J. I. Cole, T. R. Allen, H. Kusanagi, K. Dohi, and J. Ohta "Microstructure and Post-irradiation annealing Behavior of 20\% Cold-worked 316 Stainless Steel," Proceedings of the MRS Fall Meeting: Microstructure Processes in Irradiated Materials-2000, Vol. 650, Materials Research Society, Warrendale, PA, p. R3.12.

33. R. L Fish, Cannon, N. S., and Wire, G. L., "Tensile Property Correlations for Highly Irradiated 20 Percent Cold-Worked Type 316 Stainless Steel", Effects of Radiation on Structural Materials, ASTM STP 683, 1979, p. 450.

34. J. A. Venables in Deformation Twinning, Gordon breach, (New York: 1965) p. 77.

35. F. A. Garner, in Materials Science and Technology: Nuclear Materials, Vol. 10, edited by B. R. T. Frost (VCH, New York, 1993) p. 422.

36. W. J. S. Yang, in Radiation-Induced Changes in Microstructure: 13th International Symposium, ed. F. A. Garner, N. H. Packan, and A. S. Kumar. (ASTM, 1987)) p. 628.

37. J. I. Cole, T. R. Allen H. Tsai, S. Ukai, S. Mizuta, N. Akasaka, T. Donomae and T. Yoshitake, "Swelling and Microstructural Evolution in 316 Stainless Steel Hexagonal Ducts Following Long-Term Irradiation in EBR-II," Irradiation Effects in Materials: 20th International Symposium, ASTM STP 1505, S. T. Rosinski, M. L. Grossbeck, T. R. Allen and A. S. Kumar, Eds., American Society for Testing and Materials, West Conshohocken, PA, 2001, pp. 427-442.

38. F. Kroupa, Phil. Mag., 7 (1962) 783.

39. G. I. Taylor, J. Inst. Met., 62 (1938) 307.

40. J. I. Cole, J. L. Brimhall, J. S. Vetrano, and S. M. Bruemmer, "Deformation Temperature, Strain Rate and Irradiation Microstructure Effects on Localized Plasticity in 304L SS", Proceedings of the 7th International Symposium on Environmental Degradation of Materials in Nuclear Power Systems-Water Reactors, (NACE, 1995) 817.

41. E.W Hart, A Phenomenological Theory for Plastic Deformation of Polycrystalline Metals. Acta Metallurgica, 1970. 18: pp. 599-610. 